\author{
UNIVERSIDADE de SÃO PAULO \\ Instituto de Química \\ Departamento de Química Fundamental
}

\title{
DESENVOLVIMENTO DE ELETRODOS DE PASTA DE CARBONO MODIFICADOS COM FILMES DE AZUL DA PRÚSSIA
}

Dissertação de Mestrado

Viviane Midori Ivama

2003 


$$
\begin{gathered}
\text { BIBL L IOTECA } \\
\text { USTITUTO DE QUIMICA } \\
\text { Unvereddade de Säo Perto } \\
20.385 \\
\text { UNIVERSIDADE de SÃO PAULO }
\end{gathered}
$$

\author{
Instituto de Química \\ Departamento de Química Fundamental
}

\title{
DESENVOLVIMENTO DE ELETRODOS DE PASTA DE CARBONO MODIFICADOS COM FILMES DE AZUL DA PRÚSSIA
}

Estudante: Viviane Midori Ivama

Orientadora: Prof $^{a} \operatorname{Dr}^{\text {a. }}$ Silvia Helena Pires Serrano 
DEDALUS - Acervo - CQ

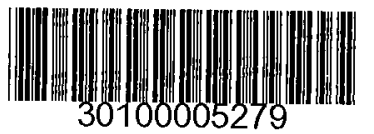

Ficha Catalográfica

Elaborada pela Divisão de Biblicteca e

Documentação do Conjunto das Quimicas dâ L'SP.

Ivama, Viviane Midori

I93d Desenvolvimento de eletrodos de pasta de carbcino modificados com filmes de azul da prússia / Viviane Midori Ivama. -- São Paulo, 2003.

$119 \mathrm{p}$.

Dissertação (mestrado) - Instituto de Química da Universidade de São Paulo. Departamento de Química Fundamental.

Orientador: Serrano, Silvia Helena Pires

1. Eletroanálise : Química I. T. II. Serrano, Silvia Helena Pires, orientador. 


\section{"Desenvolvimento de Eletrodos de Pasta de Carbono Modificados com Filmes de Azul da Prússia"}

\section{VIVIANE MIDORI IVAMA}

Dissertação de Mestrado submetida ao Instituto de Química da Universidade de São Paulo como parte dos requisitos necessários à obtenção do grau de Mestre em Química - Área: Química Analítica.

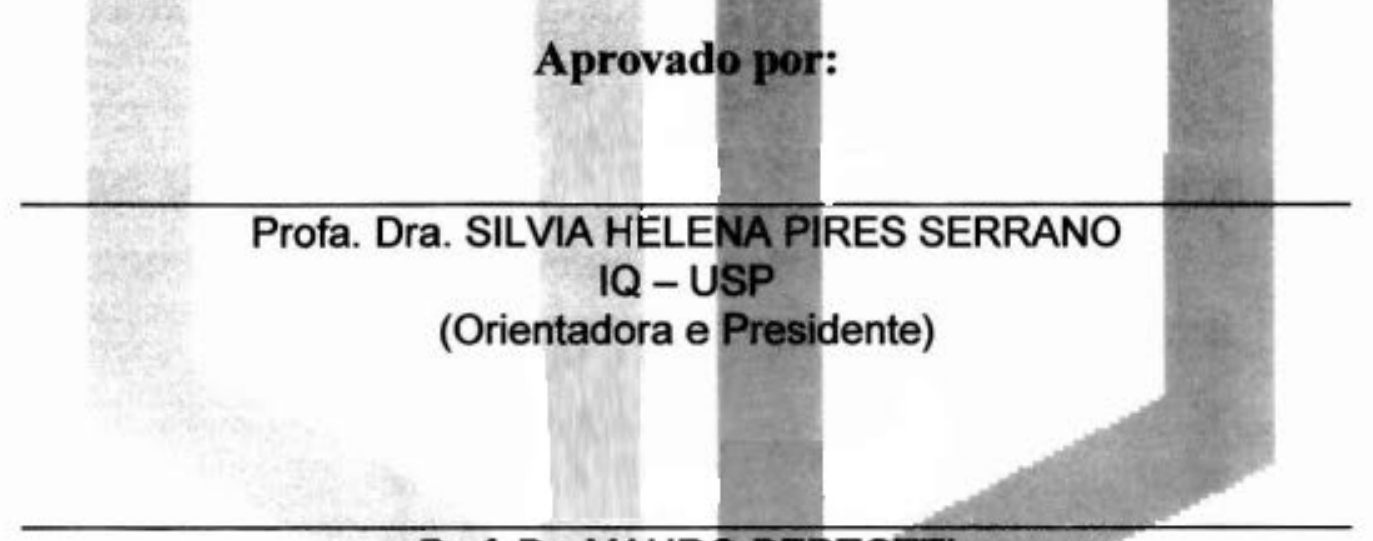

Prof. Dr. MAURO BERTOTTI

IQ - USP

Profa. Dra. MARIA VALNICE BOLDRIN ZANONI

IQ - USP - Araraquara

24 DE FEVEREIRO 2003. 


\section{Ouvir estrelas}

\section{Olavo Bilac}

"Ora (direis) ouvir estrelas! Certo perdeste o senso!" E eu vos direi, no entanto, que para ouvi-las, muitas vezes desperto e abro as janelas, pálido de espanto...

E conversamos toda a noite, enquanto a Via-Láctea, como um pálido aberto, cintila. E ao vir do sol, saudoso e sem pranto, ainda as procuro pelo céu deserto.

Direis agora: "Tresloucado amigo! Que conversas com elas? Que sentido tem o que dizem, quando estão contigo?".

E eu vos direi: "Amai para entende-las! Pois só quem ama pode ter ouvido capaz de ouvir e de entender estrelas".

(Poesias, Via-Láctea, 1888). 
Ao meu futuro marido Ricardo Shin Tachibana. 


\section{Agradecimentos}

A meus pais e amigos, pelo carinho e apoio.

A Profa. Dra. Silvia Helena Pires Serrano, pela orientação, continuo incentivo e a amizade dentro e fora do laboratório.

Aos meus colegas do laboratório, pelo apoio e amizade.

As funcionárias Cristina e Lucia pela colaboração e amizade.

Ao CNPq pela concessão da Bolsa de Estudos, à FAPESP pelo apoio financeiro cedido para manutenção da infraestrutura do laboratório e à Pró-Reitoria de Pós-graduação pelo apoio na participação em congressos: 


\section{ABSTRACT}

Prussian Blue carbon paste modified electrodes were prepared using cyclic voltammetry and deposition at one and two controlled potentials. The last method was the best and produced modified electrodes with higher sensitivity and stability during the catalytic reduction of hydrogen peroxide.

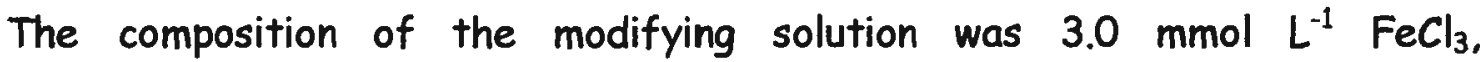
$2.0 \mathrm{mmol} \mathrm{L}^{-1} \mathrm{~K}_{3}\left[\mathrm{Fe}(\mathrm{CN})_{6}\right]$ in $\mathrm{pH} 2.0$ with $\mathrm{HCl}$. The electrode system was immersed in the modifying solution and $+0.4 \mathrm{~V}$ was applied to the working electrode during two minutes. After, the potential was just reverted to $-0.4 \mathrm{~V}$ once more two minutes. The total process was repeated twice.

Further, to improve the stability of the Prussian Blue carbon paste modified electrodes (PB-CPME), they were cycled in a solution containing $1.0 \mathrm{mmol} \mathrm{L}^{-1} \mathrm{RhCl}_{3}$, $0,05 \mathrm{~mol} \mathrm{~L}^{-1} \mathrm{KCl}$ and $0.02 \mathrm{~mol} \mathrm{~L}^{-1} \mathrm{HCl}$ in $a-0.4 \leq E \leq 0.6 \mathrm{~V}$ potential range at $60 \mathrm{mV} \mathrm{s}^{-1}$ (50 cycles). These electrodes, denominated of Rh-PBCPME, were dried at ambient temperature during 24 hours before use.

The Rh-PBCPME shows good stability during successive cycles, with anodic and cathodic peaks recorded at $0.30 \mathrm{~V}$ and $0.18 \mathrm{~V}$ being attributed to a redox process involving Prussian White / Prussian Blue couple. Em, calculated as $(E p, a+E p, c / 2)$, is 0.24 V. In potassium citratel citric acid buffer solution containing $0.5 \mathrm{~mol} \mathrm{~L}^{-1} \mathrm{KCl}, \mathrm{pH} 6.1$, the peak currents changed linearly with the square of sweep velocity in the range $0.025 \mathrm{Vs}^{-1} \leq v \leq 0.400 \mathrm{Vs}^{-1}$ showing that the process is governed by ion diffusion from support electrolyte to the electrode surface (during the reduction step) or from the electrode to the solution (during the oxidation step) to ensure the electroneutrality rule. 
The modifier surface excess was $4.3 \times 10^{-8} \mathrm{~mol} \mathrm{~cm}^{-2}$, calculated using the anodic charge obtained from cyclic voltammograms, after subtraction of the background charge recorded with an unmodified carbon paste electrode in an electrolyte support solution $\left(1.0 \mathrm{mmol} \mathrm{L}^{-1} \mathrm{RhCl}_{3}, 0.5 \mathrm{~mol} \mathrm{~L}^{-1} \mathrm{KCl}\right.$ and $0.02 \mathrm{~mol} \mathrm{~L}^{-1} \mathrm{HCl}$, $v=60 \mathrm{mV} \mathrm{s}^{-1}$ ).

The supporting electrolyte used to detection of hydrogen peroxide was $10 \mathrm{mmol} \mathrm{L}^{-1}$ potassium citrate $/ 2 \mathrm{mmol} L^{-1}$ Citric acid buffer, $\mathrm{pH} 6.1$ (ionic strength = $0.16 \mathrm{~mol} \mathrm{~L}^{-1}$ ) containing $0.5 \mathrm{~mol} \mathrm{~L}^{-1} \mathrm{KCl}$. The absence of this electrolyte or the presence of phosphate ions decreased the stability of the sensor.

Hydrogen peroxide was detected at $0.04 \mathrm{~V}$ (vS $E_{A g / A g C l,} \mathrm{KCl}$ sat) in $5.1 \times 10^{-5}-8.6 \times 10^{-4} \mathrm{~mol}^{-1}$ linear range with sensitivity of (1.4 \pm 0.2$) \mathrm{A} \mathrm{mol}^{-1} \mathrm{~L} \mathrm{~cm}^{-2}$ and detection limit of $(2.5 \pm 0.02) \times 10^{-5} \mathrm{~mol} \mathrm{~L}^{-1}$. At this applied potential the contribution of oxygen reduction current was $8.0 \%$ in the presence of $1.0 \mathrm{mmol} \mathrm{L}^{-1} \mathrm{H}_{2} \mathrm{O}_{2}$.

Analytical curves obtained during hydrogen peroxide detections along 5 days, each one of them representing an average of 6 consecutive amperometric analytical curves, carried out in the same day, showed a decrease of only $27 \%$ in the sensitivity of the modified electrodes. When was not using the electrode was kept in $0.5 \mathrm{~mol} \mathrm{~L}^{-1} \mathrm{KCl}$.

At $0.04 \mathrm{~V}$ applied potential no interference was detected due to mediated or direct oxidation of uric acid. The interference of ascorbic acid was only significant to $0.060 \mathrm{~V}$ or higher applied potentials. 


\section{Resumo}

Os eletrodos de pasta de carbono modificados com Azul da Prússia foram preparados usando a voltametria cíclica, deposição a um potencial controlado e a deposição a dois potenciais controlados. $O$ último método foi melhor e produziu eletrodos modificados com alta sensibilidade e estabilidade durante a redução catalítica de peróxido de hidrogênio.

A composição da solução modificadora foi $3,0 \mathrm{mmol} \mathrm{L}^{-1}$ de $\mathrm{FeCl}_{3}$ e $2,0 \mathrm{mmol} \mathrm{L}^{-1}$ de $\mathrm{K}_{3}\left[\mathrm{Fe}(\mathrm{CN})_{6}\right]$ em pH 2,0 com HCl. O sistema de eletrodos foi imerso na solução modificadora e $+0,4 \mathrm{~V}$ foi aplicado no eletrodo de trabalho durante 2 minutos. Depois, o potencial foi revertido para $-0,4 \mathrm{~V}$ por mais 2 minutos. O processo total foi repetido mais duas vezes.

Além disso, para melhorar a estabilidade dos eletrodos de pasta de carbono modificados com Azul da Prússia (EPC-AP), estes foram ciclados em soluçăo contendo $1,0 \mathrm{~m} \mathrm{~mol} \mathrm{~L}^{-1}$ de $\mathrm{RhCl}_{3}, 0,05 \mathrm{~mol} \mathrm{~L}^{-1}$ de $\mathrm{KCl}$ e $0,02 \mathrm{~mol} \mathrm{~L}^{-1}$ de $\mathrm{HCl}$ na faixa de potencial $-0,4 \mathrm{~V} \leq \mathrm{E}_{\mathrm{apl}} \leq 0,6 \mathrm{~V}$ a $60 \mathrm{mV} \mathrm{s}^{-1}$ (50 ciclos). Estes eletrodos, denominados de EPC-AP-Rh, foram secos a temperatura ambiente por 24 horas antes de serem utilizados.

Os EPC-AP-Rh apresentaram boa estabilidade durante sucessivos ciclos, com os picos anódico e catódico, referentes a $0,30 \mathrm{~V}$ e 0,18 $\mathrm{V}$ inicialmente atribuídos para um processo redox envolvendo Branco da Prússia / Azul da Prússia. Cálculos com (Ep,a $+E p, c / 2)$, é $0,24 \mathrm{~V}$. Em solução tampão citrato de potássio / ácido cítrico contendo $0,5 \mathrm{~mol} \mathrm{~L}^{-1} \mathrm{de} \mathrm{KCl}, \mathrm{pH} 6,1$, as correntes de picos variam linearmente com a velocidade de varredura $0,025 \mathrm{Vs}^{-1} \leq v \leq 0,400 \mathrm{~V} \mathrm{~s}^{-1}$ mostrando que o processo é governado por difusão de íons do eletrólito suporte para a superfície do eletrodo (durante a etapa de redução) ou do eletrodo para a solução (durante a etapa de oxidação) para manter a eletroneutralidade.

$O$ excesso superficial foi $4,310^{-8} \mathrm{~mol} \mathrm{~cm}^{-2}$, calculado usando a carga anódica obtida pelo voltamograma cíclico, depois da subtração do fundo de carga referente a um eletrodo não modificado de pasta de carbono em solução eletrólito 
suporte $\left(1,0 \times 10^{-3} \mathrm{~mol} \mathrm{~L}^{-1}\right.$ de $\mathrm{RhCl}_{3}, 0,05 \mathrm{~mol} \mathrm{~L}^{-1}$ de $\mathrm{KCl}$ e $0,02 \mathrm{~mol} \mathrm{~L}^{-1}$ de $\mathrm{HCl}$, $\left.v=60 \mathrm{mV} \mathrm{s}^{-1}\right)$.

O eletrólito suporte usado para detecçäo para determinação de peróxido de hidrogênio foi o tampāo10 $\mathrm{mmol} \mathrm{L}^{-1}$ de citrato de potássio/ $2 \mathrm{mmol} \mathrm{L}^{-1}$ de ácido cítrico, pH 6,1 (força iônica $=0,16 \mathrm{~mol} \mathrm{~L}^{-1}$ ) contendo $0,5 \mathrm{~mol} \mathrm{~L}^{-1}$ de $\mathrm{KCl}$. A ausência deste eletrólito ou a presença de íons fosfatos diminui a estabilidade deste sensor.

Peróxido de hidrogênio foi determinado a $0,04 \mathrm{~V}$ (vs $\left.\mathrm{E}_{\mathrm{Ag} / \mathrm{AgCl}, \mathrm{KCl} \text { sat }}\right)$ na faixa linear de $5,1 \times 10^{-5} \mathrm{~mol} \mathrm{~L}^{-1}$ a $8,6 \times 10^{-4} \mathrm{~mol} \mathrm{~L}^{-1}$ com sensibilidade média de $1,4 \pm 0,2 \mathrm{~A} \mathrm{~mol}^{-1} \mathrm{~L} \mathrm{~cm}^{-2}$ e limite de detecção de $(2,5 \pm 0,02) \times 10^{-5} \mathrm{~mol} \mathrm{~L}^{-1}$. Neste potencial aplicado a contribuição da corrente de redução do oxigênio foi de $8,0 \%$ na presença de $1,0 \mathrm{mmol} \mathrm{L}^{-1}$ de $\mathrm{H}_{2} \mathrm{O}_{2}$.

Curvas analíticas obtidas durante a determinação de peróxidos de hidrogênio ao longo de 5 dias, cada curva analítica representa uma média de 6 curvas amperométricas consecutivas, que desempenhou em cada dia, apresentando uma diminuição de somente $27 \%$ na sensibilidade do eletrodo modificado. Quando fora de uso o eletrodo foi armazenado em solução $0,5 \mathrm{~mol} \mathrm{~L}^{-1}$ de $\mathrm{KCl}$.

A um potencial aplicado de $0,04 \mathrm{~V}$ não foi detectada uma interferência do mediador ou oxidação direta do ácido úrico. A interferência de ácido ascórbico foi apenas significativa para potenciais iguais ou superiores a $0,060 \mathrm{~V}$. 


\section{Sumário}

I - INTRODUÇÃO E OBJETIVOS 01

II - PARTE EXPERIMENTAL 28

II.1 - Reagentes e Soluções 28

II.1.1 - Composição da Solução Modificadora Utilizada para 30

Preparação dos Filmes de Azul da Prússia (AP)

II.1.1.a- Por Voltametria Cíclica 30

II.1.1.b- Por Deposição a Potencial Controlado 31

II.1.1.c- Por Deposição a dois Potenciais Controlados 31

II.2 - Equipamentos 31

II.2.1 - Sistema de Eletrodos 32

II.2.2.1 - Preparação dos Eletrodos Modificados com Azul da 33 Prússia

II.2.2.1.a - Por Voltametria Cíclica 33

II.2.2.1.b - Por Deposição a Um Potencial Controlado 34

II.2.2.1.c - Por Deposição a Dois Potenciais Controlados 34

II.2.2.1.d - Por Deposição a Dois Potenciais Controlados e Ativação em 34 Solução contendo $\mathrm{KCl} 0,5 \mathrm{~mol} \mathrm{~L}^{-1}$ e $\mathrm{RuCl}_{3} 1,0 \times 10^{-3} \mathrm{~mol} \mathrm{~L}^{-1}$

II.2.2.1.e - Por Deposição a Dois Potenciais Controlados e Ativação em 35 Solução contendo $\mathrm{KCl} 0,5 \mathrm{~mol} \mathrm{~L}^{-1}$ e $\mathrm{RhCl}_{3} 1,0 \times 10^{-3} \mathrm{~mol} \mathrm{~L}^{-1}$

II.2.2.2 - Preparação dos Eletrodos Modificados em Solução 35 de $\mathrm{RhCl}_{3}$

II.2.2.2.a - Por Deposição a Dois Potenciais Controlados em Solução 35 contendo $1,0 \times 10^{-3} \mathrm{~mol} \mathrm{~L}^{-1}$ de $\mathrm{RhCl}_{3}$

\section{II.2.3.1 - Curvas Analíticas para Determinação de $\mathrm{H}_{2} \mathrm{O}_{2}$}

11.2.3.1.a - Curvas Analíticas para Determinação de $\mathrm{H}_{2} \mathrm{O}_{2}$ Utilizando o 36 Eletrodo Modificado com Azul da Prússia 
II.2.3.1.b - Curvas Analíticas para Determinação de $\mathrm{H}_{2} \mathrm{O}_{2}$ Utilizando o Eletrodo Modificado com Azul da Prússia e Posteriormente Ativado em Solução contendo $1,0 \times 10^{-3} \mathrm{~mol} \mathrm{~L}^{-1}$ de $\mathrm{RhCl}_{3}$

II.2.3.1.c - Curvas Analíticas Utilizadas para Estabelecer o Limite de Deteç̧ão para Determinação de $\mathrm{H}_{2} \mathrm{O}_{2}$ Utilizando o Eletrodo Modificado com Azul da Prússia e Posteriormente Ativado em Solução contendo $1,0 \times 10^{-3} \mathrm{~mol} \mathrm{~L}^{-1}$ de $\mathrm{RhCl}_{3}$

II.2.3.2- Avaliação da Interferência dos ácidos Ascórbico e Úrico na Determinação de $\mathrm{H}_{2} \mathrm{O}_{2}$ Utilizando os Eletrodos Modificados com Azul da Prússia e Posteriormente Ativados em Solução contendo $1,0 \times 10^{-3} \mathrm{~mol} \mathrm{~L}^{-1}$ de $\mathrm{RhCl}_{3}$

II.2.3.2a - Curva Corrente vs Potencial - Interferência do ácido Ascórbico na Determinação de $\mathrm{H}_{2} \mathrm{O}_{2}$ Utilizando Eletrodos Modificados com Azul da Prússia e Posteriormente Ativados em Solução contendo $1,0 \times 10^{-3} \mathrm{~mol} \mathrm{~L}^{-1}$ de $\mathrm{RhCl}_{3}$

II.2.3.2b - Interferência do ácido Ascórbico na Determinação de $\mathrm{H}_{2} \mathrm{O}_{2}$ 38 Utilizando os Eletrodos Modificados com Azul da Prússia e Posteriormente Ativados em Solução contendo $1,0 \times 10^{-3} \mathrm{~mol} \mathrm{~L}^{-1}$ de $\mathrm{RhCl}_{3}$

\section{III- RESULTADOS E DISCUSSÕES}

Ill.1 - Preparação de Eletrodos de Pasta de Carbono 39 Modificados com Azul da Prússia por Voltametria Cíclica

III.1.1 - Formação do Filme de Azul da Prússia como Descrito 39 por Chi et al ${ }^{(29)}$.

III.1.2 - Influência da Concentração de $\mathrm{HCl}$ na Solução 39 Modificadora. 
III.1.3 - Influência da Concentração de $\mathrm{KNO}_{3}$ na Solução 44 Modificadora.

III.1.4 - Estabilidade dos Filmes de Azul da Prússia Durante 48 Ciclagens Sucessivas em Solução de Eletrólito Suporte.

III.1.4.a - Influência da Secagem Prévia dos Filmes. 48

III.1.4.b - Influência do pH da Solução de Eletrólito Suporte na 49 Estabilidade dos Eletrodos Modificados.

III.1.4.c - Influência da Concentração de $\mathrm{FeCl}_{3}$ da Solução 53 Modificadora na Estabilidade dos Eletrodos Modificados.

III.1.5 - Redução Catalítica de $\mathrm{H}_{2} \mathrm{O}_{2}$ em Eletrodos de Pasta de 59 Carbono Modificados com Filmes de Azul da Prússia.

III.1.5.a - Redução Catalítica de $\mathrm{H}_{2} \mathrm{O}_{2}$ Usando Voltametria Cíclica. 59

III.1.5.b - Escolha do Potencial Adequado para Redução Catalítica de 64 $\mathrm{H}_{2} \mathrm{O}_{2}$.

III.1.5.c - Determinação Amperométrica de $\mathrm{H}_{2} \mathrm{O}_{2}$.

III.2 - Preparação de Eletrodos de Pasta de Carbono 70 Modificados com Azul da Prússia por Deposição a Um Potencial Controlado

III.2.1 - Crescimento dos Filmes de Azul da Prússia Durante 70 Ciclagens Sucessivas em Solução de Eletrólito Suporte.

III.2.1.a - Influência do Ânion do Sal de Potássio nas Correntes de 73 Picos dos Filmes de Azul da Prússia.

III.2.1.b - Influência da Introdução de $\mathrm{KCl}$ na Solução Modificada 75 Durante o Processo de Formação dos Filmes.

III.2.2 - Determinação Amperométrica de $\mathrm{H}_{2} \mathrm{O}_{2}$.

III.3 - Preparação de Eletrodos de Pasta de Carbono 79 Modificados com Azul da Prússia por Deposição a Dois Potenciais Controlados 
III.3.1.a - Crescimento dos Filmes de Azul da Prússia Durante 82 Ciclagens Sucessivas em Solução de Eletrólito Suporte contendo $\mathrm{RuCl}_{3}$.

III.3.1.b - Crescimento dos Filmes de Azul da Prússia Durante 86 Ciclagens Sucessivas em Solução de Eletrólito Suporte contendo $\mathrm{RhCl}_{3}$.

III.3.2 - Escolha do Potencial Adequado para Redução 90 Catalítica de $\mathrm{H}_{2} \mathrm{O}_{2}$ em Eletrodos de Pasta de Carbono Modificados com Azul da Prússia e Posteriormente Ativados em solução contendo $0,5 \mathrm{~mol} \mathrm{~L}^{-1}$ de $\mathrm{KCl}$ e $1 \mathrm{~m} \mathrm{~mol} \mathrm{~L}^{-1}$ de $\mathrm{RhCl}_{3}$ (EPCAP-Rh)

III.3.3 - Preparação de Eletrodo de Pasta de Carbono 92 Modificado em solução $1 \mathrm{~m} \mathrm{~mol} \mathrm{~L}{ }^{-1}$ de $\mathrm{RhCl}_{3}$ por Deposição a Dois Potenciais Controlados (EPC-Rh).

III.3.4 - Comportamento Eletroquímico do Eletrodo de Pasta 98 de Carbono Modificado com Filme de Azul da Prússia ativado em solução contendo $0,5 \mathrm{~mol} \mathrm{~L}^{-1}$ de $\mathrm{KCl}$ e $1 \mathrm{~m} \mathrm{~mol} \mathrm{~L}^{-1}$ de $\mathrm{RhCl}_{3}$, (EPCAP-Rh).

III.3.5 - Faixas Lineares e Limites de Detecção para 102 Determinação de $\mathrm{H}_{2} \mathrm{O}_{2}$ em Eletrodos de Pasta de Carbono Modificados com AP ativados com $\mathrm{RhCl}_{3}$ (EPCAP- Rh).

III.3.6 - Armazenamento e Tempo de Vida dos EPCAP-Rh. 
III.3.7 - Avaliação da Interferência dos ácidos Ascórbico e Úrico

Durante a Determinação de $\mathrm{H}_{2} \mathrm{O}_{2}$ Utilizando os Eletrodos Modificados com Azul da Prússia e Posteriormente Ativados em Solução contendo $1,0 \times 10^{-3} \mathrm{~mol} \mathrm{~L}^{-1}$ de $\mathrm{RhCl}_{3}$

\section{IV - CONCLUSÕES




\section{DESENVOLVIMENTO DE ELETRODOS DE PASTA DE CARBONO MODIFICADOS COM FILMES DE Fe $4\left[\mathrm{Fe}(\mathrm{CN})_{6}\right]_{3}$, AZUL DA PRÚSSIA PARA DETERMINAÇÂO DE $\mathrm{H}_{2} \mathrm{O}_{2}$}

\section{I- INTRODUCÃO}

O monitoramento de $\mathrm{H}_{2} \mathrm{O}_{2}$ e peróxidos orgânicos é importante em diversos processos bioquímicos ${ }^{(1)}$, hospitalares ${ }^{(2)}$, industriais e ambientais ${ }^{(3)}$. Nos processos bioquímicos como, por exemplo, o "stress" oxidativo ${ }^{(1)}$, o equilíbrio entre espécies próoxidantes e antioxidantes é quebrado em favor do estado próoxidante. Os resultados deste desequilíbrio são lesões no DNA gerando produtos degradados de desoxirribose, bases modificadas como exemplo a 8-oxo-guanina promutagênica que, se presente no DNA durante a replicação, incorpora dAMP resíduos, o que induz a transversão mutagênica e pode levar ao câncer ${ }^{(4)}$ (Figura 1).

transversão mutagênica

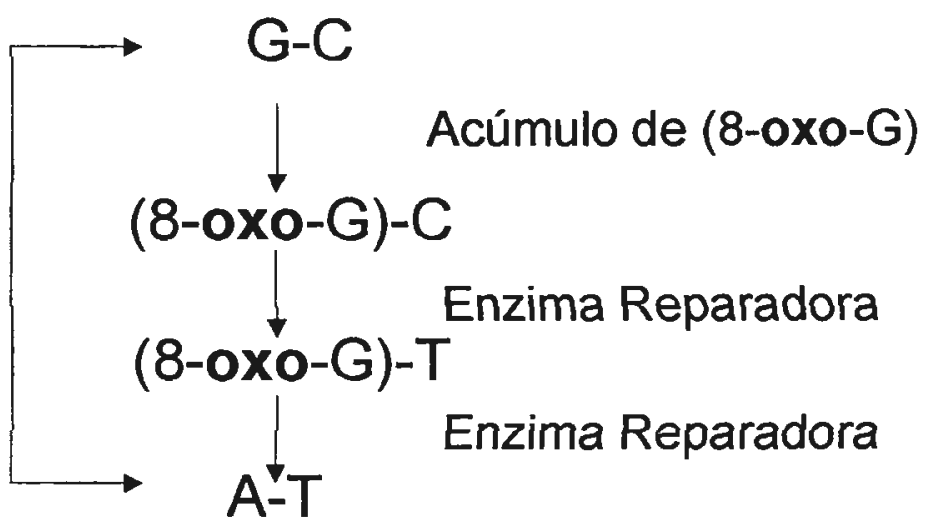

Figura 1. Transversão mutagênica no pareamento normal de Watson Crick. -

Nos processos hospitalares o peróxido de hidrogênio tem sido utilizado como um agente despirogenizante ${ }^{(2)}$ alternativo, eliminando as endotoxinas 
causadoras de febre dos componentes médicos hospitalares. Este procedimento tem sido adotado porque o solvente utilizado para a lavagem destes componentes, o clorofluorcarbono (CFC) é particularmente o freon 12. Buscando a diminuição do impacto causado pelo freon 12 na camada de ozônio na estratosfera e ainda, visando obediência ao protocolo de Montreal se buscam alternativas, ainda que menos eficientes no aspecto técnico, para a substituição deste fluorado.

O peróxido também é importante para fabricação de muitos produtos industriais ${ }^{(5)}$ tais como: pastas de alto rendimento (PAR) nas formulações de papéis de imprensa, papéis de impressão, escrita e pasta fofa. Entretanto, esta última deve ser previamente submetida a processos de branqueamento ${ }^{(5)}$, seja pelo uso de agentes oxidantes ou pelo uso de agentes redutores. Quando se deseja alto ganho de percentuais em alvura o reagente mais utilizado é a $\mathrm{H}_{2} \mathrm{O}_{2}$ ou uma aplicação desta seguida de tratamento com ditionito de sódio (ou hidrossulfito de sódio).

Sob o aspecto ambiental, a importância da água oxigenada reside no fato da mesma ser o oxidante fotoquimico de maior participação na oxidação de $\mathrm{SO}_{2}$ a $\mathrm{H}_{2} \mathrm{SO}_{4}$ na fase aquosa da atmosfera auxiliando na produção de chuva ácida. A principal fonte de $\mathrm{H}_{2} \mathrm{O}_{2}$ é a reação de radicais hidroperoxil em fase gasosa, gerada a partir da emissão de poluentes primários e poluentes secundários ${ }^{(3)}$ como mostra a Figura 2 . 

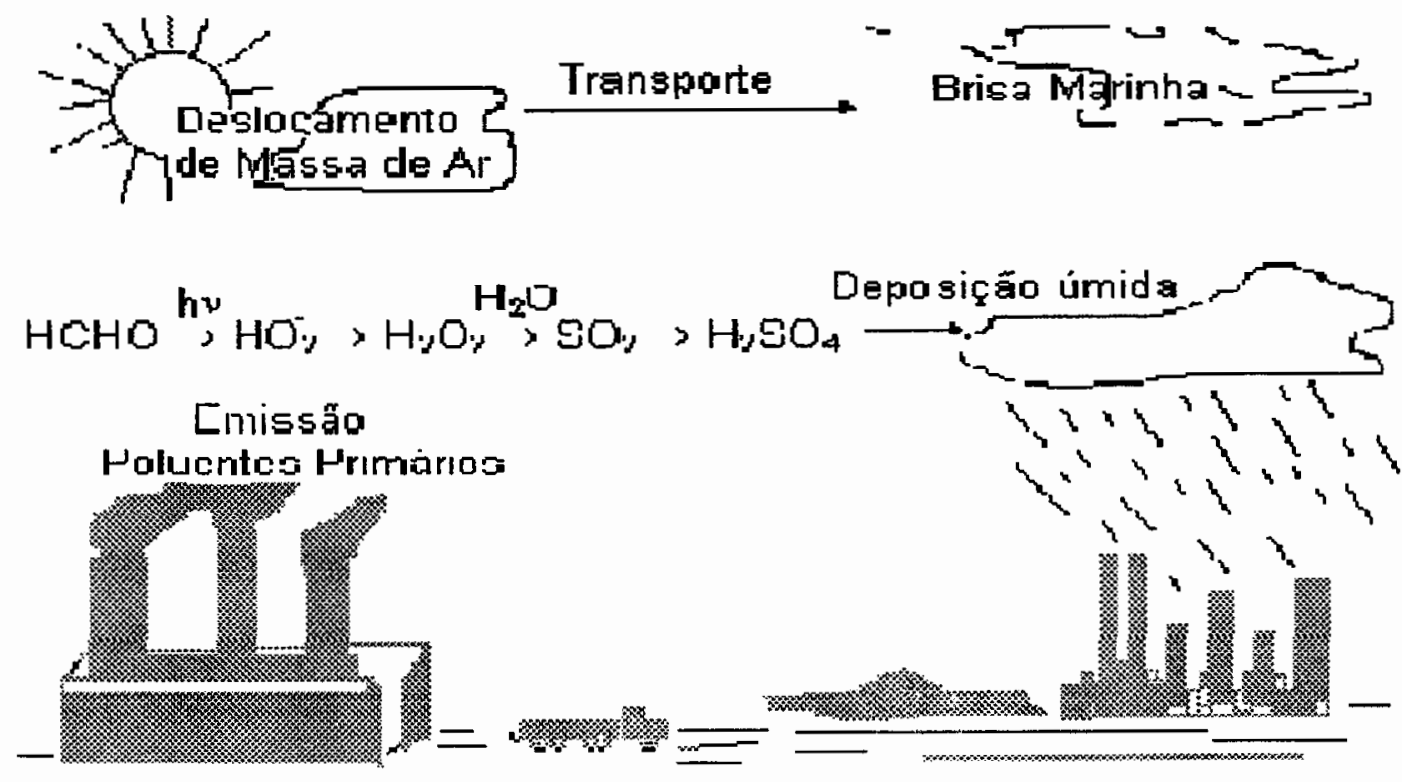

Figura 2. Processo de formação e propagação da chuva ácida ${ }^{(3)}$.

A determinação eletroanalítica de peróxidos pode ser efetuada com eletrodos de trabalho não modificados, como por exemplo, eletrodos $e$ micro-eletrodos de platina ou carbono vítreo ${ }^{(6)}$. Os maiores problemas associados à utilização de eletrodos não modificados são o alto potencial empregado $(0,584 \mathrm{~V}$ vs $\mathrm{Ag} / \mathrm{AgCl}$ ), o envenenamento do eletrodo ${ }^{(7)}$ e a alta concentração de $\mathrm{H}_{2} \mathrm{O}_{2}$ necessária para a detecção $\left(1 \mu-80 \mathrm{mmol} \mathrm{L}^{-1}\right)^{(8)}$.

Por outro lado, estes problemas parecem ter sido satisfatoriamente resolvidos determinando-se $\mathrm{H}_{2} \mathrm{O}_{2}$ em meio alcalino com eletrodo gotejante de mercúrio ${ }^{(3)}$. A determinação pode ser feita por redução ou oxidação:

Redução: $\quad \mathrm{H}_{2} \mathrm{O}_{2}+2 \mathrm{e}^{-}+2 \mathrm{H}^{+} \rightleftarrows 2 \mathrm{H}_{2} \mathrm{O} \quad$ (I.1)

Oxidação: $\mathrm{H}_{2} \mathrm{O}_{2} \rightleftarrows 2 \mathrm{e}^{-}+2 \mathrm{H}^{+}+\mathrm{O}_{2} \quad(\mathrm{l} .2) \mathrm{E}_{\text {apl }}=-0,07 \mathrm{~V}$ vs $\mathrm{Ag} / \mathrm{AgCl}$

A melhor opção para a determinação de peróxido na faixa de concentração entre $1-10 \mu \mathrm{mol} \mathrm{L}^{-1}$ é trabalhar na faixa onde se elimina a interferência do $\mathrm{O}_{2}$.

Alternativamente pode-se utilizar sistemas enzimáticos, que conferem maior seletividade no reconhecimento molecular do analíto. Neste caso, a enzima mais 
utilizada é a peroxidase, enzima redox glicolisada que possui uma ferroporfinina ou ainda a flavina adenina dinucleotídeo $\left(\mathrm{FADH}_{2}\right)$, como cofator fortemente ligado à estrutura da enzima. Na reação catalítica com peróxido, o centro ativo da enzima nativa é oxidado, em uma única etapa envolvendo dois elétrons, a um composto intermediário denominado de composto (I) enquanto o substrato é reduzido. Para completar o ciclo catalítico, a enzima pode ser diretamente reduzida, na superfície do eletrodo, à sua forma nativa. O processo ocorre em duas etapas, envolvendo um elétron na etapa de formação de um composto intermediário, denominado de composto (II) que também deve receber um elétron para regeneração final do centro ativo da enzima. Assim, a corrente de redução registrada é então proporcional à concentração de $\mathrm{H}_{2} \mathrm{O}_{2}$, Figura 3 .

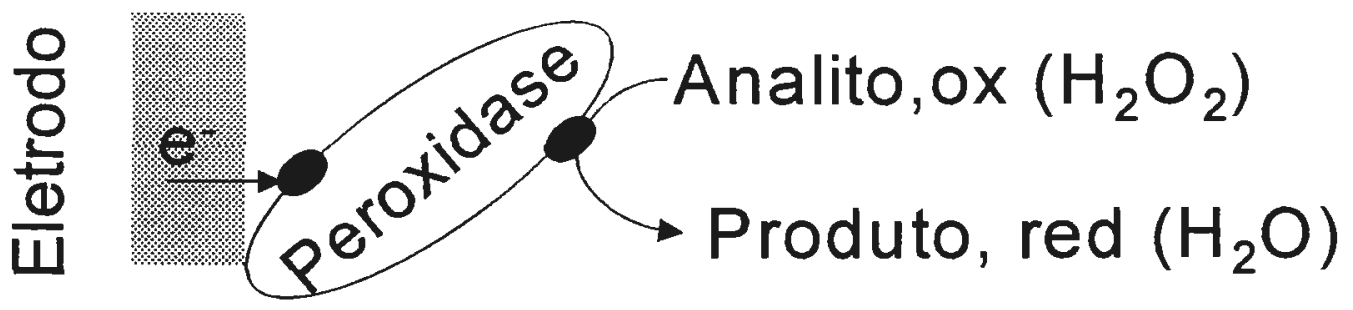

Figura 3. Redução de $\mathrm{H}_{2} \mathrm{O}_{2}$ efetuada pela enzima peroxidase.

Alternativamente, biossensores podem ser construídos utilizando transdutores quimicamente modificados com doadores ou aceptores eletrônicos, denominados de mediadores, compostos intermediários que facilitam a transferência de elétrons entre o eletrodo e o centro ativo de uma enzima, como por exemplo, íons ferrocianeto ${ }^{(9)}$, fenóis ${ }^{(13)}$, orto- e para- fenilenodiamina ${ }^{(10)}$, ferroceno ${ }^{(11)}$ e seus derivados ${ }^{(12)}$, figuras 3 e 4 . 


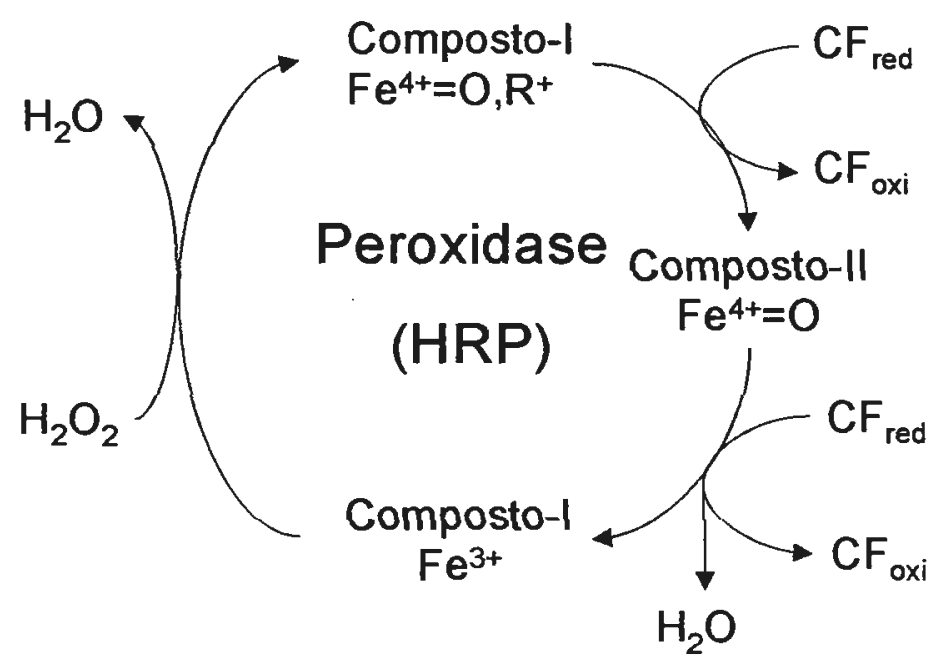

Figura 4. Ciclo catalítico da enzima peroxidase $(H R P)^{(13)} \cdot R+=$ radical protoporfirina. CF = composto fenólico, (mediador).

Os eletrodos quimicamente modificados (EQM) com mediadores de elétrons podem ser utilizados para determinação direta de $\mathrm{H}_{2} \mathrm{O}_{2}$ e, além de economicamente mais viáveis permitem o monitoramento do analíto a potenciais relativamente mais baixos do que os eletrodos não modificados (13), proporcionando maior seletividade à metodologia analítica. A utilização de eletrodos modificados envolve a disponibilidade de um mediador adequado que apresente alta velocidade de transferência eletrônica na superfície do eletrodo ${ }^{(7,12,13,37)}$.

Existe ainda interesse adicional na preparação dos eletrodos quimicamente modificados para determinação de $\mathrm{H}_{2} \mathrm{O}_{2}$, uma vez que inúmeros sistemas enzimáticos, empregando as mais diversas enzimas, produzem água oxigenada como produto final, Tabela I.1. Assim, inúmeros biossensores poderão vir a ser construídos empregando-se mediadores capazes de reduzir ou oxidar cataliticamente o peróxido de hidrogênio. Neste caso, os mediadores devem possuir comportamento redox reversivel a baixos potenciais e reagir rapidamente com o centro ativo da enzima. 


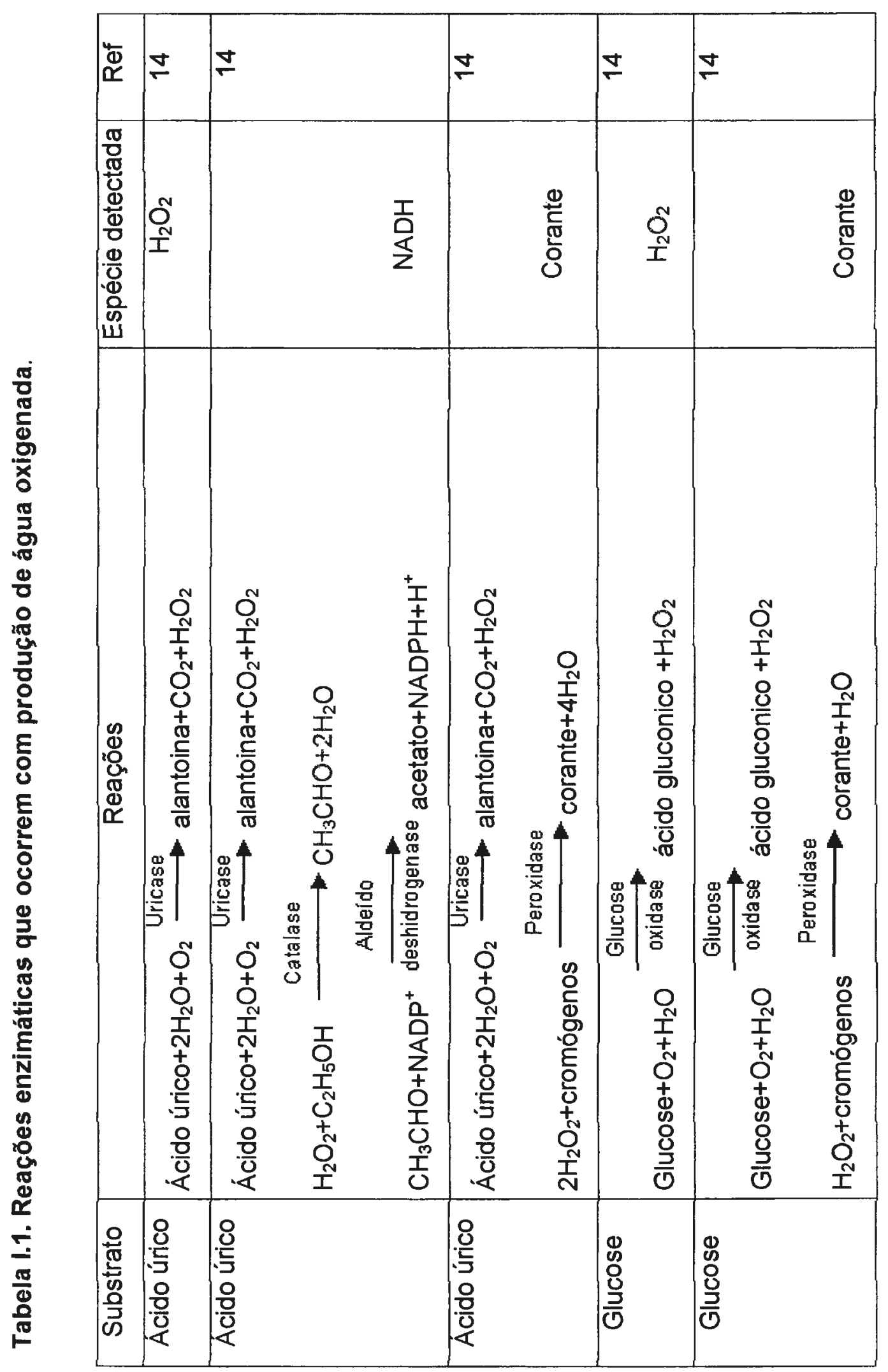




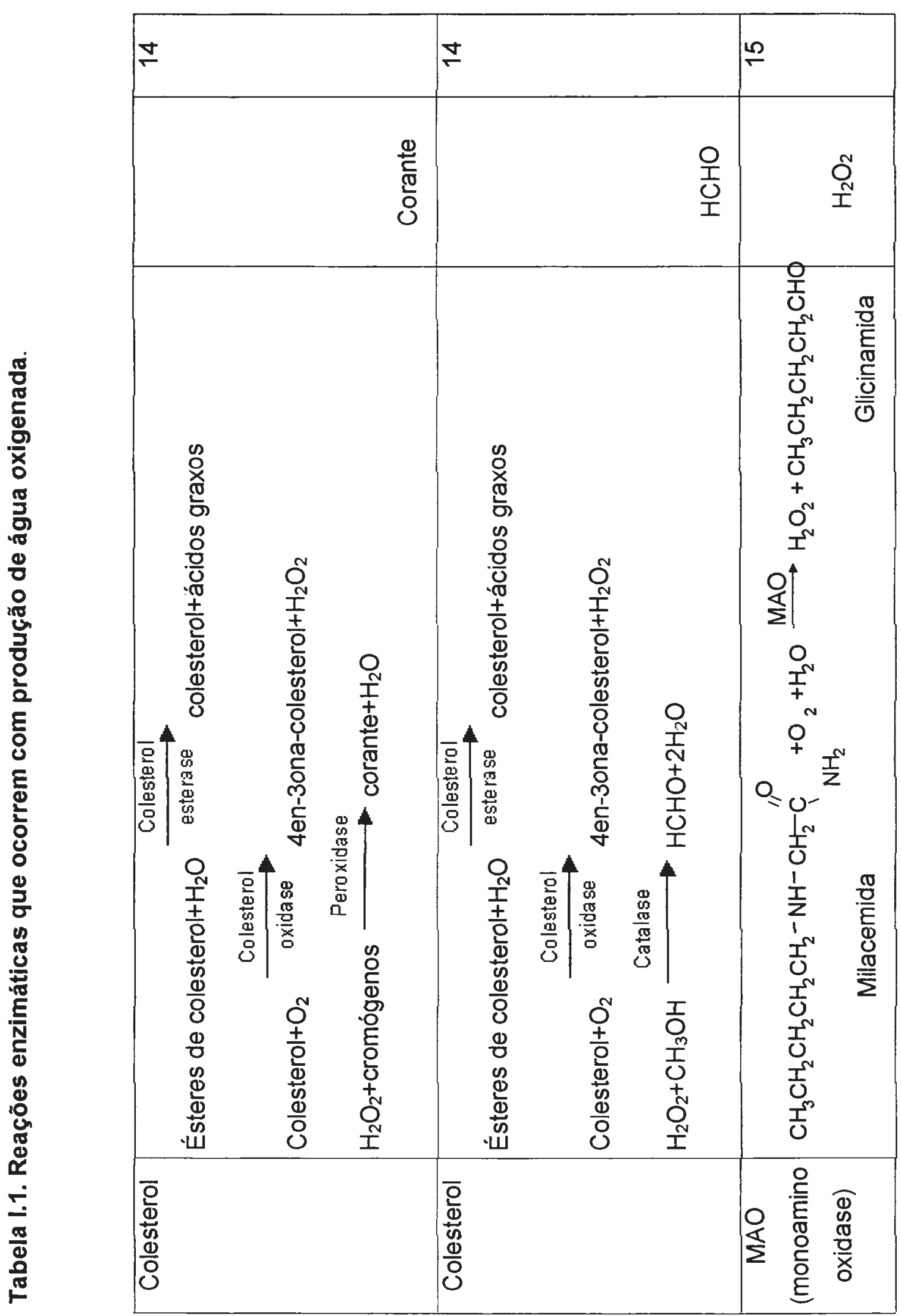




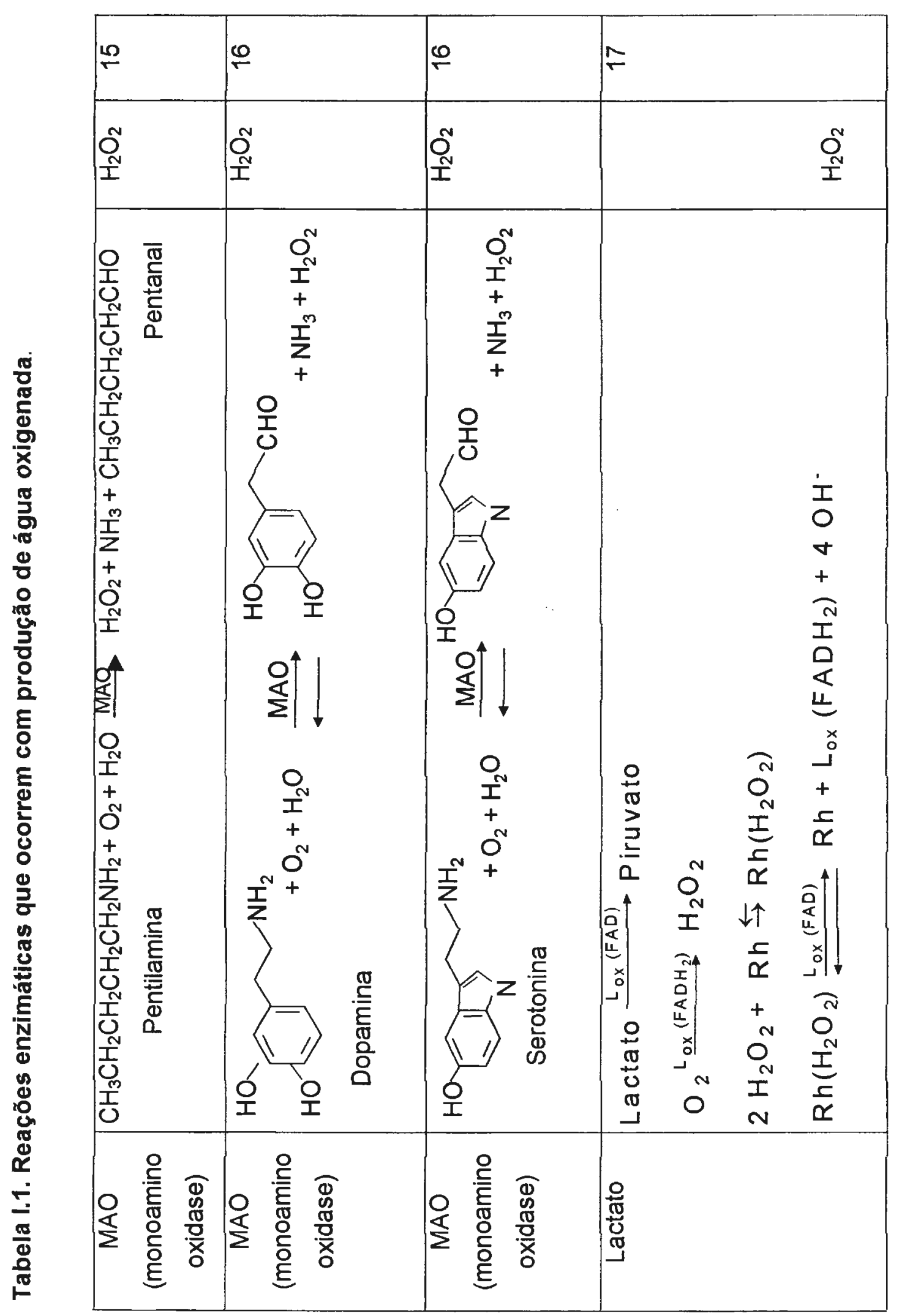


Evidentemente, outros métodos analíticos podem ser utilizados para determinação de $\mathrm{H}_{2} \mathrm{O}_{2}$ e entre estes podem ser citados os métodos espectrométricos (fluorimetria ${ }^{(18)}, \quad$ espectrofotometria ${ }^{(19,20)}$ e quimiluminescência ${ }^{(22)}$ ), envolvendo ou não sistemas enzimáticos, Tabela I.2. 


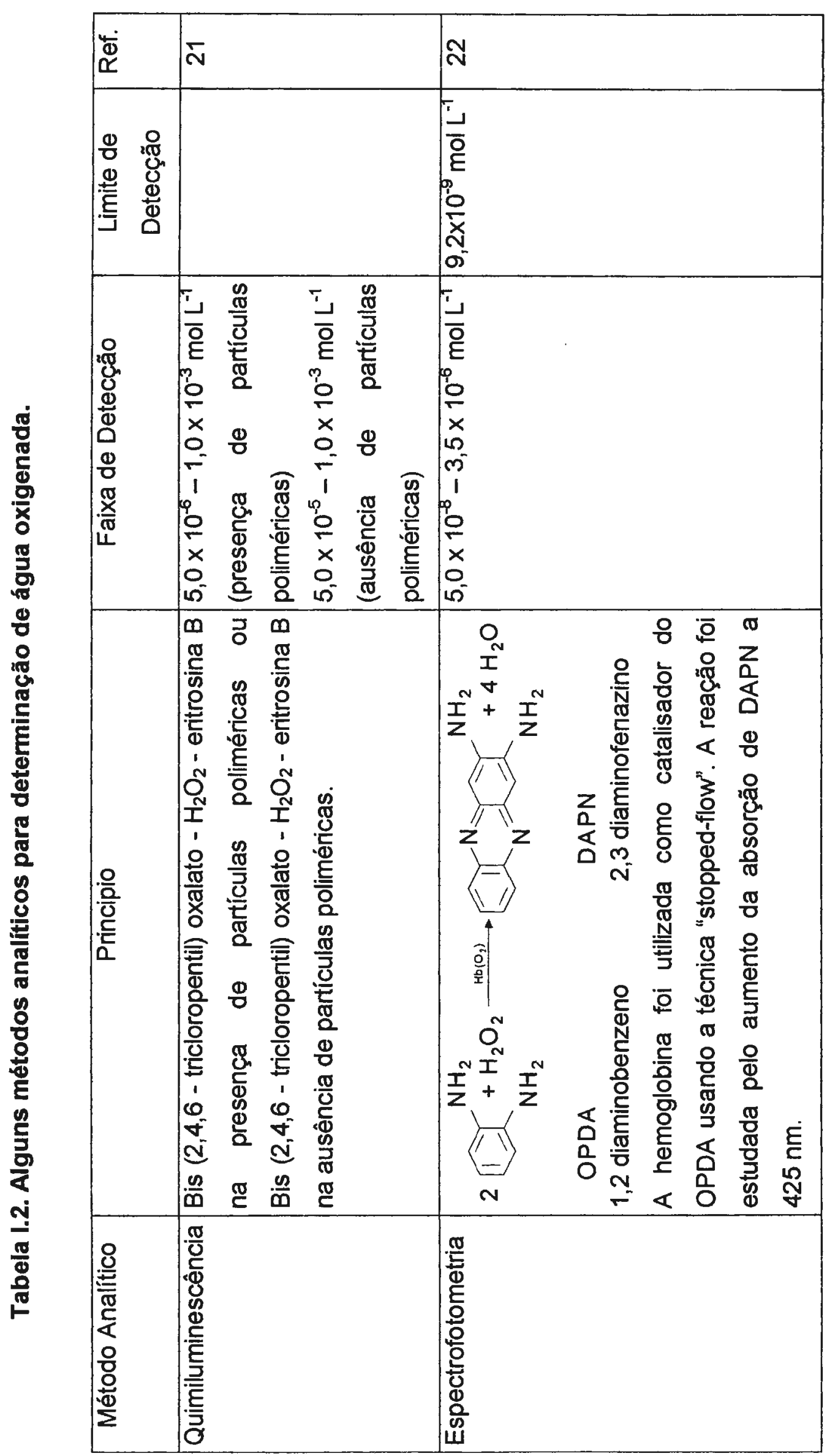




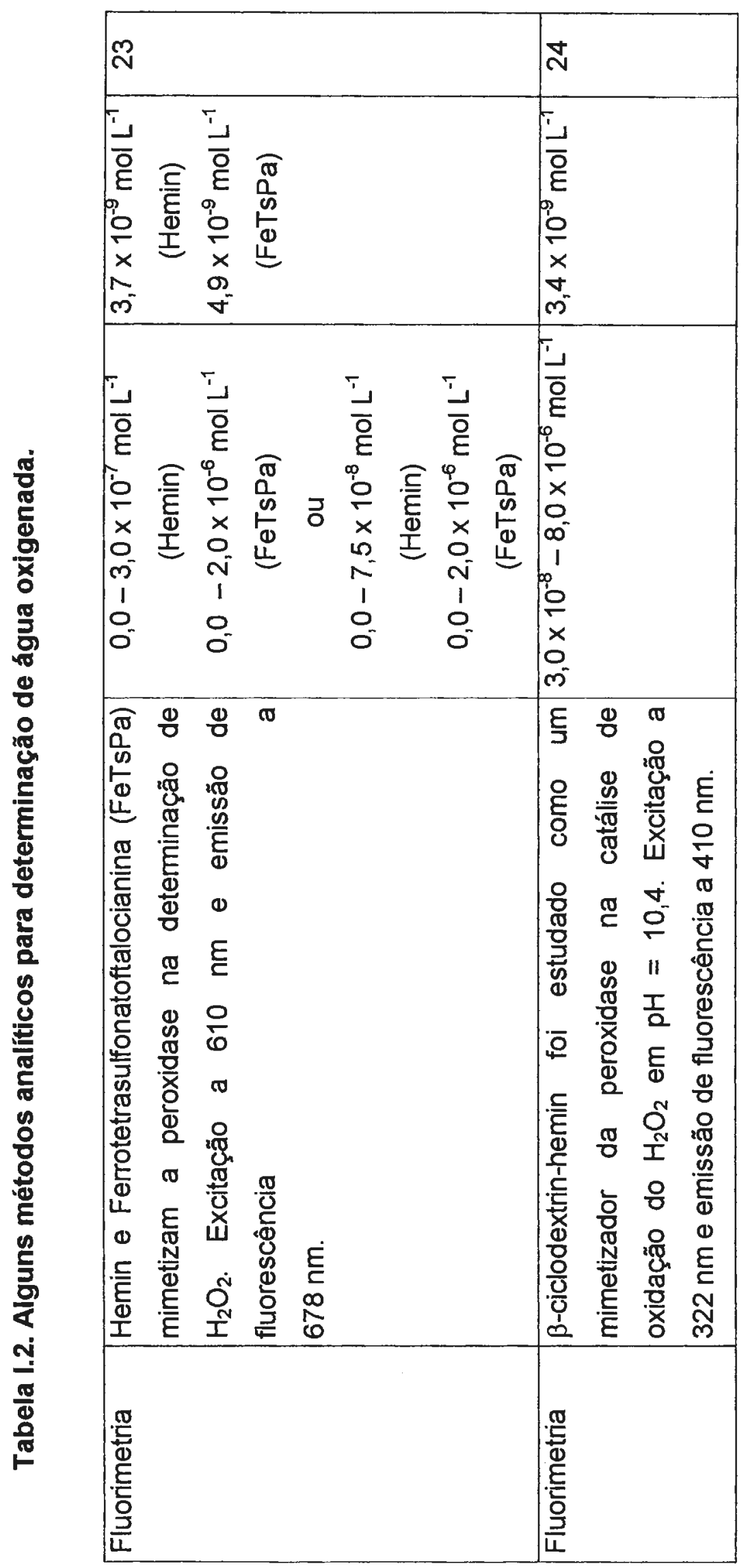




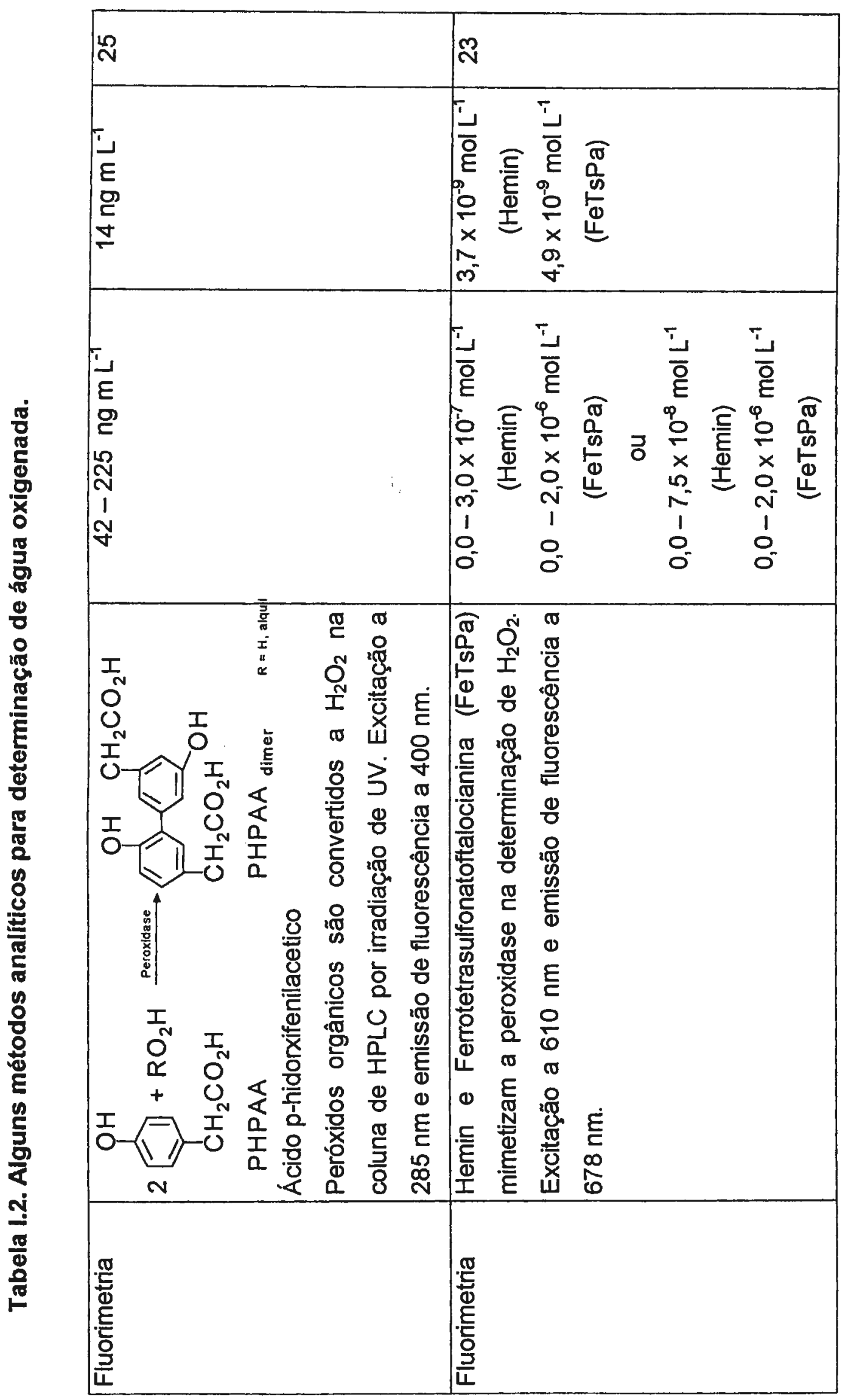


Recentemente, eletrodos quimicamente modificados com Azul da Prússia têm sido utilizados na determinação eletrocatalítica de $\mathrm{H}_{2} \mathrm{O}_{2}$.

Os filmes de $\mathrm{Fe}_{4}\left[\mathrm{Fe}(\mathrm{CN})_{6}\right]_{3}$ Azul da Prússia (AP) apresentam transição redox a baixo potencial e acentuado efeito catalítico. Em comparação à enzima peroxidase são eletrocatalisadores baratos, além de serem utilizados como mediadores para determinação de $\mathrm{H}_{2} \mathrm{O}_{2}$ em presença de oxigênio molecular no desenvolvimento de biossensores ${ }^{(26-38)}$, figura 5 .

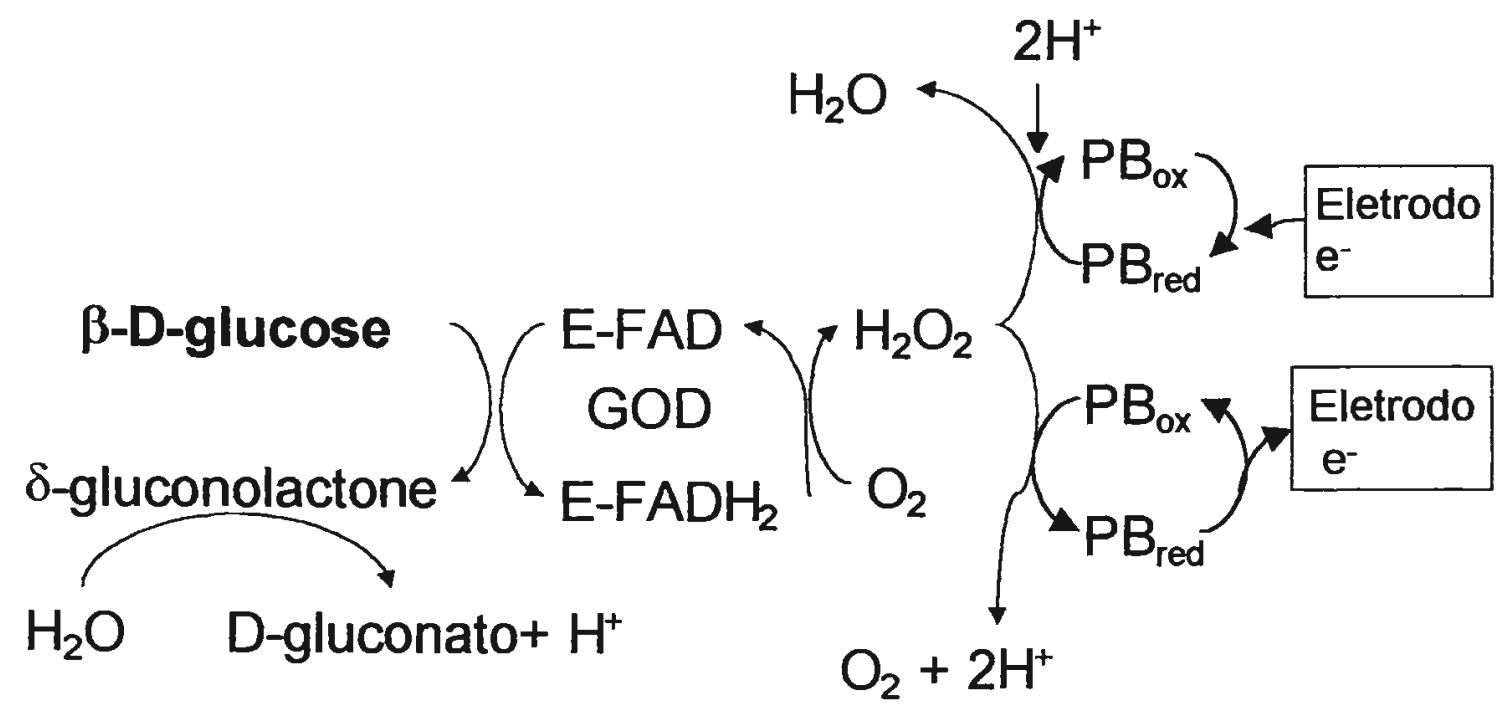

Figura 5. Redução e Oxidação eletroquímica de $\mathrm{H}_{2} \mathrm{O}_{2}$ em eletrodos modificados com filme de Azul da Prússia ${ }^{(29)}$.

O Azul da Prússia (AP), $\mathrm{Fe}_{4}\left[\mathrm{Fe}(\mathrm{CN})_{6}\right]_{3}$, é um composto de coordenação conhecido há muito tempo e intensamente estudado. Ele tem sido formulado em duas variedades conhecidas como "solúvel" (KFe" $\left.\left[\mathrm{Fe}^{\prime \prime}(\mathrm{CN})_{6}\right]\right)$ e "insolúvel" $\left(\mathrm{Fe}_{4}{ }^{\mathrm{III}}\left[\mathrm{Fe}{ }^{\prime \prime}(\mathrm{CN})_{6}\right]_{3}\right)$, apesar de ambas as formas apresentarem solubilidade baixa ${ }^{(39)}$, $\mathrm{Ks} \approx 10^{-40}$. Na realidade, tais termos foram empregados para indicar a tendência do AP para formar soluções coloidais ${ }^{(40)}$, além da facilidade da utilização do mesmo na fabricação de tintas e verniz ${ }^{(41)}$ devido à peptização de pigmentos ${ }^{(42)}$. 
A primeira estrutura para o AP foi proposta em 1936 por Kegging e Milles ${ }^{(43)}$ utilizando difratometria de raio - X. A forma "insolúvel" consiste em cadeias de $\mathrm{Fe}($ III)-NC-Fe(II) em retículo cúbico de face centrada (Figura 6), onde os ions $\mathrm{Fe}$ (III) e Fe(II) são cercados octaedricamente por átomos de nitrogênio $(\mathrm{N})$ e carbono $(\mathrm{C})$ do cianeto. As diferenças entre vários compostos surgem porque metais alcalinos podem ser incorporados na estrutura cristalina e além disto, o átomo de ferro pode estar em diferentes estados de oxidação.

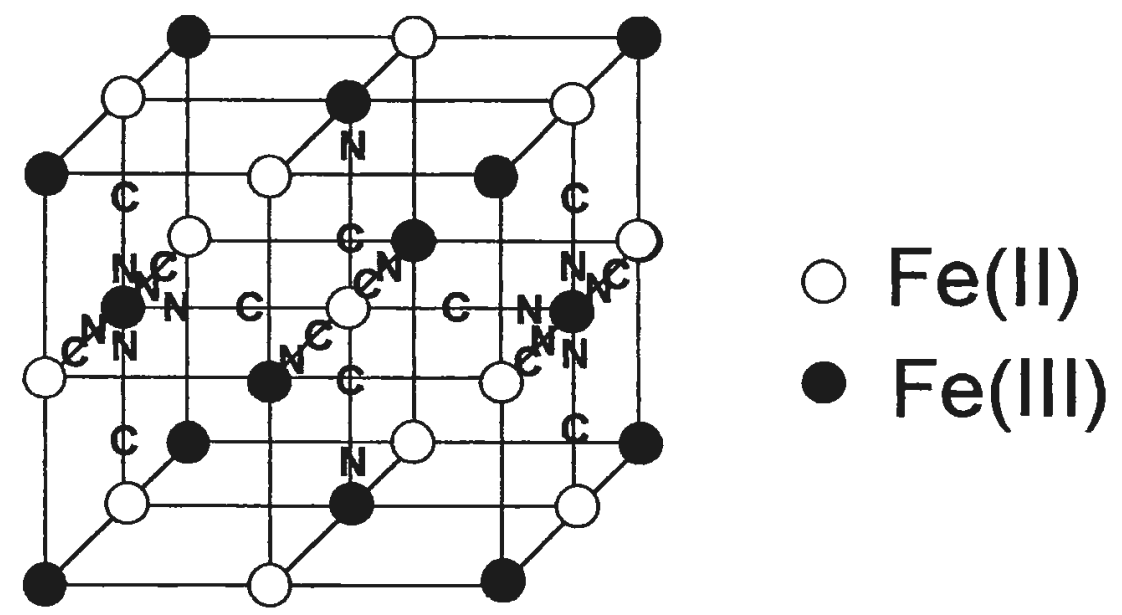

Figura 6. Representação simplificada da estrutura inicialmente proposta para o Azul da Prússia ${ }^{(42,44)}$.

Ludi et al. ${ }^{(40)}$ determinaram, por difração de raios- $X$, a densidade do AP $\left(d_{\text {experimental }}=1,75-1,81 \mathrm{~g} \mathrm{~cm}^{-3}\right.$ ) e com isso comprovaram que 1 unidade de célula estrutural do AP "insolúvel" $\mathrm{Fe}_{4}\left[\mathrm{Fe}(\mathrm{CN})_{6}\right]_{3} \mathrm{xH}_{2} \mathrm{O}$ é constituida por uma rede cúbica primitiva de cadeias de $\mathrm{Fe}(\mathrm{III})-\mathrm{NC}-\mathrm{Fe}(\mathrm{II})$ com aresta (a) $=10,166 \AA$ e $d_{\text {ideal }}=1,78 \mathrm{~g} \mathrm{~cm}^{-3}$ para $x=15$. Deste modo, o modelo de Ludi et al ${ }^{(40)}$ discorda do modelo proposto de Kegging e Milles ${ }^{(43)}$ que não pressupõe coordenação intersticial dos estados de transição dos íons metálicos, nem posições cristalográficas suficientes para as moléculas de água de rede e moléculas de água de coordenação de acordo com o grau de hidratação do composto. 
O Azul da Prússia em diferentes estados de hidratação e desidratação(45,46) tem sido estudado por difração de nêutrons. O resultado do cálculo estrutural utilizado na análise de difração revela duas estruturas distintas de moléculas de $\mathrm{H}_{2} \mathrm{O}$, onde 6 delas estão coordenadas ao Fe(III) ligado ao nitrogênio do cianeto e aproximadamente 8 moléculas de $\mathrm{H}_{2} \mathrm{O}$ adicionais estão presentes ou isoladas no centro da célula unitária octante ou como moléculas de $\mathrm{H}_{2} \mathrm{O}$ conectadas por pontes de hidrogênio para uma coordenação(46).

Além disso, Ganguli e Bhattacharya ${ }^{(47)}$ estudaram por termogravimetria todos os diferentes estados de hidratação do AP. O efeito da hidratação sobre a condutividade foi estudado por RMN de $\mathrm{H}$, comprovando a cristalização de $\mathrm{H}_{2} \mathrm{O}$ para íons de $\mathrm{Fe}^{3+}$ em $\mathrm{Fe}_{4}\left[\mathrm{Fe}(\mathrm{CN})_{6}\right]_{3} \mathrm{nH}_{2} \mathrm{O}$ como previsto pelo modelo de Ludi ${ }^{(40)}$. Os autores também concluíram que a energia de ativação para a formação do Azul da Prússia varia com a hidratação do complexo e quanto mais hidratado este for menor será a energia de ativação de formação do mesmo. Conseqüentemente o AP pode ser um semicondutor do tipo $\mathrm{p}$ que apresenta dois níveis de $\mathrm{Fe}^{3+}$ (ativação e acepção) perto da banda de valência, que é formada por ambos orbitais de ligação e $\mathrm{Fe}^{2+}$. Dependendo do nível de $\mathrm{Fe}^{3+}$, o composto seria um isolante. Então a transferência de elétrons entre $\mathrm{Fe}^{2+}$ e $\mathrm{Fe}^{3+}$ (para a banda de valência do nível de $\mathrm{Fe}^{3+}$ ) torna-se característica de um composto de valência mista responsável pela mudança drástica nas propriedades eletrônicas do material.

Os mesmos autores ${ }^{(48)}$ também propuseram, com base em estudos DTA e RMN, que há 3 classes de moléculas de $\mathrm{H}_{2} \mathrm{O}$ caracterizadas como água zeolítica, água de rede e água de coordenação natural e não apenas duas como proposto no modelo de Ludi $^{(40)}$. Os estudos com RMN demonstram que existem moléculas de $\mathrm{H}_{2} \mathrm{O}$ intermediárias, denominadas de água de rede, além das moléculas de água de coordenação. Estas últimas encontram-se fortemente ligadas à estrutura cristalina. 
Então, em termos de coordenação pode ser estabelecido que as moléculas de $\mathrm{H}_{2} \mathrm{O}$ são distribuídas em $1^{\mathrm{a}}, 2^{\mathrm{a}}$ e $3^{\mathrm{a}}$ esferas de coordenação respectivamente água de zeolítica, água de rede e água de coordenação(48).

As características de eletrodos modificados com filmes de AP dependem principalmente das condições de formação dos filmes. Estes últimos podem ser preparados química ou eletroquimicamente.

Dentre os trabalhos que descrevem a preparação química podem ser citados os trabalhos de Melvin e Robin ${ }^{(42)}$, Duncan e Wigley ${ }^{(49)}$, Buser et al. ${ }^{(40)}$, Neff ${ }^{(50,51)}$, Day et al. ${ }^{(45)}$, Ellis et al. ${ }^{(39)}$, Itaya et al ${ }^{(41)}$ e Ganguli e Bhattacharya ${ }^{(47,48)}$.

Melvin e Robin ${ }^{(42)}$ prepararam uma dispersão aquosa de AP por adição estequiométrica de solução $\mathrm{K}_{4} \mathrm{Fe}^{\prime \prime}(\mathrm{CN})_{6}$ a uma solução $\mathrm{Fe}^{\prime \prime \prime}\left(\mathrm{ClO}_{4}\right)_{2}$. O mesmo procedimento foi realizado substituindo-se $0 K_{4} \mathrm{Fe}^{\prime \prime}(\mathrm{CN})_{6}$ por $\mathrm{K}_{4} \mathrm{Ru}^{\prime \prime}(\mathrm{CN})_{6}$ ou $\mathrm{K}_{4} \mathrm{Os}^{\prime \prime}(\mathrm{CN})_{6}$. Os autores atribuiram a coloração azul à mudança da transferência de carga entre $\mathrm{Fe}^{\prime \prime}(\mathrm{CN})_{6}{ }^{4-}$ e $\mathrm{Fe} \mathrm{I}^{\mathrm{II \prime}}$. A medida da intensidade de transição indica que os elétrons da última camada externa estão em geral (99\%) localizados no $\mathrm{Fe}^{\prime \prime}(\mathrm{CN})_{6}^{4}$.

Neff ${ }^{(50)}$ observou que filmes finos e aderentes de Azul da Prússia sobre eletrodos de Pt eram formados por imersão do eletrodo (previamente catodizado em $\mathrm{HCl} 1 \mathrm{~mol} \mathrm{~L}^{-1}$ a $1 \mathrm{~mA}$ por 1 hora) em soluções contendo íns $\mathrm{Fe}^{3+} \mathrm{e}$ $\left[\mathrm{Fe}(\mathrm{CN})_{6}\right]^{3-}$ na proporção de 1:1 por alguns minutos. Nesta solução modificadora formou-se o complexo $\mathrm{Fe}^{\mathrm{III}}\left[\mathrm{Fe} \mathrm{e}^{\mathrm{II \prime}}(\mathrm{CN})_{6}\right]$, Marrom da Prússia, que pode sofrer polimerização lenta promovendo a eventual precipitação do Verde de Berlim, $\mathrm{Fe}^{\prime \prime \prime}\left[\mathrm{Fe} \mathrm{F}^{\mathrm{II \prime}}(\mathrm{CN})_{6}\right]$. Por este motivo, soluções recém preparadas devem ser utilizadas. O voltamograma cíclico, registrado com um eletrodo assim modificado, em soluçăo de $\mathrm{KCl} 1 \mathrm{~mol} \mathrm{~L}^{-1}$ apresentou na varredura anódica ( $E_{\text {final }}=0,6 \mathrm{Vvs} E C S$ ) a coloração azul devido à formação do AP enquanto na varredura catódica a superficie do eletrodo tornou-se incolor, ao redor de $0,0 \mathrm{~V}$, devido à redução do Azul da Prússia ao sal de Everitt, $\mathrm{K}_{2} \mathrm{Fe}^{\prime \prime} \mathrm{Fe} \mathrm{e}^{\prime \prime}(\mathrm{CN})_{6}$, também denominado de Branco da Prússia. Em potenciais mais positivos do que 1,0 V, o filme tornou-se verde, 
aparentemente devido à oxidação do Azul da Prússia ao Verde de Berlim. Como no caso anterior, as colorações sobre o eletrodo se alternaram em função do potencial aplicado.

Ellis et al ${ }^{(39)}$ descreveram a deposição de micro-cristais do Azul da Prússia sobre eletrodo de Pt previamente catodizado em solução $1 \mathrm{~mol} \mathrm{~L}^{-1}$ de $\mathrm{HCl}$ por 15 minutos a 0,1 mA. O eletrodo, previamente tratado foi imerso em soluçōes aquosas contendo $1 \mathrm{mmol} \mathrm{L}^{-1}$ de $\mathrm{FeCl}_{3}, 2 \mathrm{mmol} \mathrm{L}^{-1}$ de $\mathrm{k}_{3}\left[\mathrm{Fe}(\mathrm{CN})_{6}\right]$, $0,01 \mathrm{~mol} \mathrm{~L}^{-1}$ de $\mathrm{KCl}$ em $0,1 \mathrm{~mol} \mathrm{~L}^{-1}$ de $\mathrm{HCl}$ e a formação do AP identificada pelo aparecimento de coloração azul clara na superfície do eletrodo. Os autores admitiram que a primeira etapa da reação de formação do filme envolve a redução de íons $\mathrm{Fe}^{3+}$ livres ou no complexo de $\mathrm{Fe}\left[\mathrm{Fe}(\mathrm{CN})_{6}\right]$ :

$$
\begin{aligned}
\mathrm{Fe}^{3+}+1 / 2 \mathrm{H}_{2} \mathrm{O} & \rightleftarrows 1 / 4 \mathrm{O}_{2}+\mathrm{H}^{+}+\mathrm{Fe}^{2+} \\
\mathrm{K}^{+}+\mathrm{Fe}^{2+}+\mathrm{Fe}(\mathrm{CN})_{8}{ }^{3-} & \rightleftarrows \mathrm{KFe}\left[\mathrm{Fe}(\mathrm{CN})_{6}\right]
\end{aligned}
$$

(Forma "solúvel" do AP)

Apesar da reação (l.3) ser desfavorável, o processo total possui energia livre de - $177 \mathrm{~kJ} \mathrm{~mol}^{-1}$, permitindo a formação química do filme. Os autores acreditam que metais como ouro e platina catalisam a reação (I.3) uma vez que os potenciais redox do Azul da Prússia foram independentes do material do eletrodo. Assim, este último deveria atuar apenas como catalisador da reação durante a redução do íon $\mathrm{Fe}^{3+}$ ao íon $\mathrm{Fe}^{2+}$. Esta proposta foi comprovada pela introdução, junto ao eletrodo de trabalho, de um fio de cobre ou ferro, a qual resultou no aumento da velocidade de formação do filme, uma vez que estes metais atuaram como ânodo de sacrificio. Deste modo, o eletrodo de trabalho comportou-se como um cátodo para a redução do íon $\mathrm{Fe}^{3+}$.

Após lavagem com água deionizada, o eletrodo modificado com AP foi condicionado em solução $0,01 \mathrm{~mol} \mathrm{~L}^{-1}$ de $\mathrm{FeCl}_{2}$ contendo $0,01 \mathrm{~mol} \mathrm{~L}^{-1}$ de $\mathrm{HCl}$ por 30 minutos, com o objetivo de eliminar o excesso de ions ferricianeto da superfície do filme.

Os autores salientaram a importância da preparação dos filmes em meio ácido, como um procedimento importante para evitar a contaminação dos filmes 
com $\mathrm{Fe}_{2} \mathrm{O}_{3}$. Além disso, salientaram ainda, que filmes preparados na presença de $\mathrm{KCl}$ originam, preferencialmente a forma solúvel do Azul da Prússia.

Neff et al ${ }^{(51)}$ assumiram que o AP "solúvel" era quimicamente depositado sobre a superfície de eletrodos e que as reações de redução e oxidação do AP poderiam ser descritas pelas equações:

$\mathrm{KFe}^{\prime \prime \prime} \mathrm{Fe}^{\prime \prime}(\mathrm{CN})_{6}+\mathrm{e}^{-}+\mathrm{K}^{+} \rightleftarrows \mathrm{K}_{2} \mathrm{Fe}^{\prime \prime} \mathrm{Fe}^{\prime \prime}(\mathrm{CN})_{6}$

$\mathrm{KFe}^{\prime \prime \prime} \mathrm{Fe}^{\prime \prime}(\mathrm{CN})_{6} \rightleftarrows 1 / 3 \mathrm{Fe}^{\mathrm{II \prime}}\left[\mathrm{Fe}{ }^{\prime \prime}(\mathrm{CN})_{6}\right]+2 / 3 \mathrm{Fe}^{\mathrm{II \prime}}\left[\mathrm{Fe} \mathrm{e}^{\prime \prime \prime}(\mathrm{CN})_{6}\right]+2 / 3 \mathrm{e}^{-}+\mathrm{K}^{+}(\mathrm{I} .6)$

Entretanto não foi encontrada nenhuma evidência espectroscópica da presença de potássio nos filmes ${ }^{(41)}$.

Apesar dos trabalhos que descrevem a preparação química destes filmes terem fornecido informações importantes à cerca das condições de preparação e caracterização da estrutura dos filmes de Azul da Prússia ${ }^{(42,40,50,45,39,47,48,51)}$, a preparação eletroquímica ainda continua sendo o método mais amplamente utilizado, principalmente no desenvolvimento de eletrodos modificados e biossensores, sempre utilizados na determinação direta de $\mathrm{H}_{2} \mathrm{O}_{2}$, ou desta,como produto de uma reação enzimática. Conseqüentemente, são nestes trabalhos que um maior número de informações acerca da estabilidade dos filmes, principalmente durante a redução catalítica do peróxido, é encontrada.

Vários trabalhos descrevem a preparação eletroquímica de filmes de Azul da Prússia (41,56,57,51,59,52,60,26-30,58,31-33,53,34-37,54,55,38); estes podem ser distinguidos quanto a método de preparação: voltametria cíclica ${ }^{(26,27,29)}$, deposição a corrente constante ${ }^{(41,56,57,51,58,54)}$ e deposição a potencial controlado ${ }^{(52,60,30,59,53,36,55)}$.

Itaya et al ${ }^{(41)}$ preparam filmes de AP, via eletroquímica, sobre eletrodos de $\mathrm{Pt}$, carbono vitreo e $\mathrm{SnO}_{2}$ a partir de solução contendo concentrações equimolares de $\mathrm{FeCl}_{3}$ e $\mathrm{K}_{3} \mathrm{Fe}(\mathrm{CN})_{6}, 0,02 \mathrm{~mol} \mathrm{~L} \mathrm{~L}^{-1}$. O eletrodo de trabalho, juntamente com demais eletrodos, foi imerso na solução modificadora e polarizado catodicamente por 120 segundos sob condições galvanostáticas com densidade de corrente de $40 \mu \mathrm{A} / \mathrm{cm}^{2}$. O comportamento eletroquímico dos eletrodos modificados foi estudado em solução de $\mathrm{KCl} 1 \mathrm{~mol} \mathrm{~L}^{-1},(\mathrm{pH}=4,0)$. Os filmes de AP apresentaram maior espessura do que os obtidos por reação química, porém não resistiriam a 
sucessivas ciclagens a potencias positivos $(0,9 \mathrm{~V})$ em solução de $\mathrm{KCl} 1 \mathrm{~mol} \mathrm{~L}^{-1}$, $(\mathrm{pH}=4,0)$.

Chi et al. ${ }^{(29)}$ propuseram a formação do filme de Azul da Prússia por voltametria cíclica sobre eletrodo de grafite pirolítico. Os autores utilizaram um sistema de três eletrodos com $\mathrm{Ag} / \mathrm{AgCl}(\mathrm{KCl}$ sat) como eletrodo de referência, $\mathrm{Pt}$ como eletrodo auxiliar e grafite pirolítico como eletrodo de trabalho, preparando o filme em solução tampão fosfato $\mathrm{pH} 6,0$ contendo $2 \mathrm{mmol} \mathrm{L}^{-1}$ de $\mathrm{K}_{3} \mathrm{Fe}(\mathrm{CN})_{6} \mathrm{e}$ $2 \mathrm{mmol} \mathrm{L}^{-1}$ de $\mathrm{Fe}_{2}\left(\mathrm{SO}_{4}\right)_{3}$. Entretanto sabe-se que neste $\mathrm{pH}$ o $\mathrm{Fe}^{\mathrm{III}}$ é hidrolisado a hidróxido férrico ${ }^{(61)}$, o que impossibilita a formação do filme neste meio.

Karyakin et al. $^{(30)}$ descreveram um biossensor amperométrico para determinação de glucose e álcool em sistemas de análise por injeção em fluxo (FIA), através da detecção do peróxido de hidrogênio formado em eletrodos modificados com Azul da Prússia. O filme foi formado por eletrodeposição na superfície do eletrodo de trabalho, a partir de solução contendo $1 \mathrm{~mol} \mathrm{~L}^{-1}$ de $\mathrm{KCl}$; $3 \mathrm{mmol} \mathrm{L}^{-1}$ de HCl; $1 \mathrm{mmol} \mathrm{L}^{-1}$ de $\mathrm{K}_{3}\left[\mathrm{Fe}(\mathrm{CN})_{6}\right]$ e $1 \mathrm{mmol} \mathrm{L}^{-1}$ de $\mathrm{FeCl}_{3}$ por aplicação de um potencial constante de $0,4 \mathrm{~V}$ por 30 ou 100 segundos. Nesta etapa os reagentes foram adsorvidos na superfície do eletrodo e posteriormente o filme foi ativado (reação de oxi-redução) em solução $0,1 \mathrm{~mol} \mathrm{~L}^{-1}$ de $\mathrm{KCl}$ por ciclagem no intervalo $-0,05 \mathrm{~V} \leq \mathrm{E}_{\text {aplicado }} \leq 0,35 \mathrm{~V}$ a uma velocidade de varredura de $50 \mathrm{~m} \mathrm{~V} \mathrm{~s}^{-1}$. Não apenas estes autores ${ }^{(30)}$, mas outros ${ }^{(60,55)}$ adotaram procedimento similar.

Karyakin et al. ${ }^{(53)}$ utilizaram um sistema de três eletrodos com $\mathrm{Ag} / \mathrm{AgCl}$ ( $\mathrm{KCl}$ sat) como eletrodo de referência, $\mathrm{Pt}$ como eletrodo auxiliar e carbono vítreo como eletrodo de trabalho. A partir de solução contendo $2 \mathrm{mmol} \mathrm{L}^{-1}$ de $\mathrm{K}_{3}\left[\mathrm{Fe}(\mathrm{CN})_{6}\right]$ e $2 \mathrm{mmol} \mathrm{L}^{-1}$ de $\mathrm{FeCl}_{3}$ o filme foi preparado por deposição a potencial controlado $E_{a p l}=0,4 \mathrm{~V}$ por $60 \mathrm{~s}$. Depois da deposição do filme, o eletrodo foi ciclado em eletrólito suporte $0,1 \mathrm{~mol} \mathrm{~L}^{-1}$ de $\mathrm{KCl}$ contendo $0,1 \mathrm{~mol} \mathrm{~L}^{-1} \mathrm{de} \mathrm{HCl}$, no intervalo de $-0,05 \mathrm{~V} \leq \mathrm{E}_{\mathrm{apl}} \leq 0,35 \mathrm{~V}$ com velocidade de varredura de $50 \mathrm{mVs}^{-1}$. A estabilidade do filme foi avaliada em solução $0,1 \mathrm{~mol} \mathrm{~L}^{-1}$ de $\mathrm{KCl}$, no intervalo de potencial de $-0,05 \mathrm{~V} \leq \mathrm{E}_{\mathrm{apl}} \leq 0,35 \mathrm{~V}$ e com velocidade de varredura de $50 \mathrm{~m} \mathrm{~V} \mathrm{~s}^{-1}$. Após 25 ciclos, o eletrodo foi submetido a 
um potencial constante de $-0,05 \mathrm{~V}$ por algum tempo e em seguida foi seco a $100^{\circ} \mathrm{C}$ por 1 hora o que promoveria maior estabilidade ao filme.

Garcia-Jareño et al ${ }^{(54)}$ prepararam filmes de Azul da Prússia por deposição a corrente catódica constante sobre eletrodos de óxido de índio $\left(i_{c}=40 \mu \mathrm{A} \mathrm{cm}^{-2}\right.$; $150 \mathrm{seg}$ ) e ouro ( $i_{c}=600 \mu \mathrm{A} \mathrm{cm}^{-2} ; 150 \mathrm{seg}$ ), utilizando como solução modificadora $20 \mathrm{mmol} \mathrm{L}^{-1}$ de $\mathrm{K}_{3}\left[\mathrm{Fe}(\mathrm{CN})_{6}\right]$ e $20 \mathrm{mmol} \mathrm{L}^{-1}$ de $\mathrm{FeCl}_{3}$. Os autores concluíram que filmes insolúveis de Azul da Prússia são convertidos em filmes solúveis por ciclagens sucessivas ao redor do sistema de redução Azul da Prússia $\rightarrow$ Branco da Prússia, pela incorporação de ions $K^{+}$na forma insolúvel do filme. $A$ estabilidade dos filmes de Azul da Prússia aumentou quando estes foram recobertos com Náfion.

O AP pode ser reduzido eletroquimicamente em solução de eletrólito suporte (sais de $\mathrm{K}^{+}$) a $\mathrm{Fe}$ (II)-NC-Fe(II) incolor (sal de Everitt), ou então oxidado de modo parcial para formar um composto verde conhecido como verde de Berlim. Com a aplicação de potenciais mais anódicos é possivel a obtenção da forma amarela totalmente oxidada, simplificada como $\mathrm{Fe}$ (III)-NC-Fe(III) (amarelo da Prússia ou marrom da Prússia). ${ }^{(58,62)}$ As reações de óxido redução do AP podem ser representadas de modo simplificado pelo seguinte esquema ${ }^{\text {(52): }}$

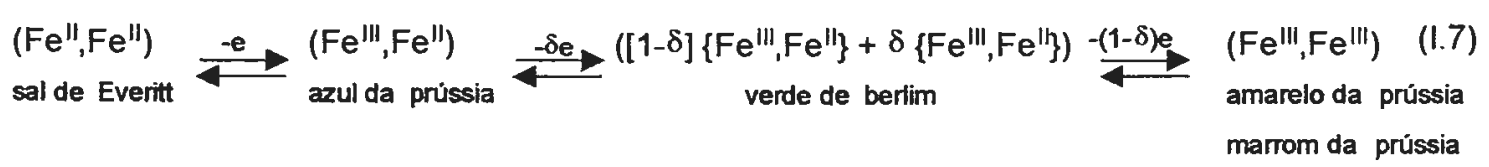

Itaya et al ${ }^{(41)}$ propuseram, com base em estudos espectrocópicos, que os filmes fossem constituídos pelo AP "insolúvel", e que as reaçōes eletroquímicas de redução e oxidação fossem:

$$
\begin{array}{ll}
\mathrm{Fe}_{4}{ }_{4}^{\prime \prime \prime}\left[\mathrm{Fe}^{\prime \prime}(\mathrm{CN})_{6}\right]_{3}+4 \mathrm{e}^{-}+4 \mathrm{~K}^{+} \rightleftarrows \mathrm{K}_{4} \mathrm{Fe}_{4}{ }_{4}\left[\mathrm{Fe}^{\prime \prime}(\mathrm{CN})_{6}\right]_{3} & 0,2 \mathrm{~V} \\
\mathrm{Fe}_{4}^{\prime \prime \prime}\left[\mathrm{Fe}^{\prime \prime}(\mathrm{CN})_{6}\right]_{3}+3 \mathrm{Cl}^{-} \rightleftarrows \mathrm{Fe}^{\prime \prime \prime}{ }_{4}\left[\mathrm{Fe}^{\prime \prime \prime}(\mathrm{CN})_{6} \mathrm{Cl}\right]_{3}+3 \mathrm{e}^{-} & 0,9 \mathrm{~V}
\end{array}
$$

Durante a oxidação ou a redução de um filme polimérico é necessária a entrada ou saída de espécies iônicas, para assegurar a eletroneutralidade. Pelas Equações 1.5 e 1.8 o potássio é responsável pela manutenção do balanceamento 
de cargas no processo de redução. Por outro lado na reação de oxidação os modelos de Neff ${ }^{(39)}$ e Itaya ${ }^{(41)}$ divergem, pois a Equação 1.6 pressupõe a expulsão de $K^{+}$do AP, enquanto na Equação I.9 pressupõe a incorporação de um ânion.

Mortimer e Rosseinky ${ }^{(63)}$ observaram que ocorria diminuição da largura da banda e diminuição do $\lambda_{\max }$ de absorção do AP de $760 \mathrm{~nm}$ para $690 \mathrm{~nm}$, após redução ao sal de Everitt e re-oxidação ao estado inicial. Com base neste dado sugeriram que inicialmente a forma "insolúvel" do complexo era formada, porém durante a ciclagem consecutiva de potencial em solução de $\mathrm{KCl}$, esta era convertida na forma "solúvel".

Um estudo extenso sobre estes eletrodos foi efetuado por Lundgren e Murray ${ }^{(59)}$, os quais encontraram quantidades significativas de cloreto e a ausência de potássio nos filmes recém preparados. Propuseram então a formulação do AP como $(\mathrm{HCl}) \mathrm{Fe}^{\prime \prime \prime}{ }_{4}\left[\mathrm{Fe}^{\prime \prime}(\mathrm{CN})_{6}\right]_{3} .6 \mathrm{H}_{2} \mathrm{O}$, onde ions cloreto estariam coordenados aos íns $\mathrm{Fe}$ (III) que não estão ligados a NC-Fe". O hidrogênio ácido pode ser facilmente trocado por íons $K^{+}$, apenas por imersão do eletrodo em solução de $\mathrm{KCl}$. Durante a redução eletroquímica do $\mathrm{AP}$ ao $\mathrm{BP}$ mais íns $\mathrm{K}^{+}$são incorporados ao filme, enquanto íns $\mathrm{Fe}^{3+}$ passam para soluçāo o que levaria, por aproximação à composição "solúvel". Porém a conversão não ocorre de maneira quantitativa e acaba-se tendo uma mistura das duas formas do AP. Os autores observaram ainda, que um voltamograma estável, na reação de oxidação, só era obtido se o filme fosse previamente reduzido a ( $\left.\mathrm{Fe}^{\prime \prime}, \mathrm{Fe}^{\prime \prime}\right)$, pois de outro modo haveria perda rápida na resposta eletroquímica. A Equação 1.9 sugere que, durante a redução, ocorra a entrada de $\mathrm{Cl}^{-}$, entretanto $\mathrm{K}^{+}$também é incorporado ao filme. A Equação I.10 foi então proposta para descrever a redução de um filme previamente oxidado:

$\mathrm{Fe}^{\prime \prime \prime \prime}{ }_{4}\left[\mathrm{Fe}^{\prime \prime \prime}(\mathrm{CN})_{6}\right]_{3}(\mathrm{OH})_{3} .3 \mathrm{H}_{2} \mathrm{O}+\mathrm{K}^{+}+\mathrm{Cl}^{-}+3 \mathrm{H}^{+}+3 \mathrm{e}^{-} \rightarrow\left(\mathrm{K}^{+}\right)(\mathrm{Cl}) \mathrm{Fe}^{\prime \prime \prime}{ }_{4}\left[\mathrm{Fe}^{\prime \prime}(\mathrm{CN})_{6}\right]_{3} .6 \mathrm{H}_{2} \mathrm{O}(\mathrm{l} .10)$

Este modelo está de acordo com os dados de eletrogravimetria com microbalança de cristal de quartzo obtidos por Feldman e Melroy ${ }^{(64)}$ que observaram perda de massa durante o processo de oxidação e a invariabilidade 
dos potenciais redox dos filmes em relação à natureza do ânion empregado como eletrólito suporte.

Examinando-se as Equações 1.5 e 1.8 pode-se supor que a natureza do cátion presente na solução deve influir na reação de redução do AP, uma vez que este tem que penetrar no interior dos canais formados pelas cadeias poliméricas $\mathrm{Fe}^{\prime \prime \prime}-\mathrm{NC}-\mathrm{Fe} e^{\prime \prime}$. Sais de $\mathrm{K}^{+}, \mathrm{Rb}^{+}, \mathrm{Cs}^{+}$e $\mathrm{NH}_{4}{ }^{+}$permitem a manutenção de voltamogramas estáveis, enquanto $\mathrm{Na}^{+}, \mathrm{Li}^{+}, \mathrm{H}^{+}$e os cátions bivalentes de metais alcalinos terrosos levam à queda na resposta eletroquímica em seguidas varreduras cíclicas consecutivas. ${ }^{(54,55)} \mathrm{A}$ facilidade com que ocorre a redução segue a ordem $\mathrm{K}^{+}>\mathrm{Na}^{+}>\mathrm{Li}^{+(50,39,29)}$, o que indica que o raio hidratado do cátion face às dimensões dos canais do retículo determina o comportamento eletroquímico do filme. Em uma situação extrema, o cátion volumoso tetraetilamônio não permite obter qualquer resposta eletroquímica, uma vez que não consegue penetrar nos canais do $\mathrm{AP}^{(39)}$. Por esse motivo a presença do íon $\mathrm{K}^{+}$ é necessária para a obtenção de resposta voltamétrica do filme, figura 7. 


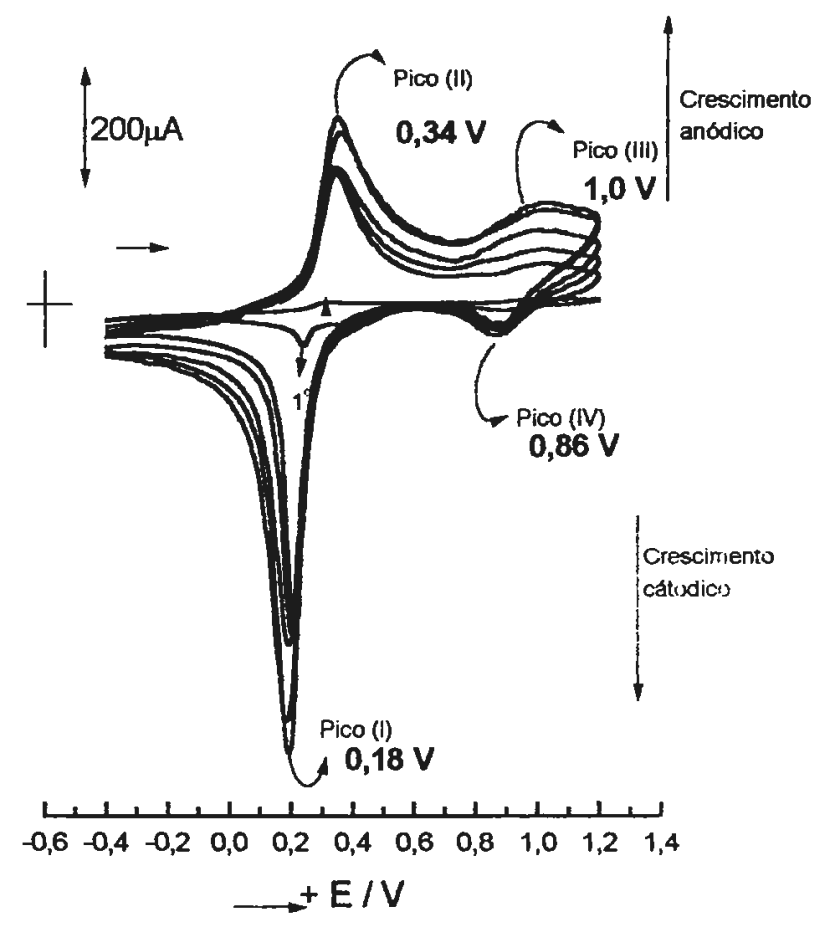

Pico (I): $\left\{\begin{aligned} {\left[\mathrm{Fe}^{\prime \prime \prime}(\mathrm{CN})_{6}\right]^{3-}+1 \mathrm{e}^{-} \rightleftarrows\left[\mathrm{Fe}^{\prime \prime}(\mathrm{CN})_{6}\right]^{4-} } \\ \mathrm{Fe}_{(\mathrm{exc})}{ }^{3+}+\mathrm{Ferrocianeto}^{4} \rightleftarrows \mathrm{Fe}_{4}\left[\mathrm{Fe}^{\prime \prime}(\mathrm{CN})_{6}\right]_{3} \\ \text { (Azul da Prússia) }\end{aligned}\right.$

$\mathrm{Fe}_{4}\left[\mathrm{Fe}^{\prime \prime}(\mathrm{CN})_{6}\right]_{3}+4 \mathrm{~K}^{+}+4 \mathrm{e}^{-} \rightleftarrows \mathrm{K}_{4} \mathrm{Fe}_{4}{ }^{\prime \prime}\left[\mathrm{Fe}^{\prime \prime}(\mathrm{CN})_{6}\right]_{3}$

(Branco da prússia)

Pico (II): $\mathrm{K}_{4} \mathrm{Fe}_{4}{ }^{\mathrm{II}}\left[\mathrm{Fe}^{\prime \prime}(\mathrm{CN})_{6}\right]_{3} \rightarrow \mathrm{Fe}_{4}\left[\mathrm{Fe}^{\prime \prime}(\mathrm{CN})_{6}\right]_{3}+4 \mathrm{~K}^{+}+4 \mathrm{e}^{-}$

Pico (III): $\mathrm{Fe}_{4}\left[\mathrm{Fe}^{\prime \prime}(\mathrm{CN})_{6}\right]_{3} \rightarrow \mathrm{Fe}_{4}\left[\mathrm{Fe}^{\prime \prime \prime}(\mathrm{CN})_{6}\right]_{3}+\mathrm{e}^{-}$

Pico (IV): $\mathrm{Fe}_{4}\left[\mathrm{Fe}^{\prime \prime \prime}(\mathrm{CN})_{6}\right]_{3}+\mathrm{e}^{-} \rightarrow \mathrm{Fe}_{4}\left[\mathrm{Fe}^{\prime \prime}(\mathrm{CN})_{6}\right]_{3}$

Figura 7. Voltamogramas cíclicos registrados em solução modificadora contendo: $2 \mathrm{mmol} \mathrm{L}^{-1}$ de $\mathrm{K}_{3} \quad\left[\mathrm{Fe}(\mathrm{CN})_{6}\right]$; $3 \mathrm{mmol} \mathrm{L} L^{-1}$ de $\mathrm{FeCl}_{3} ; 0,5 \mathrm{~mol} \mathrm{~L}^{-1}$ de $\mathrm{KNO}_{3}$ em $\mathrm{HCl} 0,02 \mathrm{~mol} \mathrm{~L}^{-1}$. Velocidade de varredura $60 \mathrm{~m} \mathrm{~V} \mathrm{~s}^{-1} \mathrm{e}-0,4 \mathrm{~V} \leq \mathrm{E}_{\mathrm{apl}} \leq 1,2 \mathrm{~V}$. 
Plichon e Besbes ${ }^{(52)}$ utilizaram a técnica do efeito miragem para estudar o AP. O efeito miragem ocorre quando um feixe de laser passa através de uma camada com índice de refração variável e é defletido. O feixe de laser pode ser direcionado paralelamente à superfície do eletrodo e sofre deflexão quando ocorre um gradiente de concentração, devido a entrada ou a saída de íons dentro de filmes durante um processo eletroquímico. Os autores observaram que ions $\mathrm{K}^{+}$ entram no filme durante a redução em meio neutro, enquanto que em meio ácido há a entrada simultânea de prótons, para a compensação de cargas. Sais de potássio $\left(\mathrm{Cl}^{-}, \mathrm{Br}^{-}, \mathrm{SO}_{4}{ }^{2-}, \mathrm{NO}_{3}^{-}\right.$e $\left.\mathrm{ClO}_{4}^{-}\right)$não causam nenhuma mudança nos

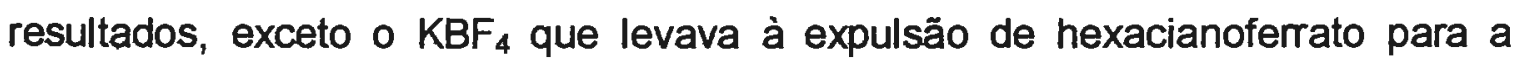
solução. Passando para a reação de oxidação, os dados de detecção pelo efeito miragem indicaram que espécies são expulsas do filme, o que descarta a Equação 1.9. A Equaçăo l.6 também não é apropriada, uma vez que os autores constataram que $\mathrm{Fe}(\mathrm{III})$ e não $\mathrm{K}^{+}$, é expulso do filme. Tal conclusão foi obtida devido à formação de um complexo de coloração vermelha sangue ao se adicionar tiocianato na solução onde se efetuou a varredura de potencial. Na varredura reversa os ions entram no filme, porém a ciclagem repetitiva por longo tempo não é aconselhável, uma vez que parte de Fe(III) difunde-se para longe do eletrodo.

Posteriormente os mesmos autores ${ }^{(60)}$ sintetizaram filmes de AP na ausência de $\mathrm{K}^{+}$, com a utilização de reagentes contendo $\mathrm{Li}^{+}$. Não foram observadas diferenças entre $O$ comportamento eletroquímico dos filmes sintetizados com sais de $\mathrm{K}^{+}$ou $\mathrm{Li}^{+}$, tanto na redução como na oxidação do filme. Portanto, o filme logo que sintetizado não deve conter estes cátions, favorecendo a sua formulação como a forma "insolúvel". Por outro lado, através de medidas coulométricas, concluíram que a conversão "insolúvel" para "solúvel" não ocorre em grande extensão durante o primeiro ciclo de oxiredução.

Como se pode constatar, há muitos dados e interpretações controversas em relação à composição de EQM de filmes da AP. 
Atualmente $e^{(54,55)}$ é aceito que a forma "insolúvel" é a que se obtém em filmes recém preparados, porém ciclagens de potencial na presença de eletrólito levam a uma mudança de composição em extensão não muito grande.

O principal problema encontrado no desenvolvimento de eletrodos modificados com filmes de AP,está relacionado com sua instabilidade durante a redução catalítica $\mathrm{H}_{2} \mathrm{O}_{2}$, na qual ocorre a liberação de íons $\mathrm{OH}^{-}{ }^{(53)}$. Deste modo diversos trabalhos tem sido publicados para tentar resolver este problema, desde métodos de preparação dos filmes química ${ }^{(62,50,39,47)}$ e eletroquímicamente ${ }^{(26-38,50,56,57)}$, condicionamento dos filmes formados em soluções contendo $\mathrm{FeCl}_{2}{ }^{(39)}$ e $\mathrm{RuCl}_{3}{ }^{(65)}$, secagem prévia dos filmes ${ }^{(39,53,55)}$ (para que sua estrutura zeolitica não contenha moléculas de $\mathrm{H}_{2} \mathrm{O}$ ), recobrimento com filme permseletivo Náfion ${ }^{(27-38)}$ (que impede a entrada de ânions e adicionalmente desidrata o filme) e controle da composição do eletrólito suporte ${ }^{(56,5,47,48,30,36)}(\mathrm{pH}$, composição do tampão, adição de sais contendo íons de $\mathrm{K}^{+}$) utilizado para o crescimento e/ou determinação da $\mathrm{H}_{2} \mathrm{O}_{2}$.

Karyakin et al. ${ }^{(53)}$ investigaram o mecanismo de redução de $\mathrm{H}_{2} \mathrm{O}_{2}$ na presença de $\mathrm{O}_{2}$ por deposição de filmes de AP sobre eletrodos de carbono vítreo. Os eletrodos modificados apresentaram estabilidade em potenciais negativos e em solução neutra de eletrólito suporte. Porém a redução direta de $\mathrm{H}_{2} \mathrm{O}_{2}$ em solução neutra, envolve $2 \mathrm{e}^{-}$formando 2 ions $\mathrm{OH}^{-}$, que complexam o ferro da estrutura cristalina desestabilizando o filme.

$$
\begin{aligned}
\mathrm{H}_{2} \mathrm{O}_{2}+2 \mathrm{e}^{-} & \rightarrow 2 \mathrm{OH}^{-}(\mathrm{I} .11) \\
\mathrm{Fe}^{3+}+\mathrm{OH} & \rightleftarrows[\mathrm{Fe}(\mathrm{OH})]^{2+}(1.12)
\end{aligned}
$$

Os autores ${ }^{(53)}$ e outros ${ }^{(39,55)}$ concluíram que eletrodos modificados recém preparados são instáveis enquanto que os eletrodos modificados, previamente secos, são mais estáveis. A existência de água no policristal inorgânico afeta a estabilidade do eletrodo modificado e alguns autores ${ }^{(55)}$ consideram que a remoção irreversível da $\mathrm{H}_{2} \mathrm{O}$ zeolítica por aquecimento a $100{ }^{\circ} \mathrm{C}$ durante 1 hora, 
propiciaria a obtenção de filmes mais estáveis . De fato a água poderia estar promovendo a hidrolise do $\mathrm{Fe}^{3+}$.

Benedetto et al ${ }^{(65)}$ criaram uma rota geral para a estabilização de filmes inorgânicos de InHCF (hexacianoferrato (IIIIII) de Indium (III)) sobre eletrodos de carbono vítreo, por ciclagem sucessiva em solução $0,5 \mathrm{~mol} \mathrm{~L}^{-1}$ de $\mathrm{KCl}, \mathrm{pH}=2$, contendo $1 \mathrm{mmol} \mathrm{L}^{-1}$ de $\mathrm{RuCl}_{3}$ no intervalo de potencial aplicado de $0,0 \mathrm{~V} \leq E_{a p l} \leq 0,9 \vee$ a $50 \mathrm{mV} \mathrm{s}^{-1}$, sendo os filmes de InHCF análogos aos filmes de AP.

O filme InHCF modificado com rutênio apresentou maior estabilidade e área ativa devido incorporaçăo no filme, de $\mathrm{Ru}(\mathrm{III})$ e espécies dinucleares $\left(\mathrm{Ru}_{2} \mathrm{O}_{6}{ }^{3+}\right)$, na estrutura zeolítica, com formação de ligações ciano e oxo, (Fe-CN-Ru e Fe-O-Ru).

Outros autores também estudaram o comportamento do Ru(III) sobre o filme de Azul da Prússia ${ }^{(66)}$ e seus análogos ${ }^{(67-71)}$, e assim como Benedetto et al ${ }^{(65)}$ concluíram que o eletrodo modificado tem sua estabilidade e ação catalitica aumentada pela incorporação de $\mathrm{Ru}(\mathrm{III})$ e $\mathrm{Ru}_{2} \mathrm{O}_{6}{ }^{3+}$ na estrutura zeolítica. Eletrodos modificados com $\mathrm{Ru} / \mathrm{Ru}(\mathrm{CN})$ de valência mista têm sido utilizados para oxidação e determinação de As(III) em meio ácido(72), mediação da oxidação de $\mathrm{N}$-nitrosamina ${ }^{(73)}$ e determinação de álcoois ${ }^{(74,75)}$ enquanto eletrodos modificados com $\mathrm{RuCl}_{3} / \mathrm{RhCl}_{3}$ tem sido utilizados na determinação de $\mathrm{H}_{2} \mathrm{O}_{2}{ }^{(76)}$.

Os principais parâmetros que devem ser estudados para a preparação, crescimento e/ou estabilização dos filmes de Azul da Prússia são: pH e concentração de íons $\mathrm{K}^{+}$na solução modificadora bem como no eletrólito suporte utilizado para avaliação da estabilidade do filme e determinação de $\mathrm{H}_{2} \mathrm{O}_{2}$, intervalo de tempo decorrido entre a formação do filme e o teste de estabilidade, temperatura e tempo de secagem do filme, influência do condicionamento prévio em solução de $\mathrm{FeSO}_{4} .7 \mathrm{H}_{2} \mathrm{O}$ e efeito do $\mathrm{O}_{2}$ na redução catalítica de $\mathrm{H}_{2} \mathrm{O}_{2}$. 


\section{OBJETIVOS}

Os objetivos deste trabalho foram: i) avaliar três métodos distintos de preparação do filme Azul de Prússia visando otimizar o sistema para deteç̧ão de peróxido de hidrogênio com vistas ao desenvolvimento futuro de biossensores; ii) estudar os fatores que podem afetar a estabilidade dos eletrodos modificados durante a redução catalitica de $\mathrm{H}_{2} \mathrm{O}_{2}$ e iii) Apresentar alternativas que permitam a obtenção do AP em sua forma insolúvel, solucionando assim os problemas de instabilidade dos filmes. 


\section{II-PARTE EXPERIMENTAL}

\section{II.1- Reagentes e Soluções}

\section{Reagentes}

A tabela II.1 apresenta os reagentes utilizados durante o desenvolvimento do trabalho.

Tabela II.1. Os reagentes utilizados durante o desenvolvimento do trabalho.

\begin{tabular}{|c|c|c|c|}
\hline Reagente & Procedência & Reagente & Procedência \\
\hline $\mathrm{HCl}$ & Merck & ácido citríco & Merck \\
\hline $\mathrm{FeSO}_{4} .7 \mathrm{H}_{2} \mathrm{O}$ & Merck & $\mathrm{K}_{3}\left[\mathrm{Fe}(\mathrm{CN})_{6}\right]$ & Merck \\
\hline $\mathrm{NaNO}_{3}$ & Merck & $\mathrm{FeCl}_{3}$ & Merck \\
\hline $\mathrm{NaH}_{2} \mathrm{PO}_{4}$ & Merck & $\mathrm{KNO}_{3}$ & Merck \\
\hline $\mathrm{RhCl}_{3} .3 \mathrm{H}_{2} \mathrm{O}$ & $\begin{array}{c}\text { Aldrich Chemical } \\
\text { Co }\end{array}$ & RuCl $3.3 \mathrm{H}_{2} \mathrm{O}$ & $\begin{array}{c}\text { Aldrich Chemical } \\
\text { Co }\end{array}$ \\
\hline $\begin{array}{c}\text { Grafite Acheson } \\
38\end{array}$ & Ficher & óleo mineral \\
nujol $(16140-3)$ & $\begin{array}{c}\text { Aldrich Chemical } \\
\text { Co }\end{array}$ \\
\hline Acetato de sódio & Merck & $\mathrm{NaOH}$ & Merck \\
\hline Ácido ascórbico & Merck & $\mathrm{Hepes}$ & Merck \\
\hline $\begin{array}{c}\text { Citrato de } \\
\text { potássio }\end{array}$ & Merck & ácido acético & Merck \\
\hline $\mathrm{Na}_{2} \mathrm{HPO}_{4}$ & Merck & $\mathrm{KCl}$ & Merck \\
\hline Peridrol 30\% & Merck & $\mathrm{K}_{2} \mathrm{C}_{2} \mathrm{O} . \mathrm{H}_{2} \mathrm{O}$ & Merck \\
\hline $\mathrm{KMnO}_{4}$ & Merck & Ácido úrico & Merck \\
\hline
\end{tabular}

Todos os reagentes foram utilizados sem punificação prévia. 


\section{Soluções:}

Todas as soluçōes foram preparadas utilizando-se água deionizada proveniente de um purificador Nanopure, da Barnstead.

Solucões de $\mathrm{HCl}$ : As soluções estoque $0,1 \mathrm{~mol} \mathrm{~L}^{-1} \mathrm{de} \mathrm{HCl}$ foram preparadas pipetando-se quantidades apropriadas de ácido clorídrico concentrado e diluindo-se em água deionizada.

Solução de $\mathrm{KCl}$ : A solução de $0,1 \mathrm{~mol} \mathrm{~L}^{-1}$ de $\mathrm{KCl}$ foi preparada dissolvendo-se quantidade apropriada do sal em solução de $\mathrm{HCl} 0,02 \mathrm{~mol} \mathrm{~L}^{-1}$.

Solucão de $\mathrm{RhCl}_{3} .3 \mathrm{H}_{2} \mathrm{O}:$ A solução de $1 \mathrm{mmol} \mathrm{L}^{-1}$ de $\mathrm{RhCl}_{3} .3 \mathrm{H}_{2} \mathrm{O}$ em $0,1 \mathrm{~mol} \mathrm{~L}^{-1}$ de $\mathrm{KCl}$ foi preparada dissolvendo-se quantidades apropriadas dos sais em solução de $\mathrm{HCl} 0,02 \mathrm{~mol} \mathrm{~L}^{-1}$.

Solucão de $\mathrm{RuCl}_{3} .3 \mathrm{H}_{2} \mathrm{O}:$ A solução de $1 \mathrm{mmol} \mathrm{L}^{-1}$ de $\mathrm{RuCl}_{3} .3 \mathrm{H}_{2} \mathrm{O}$ em $0,1 \mathrm{~mol} \mathrm{~L}^{-1}$ de $\mathrm{KCl}$ foi preparada dissolvendo-se quantidades apropriadas dos sais em solução de $\mathrm{HCl} 0,02 \mathrm{~mol} \mathrm{~L}^{-1}$.

Solucões de $\mathrm{KMnO}_{4}$ : As soluçōes de permanganato foram preparadas por dissolução de aproximadamente $3,2 \mathrm{~g}$ de permanganato de potássio em $1000 \mathrm{~m} \mathrm{~L}$ de água deionizada. As soluções foram brandamente aquecidas durante 15-30 minutos e resfriadas a temperatura ambiente. Em seguida as soluções foram filtradas através de um funil contendo lã de vidro purificada, recolhendo-se o filtrado em um frasco limpo de vidro âmbar. Estas soluçōes foram padronizadas utilizando-se $\mathrm{Na}_{2} \mathrm{C}_{2} \mathrm{O}_{4}$ como padrão primário ${ }^{(7)}$.

Solucões de $\mathrm{H}_{2} \mathrm{O}_{2}$ : As soluçōes de $\mathrm{H}_{2} \mathrm{O}_{2}$ foram preparadas pipetando-se quantidades apropriadas de água oxigenada $30 \%$ e diluindo-se em água deionizada. As soluções foram posteriormente padronizadas com a solução padrão secundário de $\mathrm{KMnO}_{4}$, como descrito na literatura(m).

Soluções de ácido ascórbico $\mathrm{C}_{6} \mathrm{H}_{8} \mathrm{O}_{6}$ : As soluções de $\mathrm{C}_{6} \mathrm{H}_{8} \mathrm{O}_{6}$ foram preparadas dissolvendo-se quantidades apropriadas do sal em água deionizada previamente desaeradas com $\mathrm{N}_{2}$. 
Soluções de ácido úrico $\mathrm{C}_{5} \mathrm{H}_{4} \mathrm{~N}_{4} \mathrm{O}_{3}$ : As soluções de $\mathrm{C}_{5} \mathrm{H}_{4} \mathrm{~N}_{4} \mathrm{O}_{3}$ foram preparadas dissolvendo-se quantidades apropriadas do sal em água deionizada previamente desaeradas com $\mathrm{N}_{2}$.

Todas as soluções tampão utilizadas foram preparadas como descrito na referência ${ }^{(78)}$.

A tabela II.2 apresenta as soluções tampão utilizadas durante 0 desenvolvimento do trabalho.

Tabela II.2. Soluções tampão utilizadas durante o desenvolvimento do trabalho(78).

\begin{tabular}{|c|c|c|}
\hline Solução tampão & Composição & $\mathrm{pH}$ \\
\hline $\mathrm{NaH}_{2} \mathrm{PO}_{4}+\mathrm{Na}_{2} \mathrm{HPO}_{4}$ & $0,05 \mathrm{~mol} \mathrm{~L}^{-1}$ de $\mathrm{NaH}_{2} \mathrm{PO}_{4} / 0,05 \mathrm{~mol} \mathrm{~L}^{-1}$ de $\mathrm{Na}_{2} \mathrm{HPO}_{4}$ & 6,1 \\
\hline $\mathrm{NaH}_{2} \mathrm{PO}_{4}+\mathrm{Na}_{2} \mathrm{HPO}_{4}$ & $0,05 \mathrm{~mol} \mathrm{~L}^{-1}$ de $\mathrm{NaH}_{2} \mathrm{PO}_{4} / 0,05 \mathrm{~mol} \mathrm{~L}^{-1}$ de $\mathrm{Na}_{2} \mathrm{HPO}_{4}$ & 6,5 \\
\hline $\mathrm{C}_{6} \mathrm{H}_{8} \mathrm{O}_{7} \cdot \mathrm{H}_{2} \mathrm{O}+\mathrm{Na}_{2} \mathrm{HPO}_{4}$ & $0,1 \mathrm{~mol} \mathrm{~L}^{-1}$ de ácido citríco $/ 0,2 \mathrm{~mol} \mathrm{~L}^{-1}$ de $\mathrm{Na}_{2} \mathrm{HPO}_{4}$ & 5,5 \\
\hline $\mathrm{H}_{3} \mathrm{CCOOH}+\mathrm{H}_{3} \mathrm{CCOONa}$ & $0,01 \mathrm{~mol} \mathrm{~L}^{-1}$ ácido acético/ $0,01 \mathrm{~mol} \mathrm{~L}^{-1}$ acetato de sódio & 5,5 \\
\hline $\mathrm{C}_{6} \mathrm{H}_{8} \mathrm{O}_{7} \cdot \mathrm{H}_{2} \mathrm{O}+$ & $2 \mathrm{mmol} \mathrm{L}^{-1}$ ácido citrico/ $10 \mathrm{mmol} \mathrm{L}^{-1}$ citrato de potássio & 6,1 \\
$\mathrm{C}_{6} \mathrm{H}_{5} \mathrm{~K}_{3} \mathrm{O}_{7} \cdot \mathrm{H}_{2} \mathrm{O}$ & & \\
\hline $\mathrm{C}_{6} \mathrm{H}_{8} \mathrm{O}_{7} \cdot \mathrm{H}_{2} \mathrm{O}+$ & $2 \mathrm{mmol} \mathrm{L}^{-1}$ ácido citrico/ $10 \mathrm{mmol} \mathrm{L}^{-1}$ citrato de potássio & 6,5 \\
$\mathrm{C}_{6} \mathrm{H}_{5} \mathrm{~K}_{3} \mathrm{O}_{7} \cdot \mathrm{H}_{2} \mathrm{O}$ & & \\
\hline
\end{tabular}

\section{Ul1.1 - Composição da Solução Modificadora Utilizada para Preparacão dos} Filmes de Azul da Prússia (AP):

\section{Il.1.1.a- Por Voltametria Cíclica ${ }^{(29)}$}

A composição da solução modificadora utilizada para preparação dos filmes de Azul da Prússia foi: $2 \mathrm{mmol} \mathrm{L}^{-1}$ de $\mathrm{K}_{3}\left[\mathrm{Fe}(\mathrm{CN})_{6}\right] ; 3 \mathrm{mmol} \mathrm{L}^{-1}$ de $\mathrm{FeCl}_{3}$; $0,5 \mathrm{~mol} \mathrm{~L}^{-1}$ de $\mathrm{KNO}_{3}$ em HCl $0,02 \mathrm{~mol} \mathrm{~L}^{-1}$. Para a preparação desta solução $0,0405 \mathrm{~g} \mathrm{FeCl}_{3}$ foram dissolvidas em $10,00 \mathrm{~mL}^{\text {de }} \mathrm{HCl} \mathrm{0,1} \mathrm{mol} \mathrm{L}^{-1}$. Em seguida, $0,0330 \mathrm{~g}$ de $\mathrm{K}_{3}\left[\mathrm{Fe}(\mathrm{CN})_{6}\right]$ e 2,53g de $\mathrm{KNO}_{3}$ foram dissolvidos em água deionizada e a solução resultante adicionada à solução de $\mathrm{FeCl}_{3}$. $\mathrm{O}$ volume final foi completado a $50,00 \mathrm{~mL}$. 


\section{II.1.1.b- Por Deposicão a Potencial Controlado ${ }^{(53)}$}

A composição da soluçăo modificadora utilizada para preparação dos filmes de Azul da Prússia foi: $2 \mathrm{mmol} \mathrm{L}^{-1}$ de $\mathrm{K}_{3}\left[\mathrm{Fe}(\mathrm{CN})_{6}\right] ; 3 \mathrm{mmol} \mathrm{L} \mathrm{L}^{-1}$ de $\mathrm{FeCl}_{3}$; $0,5 \mathrm{~mol} \mathrm{~L}^{-1}$ de $\mathrm{KCl}$ em HCl 0,02 $\mathrm{mol} \mathrm{L}^{-1}$. Para a preparação desta solução $0,0405 \mathrm{~g}$ $\mathrm{FeCl}_{3}$ foram dissolvidas em $10,00 \mathrm{~mL}$ de $\mathrm{HCl} 0,1 \mathrm{~mol} \mathrm{~L}^{-1}$. Em seguida, $0,0330 \mathrm{~g}$ de $\mathrm{K}_{3}\left[\mathrm{Fe}(\mathrm{CN})_{6}\right]$ e $1,86 \mathrm{~g}$ de $\mathrm{KCl}$ foram dissolvidos em água deionizada e a solução resultante adicionada à solução de $\mathrm{FeCl}_{3}$. $\mathrm{O}$ volume final foi completado a $50,00 \mathrm{~mL}$.

\subsubsection{C- Por Deposicão a dois Potenciais Controlados}

A composição da solução modificadora utilizada para preparação dos filmes de Azul da Prússia foi: $2 \mathrm{mmol} \mathrm{L}^{-1}$ de $\mathrm{K}_{3}\left[\mathrm{Fe}(\mathrm{CN})_{6}\right] ; 3 \mathrm{mmol} \mathrm{L}^{-1}$ de $\mathrm{FeCl}_{3}$; em $\mathrm{HCl} 0,02 \mathrm{~mol} \mathrm{~L}^{-1}$. Para a preparação desta solução $0,0405 \mathrm{~g} \mathrm{FeCl}_{3}$ foram dissolvidas em 10,00 $\mathrm{mL}$ de $\mathrm{HCl} \mathrm{0,1} \mathrm{mol} \mathrm{L}^{-1}$. Em seguida, 0,0330g de $\mathrm{K}_{3}\left[\mathrm{Fe}(\mathrm{CN})_{6}\right]$ foi dissolvido em água deionizada e a solução resultante adicionada à solução de $\mathrm{FeCl}_{3}$. O volume final foi completado a $50,00 \mathrm{~mL}$.

\section{II.2- Equipamentos}

As medidas de $\mathrm{pH}$ foram efetuadas utilizando-se pHmetro Modelo $654 \mathrm{e}$ eletrodo de vidro combinado modelo 6.0203.100 (OE), ambos da Metrohm. Todas as medidas eletroquimicas foram realizadas utilizando-se um computador 4.86 da Hundai acoplado a um potenciostato MQPG-01, com um sistema potenciostato MQPG-01. 


\section{II.2.1- Sistema de Eletrodos}

Utilizou-se um sistema de 3 eletrodos constituído de eletrodo de pasta de carbono (EPC); eletrodo auxiliar Pt e eletrodo de referência $\mathrm{Ag} / \mathrm{AgCl}$ ( $\mathrm{KCl}$ sat. ), figura 8.

A pasta de carbono foi preparada misturando-se grafite (previamente aquecido a $150{ }^{\circ} \mathrm{C}$ por pelo menos 2 horas) com óleo nujol na razão de 2:1 (grafite : nujol).

O eletrodo de trabalho foi construido no próprio laboratório constituindo-se de um cilindro de cobre de $90 \mathrm{~mm}$ de comprimento por $3 \mathrm{~mm}$ de diâmetro que tem a função de contato elétrico, envolto por um tubo de plástico de $75 \mathrm{~mm}$ de comprimento por $6 \mathrm{~mm}$ de diâmetro externo e $4 \mathrm{~mm}$ de diâmetro interno, com uma parede de $1 \mathrm{~mm}$ de espessura. A barra de cobre foi introduzida no interior do tubo de plástico por uma das extremidades até cerca de $1 \mathrm{~mm}$ da outra extremidade do tubo. Em seguida, preencheu-se o espaço entre o bastão de cobre e o tubo plástico com uma camada de cola Araldite para vedação e fixação da barra de cobre ao tubo plástico. Após a secagem da cola, a pasta de carbono foi introduzida na cavidade formada entre a extremidade do cilindro de cobre e o tubo plástico.

O eletrodo auxiliar foi constituído de um fio de platina soldado a um fio de $\mathrm{Ni}-\mathrm{Cr}$, utilizando-se um suporte de vidro como corpo para o eletrodo.

O eletrodo de referência foi $\mathrm{Ag} / \mathrm{AgCl}\left(\mathrm{KCl}_{\text {sat }}\right)$ um fio de prata foi lixado para a remoção de óxidos, lavado com etanol para a retirada de gordura e imerso com demais eletrodos (referência e auxiliar) em solução de ácido clorídrico $10^{-3} \mathrm{mmol} \mathrm{L}^{-1}$. O AgCl foi precipitado na superfície do eletrodo por oxidação do fio de prata a $8 \mathrm{mV}$ vs $\mathrm{Ag} / \mathrm{AgCl}, \mathrm{KCl}$ sat. por 700 s. A montagem do eletrodo foi efetuada como descrito por Pedrotti et al ${ }^{(79)}$. 


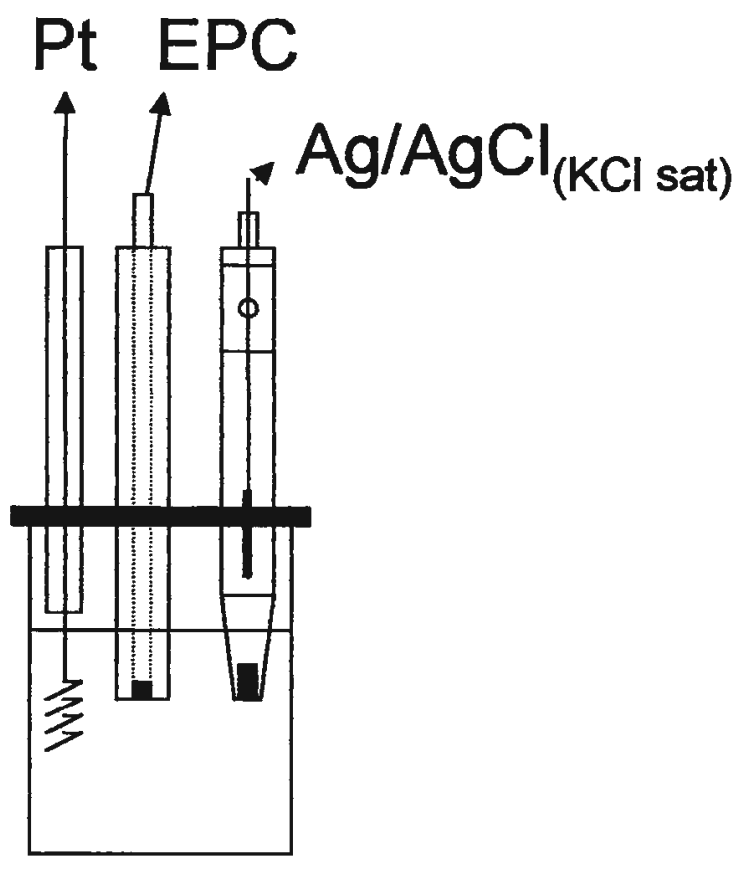

Figura 8. Esquema representativo do sistema de eletrodos.

A pasta de carbono foi utilizada por ser um material barato, facilmente removivel e que permite a imobilização enzimática durante a preparação da própria pasta de carbono.

\section{II.2.2.1- Preparação dos Eletrodos Modificados com Azul da Prússia}

\section{I1.2.2.1.a-Por Voltametria Cíclica}

Após imersão do sistema de eletrodos na solução modificadora efetuo-se 50 ciclos na solução modificadora no intervalo de potencial $-0,4 \mathrm{~V} \leq \mathrm{E}_{\mathrm{apl}} \leq 1,2 \mathrm{~V}$ com velocidade de varredura de $60 \mathrm{mV} \mathrm{s}^{-1}$. 


\subsubsection{1.b- Por Deposicão a Um Potencial Controlado}

Após imersão do sistema de eletrodos na solução modificadora aplicou-se 0,4 V por 1 minuto na solução modificadora (pré-concentração dos reagentes). Em seguida os eletrodos foram ativados em solução eletrólito suporte contendo 0,1 $\mathrm{mol} \mathrm{L}^{-1}$ de KCl em $2,0 \times 10^{-2} \mathrm{~mol} \mathrm{~L}^{-1}$ de $\mathrm{HCl}$ (realização de 50 ciclos no intervalo de $-0,05 \vee \leq E_{a p l} \leq 0,35 \vee$ a $50 \mathrm{~m} \mathrm{~V} \mathrm{~s}^{-1}$ ) e utilizados apenas após secagem a temperatura ambiente por 24 horas.

\subsubsection{1.c- Por Deposicão a Dois Potenciais Controlados}

Após imersão do sistema de eletrodos na solução modificadora aplicou-se $0,4 \mathrm{~V}$ ao eletrodo de trabalho durante 2 minutos (etapa de pré-concentração de reagentes). Em seguida, o potencial foi imediatamente revertido para $-0,4 \mathrm{~V}$ durante mais 2 minutos (etapa de redução dos reagentes e formação do filme de Azul da Prússia). O ciclo foi repetido por mais duas vezes. Em seguida, os eletrodos foram ativados em solução de eletrólito suporte contendo $0,5 \mathrm{~mol} \mathrm{~L}^{-1}$ de $\mathrm{KCl}$ e $2,0 \times 10^{-2} \mathrm{~mol} \mathrm{~L}^{-1}$ de $\mathrm{HCl}$ (realização de 50 ciclos no intervalo de $-0,4 \mathrm{~V} \leq E_{a p l} \leq 0,6 \mathrm{~V}$ a $60 \mathrm{mV} \mathrm{s}^{-1}$ ) e utilizados apenas após secagem a temperatura ambiente por 24 horas.

\subsubsection{1.d- Por Deposição a Dois Potenciais Controlados e Ativacão em} Solução contendo $\mathrm{KCl} 0,5 \mathrm{~mol} \mathrm{~L}^{-1}$ e $\mathrm{RuCl}_{3} 1,0 \times 10^{-3} \mathrm{~mol} \mathrm{~L}^{-1}$

Após imersão do sistema de eletrodos na solução modificadora aplicou-se $0,4 \mathrm{~V}$ ao eletrodo de trabalho durante 2 minutos (etapa de pré-concentração de reagentes). Em seguida, o potencial foi imediatamente revertido para $-0,4 \mathrm{~V}$ durante mais 2 minutos (etapa de redução dos reagentes e formação do filme de Azul da Prússia). O ciclo foi repetido por mais duas vezes. Em seguida, os eletrodos modificados foram ativados em solução contendo $0,5 \mathrm{~mol} \mathrm{~L}^{-1}$ de $\mathrm{KCl}$, $2,0 \times 10^{-2} \mathrm{~mol} \mathrm{~L}^{-1}$ de $\mathrm{HCl}$ e $1,0 \times 10^{-3} \mathrm{~mol} \mathrm{~L}^{-1}$ de $\mathrm{RuCl}_{3}$ (realização de 50 ciclos no 
intervalo de $-0,4 \mathrm{~V} \leq \mathrm{E}_{\text {apl }} \leq 0,6 \mathrm{~V}$ a $60 \mathrm{mV} \mathrm{s}^{-1}$ ) e utilizados após secagem a temperatura ambiente por 24 horas.

\subsubsection{1.e- Por Deposicão a Dois Potenciais Controlados e Ativacão em} Solucão contendo $\mathrm{KCl} 0,5 \mathrm{~mol} \mathrm{~L}^{-1}$ e $\mathrm{RhCl}_{3} 1,0 \times 10^{-3} \mathrm{~mol} \mathrm{~L}^{-1}$

Após imersão do sistema de eletrodos na solução modificadora aplicou-se $0,4 \vee$ ao eletrodo de trabalho durante 2 minutos (etapa de pré-concentração de reagentes). Em seguida, o potencial foi imediatamente revertido para $-0,4 \mathrm{~V}$ durante mais 2 minutos (etapa de redução dos reagentes e formação do filme de Azul da Prússia). O ciclo foi repetido por mais duas vezes. Em seguida, os eletrodos modificados foram ativados em solução contendo $0,5 \mathrm{~mol} \mathrm{~L}^{-1}$ de $\mathrm{KCl}$, $2,0 \times 10^{-2} \mathrm{~mol} \mathrm{~L}^{-1}$ de $\mathrm{HCl}$ e $1,0 \times 10^{-3} \mathrm{~mol} \mathrm{~L}^{-1} \mathrm{de} \mathrm{RhCl}_{3}$ (realização de 50 ciclos no intervalo de $-0,4 \mathrm{~V} \leq \mathrm{E}_{\mathrm{apl}} \leq 0,6 \mathrm{~V}$ a $60 \mathrm{mV} \mathrm{s}^{-1}$ ) e utilizados após secagem a temperatura ambiente por 24 horas.

Os três últimos métodos de preparação constituem-se em contribuições inéditas, as quais foram formuladas após leitura detalhada de métodos previamente descritos na literatura.

\section{II.2.2.2- Preparação dos Eletrodos Modificados em Solução de $\mathrm{RhCl}_{3}$}

11.2.2.2.a- Por Deposicão a Dois Potenciais Controlados em Solução contendo $1,0 \times 10^{-3} \mathrm{~mol} \mathrm{~L}^{-1}$ de $\mathrm{RhCl}_{3}$

Após imersão do sistema de eletrodos na solução contendo $1 \mathrm{~m} \mathrm{~mol} \mathrm{~L}^{-1}$ de $\mathrm{RhCl}_{3}$ e $0,02 \mathrm{~mol} \mathrm{~L}^{-1}$ de $\mathrm{HCl}$, aplicou-se $0,4 \mathrm{~V}$ ao eletrodo de trabalho durante 2 minutos. Em seguida, o potencial foi imediatamente revertido para $-0,4 \mathrm{~V}$ durante 
mais 2 minutos. O ciclo foi repetido por mais duas vezes. Em seguida, os eletrodos modificados foram ativados em solução contendo $0,5 \mathrm{~mol} \mathrm{~L}^{-1}$ de $\mathrm{KCl} e$ $2,0 \times 10^{-2} \mathrm{~mol} \mathrm{~L} \mathrm{~L}^{-1}$ de $\mathrm{HCl}$ (realização de 50 ciclos no intervalo de $-0,4 \vee \leq E_{a p l} \leq 0,6 \vee$ a $60 \mathrm{mV} \mathrm{s}^{-1}$ ) e utilizados após secagem a temperatura ambiente por 24 horas.

\section{II.2.3.1- Curvas Analíticas para Determinação de $\mathrm{H}_{2} \mathrm{O}_{2}$}

\section{I1.2.3.1.a- Curvas Analíticas para Determinacão de $\mathrm{H}_{2} \mathrm{O}_{2}$ Utilizando o Eletrodo Modificado com Azul da Prússia}

O eletrodo de pasta de carbono modificado com Azul da Prússia (EPC-AP) foi utilizado na determinação amperométrica de $\mathrm{H}_{2} \mathrm{O}_{2}$ no intervalo de $5,0 \times 10^{-5} \mathrm{~mol} \mathrm{~L}^{-1}$ a $8,6 \times 10^{-4} \mathrm{~mol} \mathrm{~L}^{-1} \mathrm{em}$ solução tampão (citrato de potássio/ácido citrico) $\mathrm{pH}=6,1$ contendo $0,5 \mathrm{~mol} \mathrm{~L}^{-1}$ de $\mathrm{KNO}_{3}$. O potencial aplicado foi de $0,040 \mathrm{~V}$ vs $\mathrm{E}_{\mathrm{Ag} / \mathrm{AgCl}, \mathrm{KCl}(\text { sat). }}$

\subsubsection{1.b-Curvas Analíticas para Determinacão de $\mathrm{H}_{2} \mathrm{O}_{2}$ Utilizando o Eletrodo Modificado com Azul da Prússia e Posteriormente Ativado em Solução contendo $1,0 \times 10^{-3} \mathrm{~mol} \mathrm{~L}^{-1}$ de $\mathrm{RhCl}_{3}$}

O eletrodo de pasta de carbono modificado com Azul da Prússia e posteriormente ativado em solução contendo $1,0 \times 10^{-3} \mathrm{~mol} \mathrm{~L}^{-1}$ de $\mathrm{RhCl}_{3}$ (EPC-AP-Rh) foi utilizado na determinação amperométrica de $\mathrm{H}_{2} \mathrm{O}_{2}$ no intervalo de $5,0 \times 10^{-5} \mathrm{~mol} \mathrm{~L}^{-1}$ a $8,6 \times 10^{-4} \mathrm{~mol} \mathrm{~L}^{-1}$ em solução tampão (citrato de potássio/ácido citrico) $\mathrm{pH}=6,1$ contendo $0,5 \mathrm{~mol} \mathrm{~L}^{-1} \mathrm{de} \mathrm{KCl}$. $O$ potencial aplicado foi de $0,040 \mathrm{~V}$ vs $E_{A g / A g C l, K C I(s a t)}$. 
Il.2.3.1.c-Curvas Analiticas Utilizadas para Estabelecer o Limite de Deteccão na Determinacaão de $\mathrm{H}_{2} \mathrm{O}_{2}$ Utilizando o Eletrodo Modificado com Azul da Prússia e Posteriormente Ativado em Solucão contendo $1,0 \times 10^{-3} \mathrm{~mol} \mathrm{~L}^{-1} \mathrm{de} \mathrm{RhCl}_{3}$

O eletrodo de pasta de carbono modificado com Azul da Prússia e posteriormente ativado em solução contendo $1,0 \times 10^{-3} \mathrm{~mol} \mathrm{~L}^{-1}$ de $\mathrm{RhCl}_{3}$ (EPC-AP-Rh) foi utilizado na determinação amperométrica de $\mathrm{H}_{2} \mathrm{O}_{2}$ no intervalo de $9,3 \times 10^{-8} \mathrm{~mol} \mathrm{~L}^{-1}$ a $8,6 \times 10^{-4} \mathrm{~mol} \mathrm{~L}^{-1} \mathrm{em}$ solução tampão (citrato de potássio/ácido citrico) $\mathrm{pH}=6,1$ contendo $0,5 \mathrm{~mol} \mathrm{~L}^{-1}$ de $\mathrm{KCl}$. Porém, a faixa de trabalho utilizada para cálculo do limite de detecção e sensibilidade foi de $5,1 \times 10^{-5} \mathrm{~mol} \mathrm{~L}^{-1}$ a $8,6 \times 10^{-4} \mathrm{~mol} \mathrm{~L}^{-1}$.

II.2.3.2- Avaliação da Interferência dos ácidos Ascórbico e Úrico na Determinação de $\mathrm{H}_{2} \mathrm{O}_{2}$ Utilizando os Eletrodos Modificados com Azul da Prússia e Posteriormente Ativados em Solução contendo $1,0 \times 10^{-3} \mathrm{~mol} \mathrm{~L}^{-1}$ de $\mathrm{RhCl}_{3}$

Il.2.3.2.a- Interferência do ácido Ascórbico na Determinacão de $\mathrm{H}_{2} \mathrm{O}_{2}$. Utilizando os Eletrodos Modificados com Azul da Prússia e Posteriormente Ativados em Solucão contendo $1,0 \times 10^{-3} \mathrm{~mol} \mathrm{~L}^{-1}$ de $\mathrm{RhCl}_{3}$

Os eletrodos de pasta de carbono modificados com Azul da Prússia e posteriormente ativados em solução contendo $1,0 \times 10^{-3} \mathrm{~mol} \mathrm{~L}^{-1}$ de $\mathrm{RhCl}_{3}$ (EPC-AP-Rh) foram utilizados para registrar a corrente de redução na ausência e presença de $1,0 \times 10^{-3} \mathrm{~mol} \mathrm{~L}^{-1}$ de ácido ascórbico e/ou úrico. A na faixa de 
potencial estudada foi $-0,21 \mathrm{~V} \leq \mathrm{E}_{\text {apli }} \leq 0,19 \mathrm{~V}$, em soluçăo tampão citrato de potássio / ácido cítrico $\mathrm{pH} \mathrm{6,1} \mathrm{contendo} 0,5 \mathrm{~mol} \mathrm{~L}^{-1}$ de $\mathrm{KCl}$.

Il.2.3.2.b- Interferência do Ácido Ascórbico na Determinacão de $\mathrm{H}_{2} \mathrm{O}_{2}$ Utilizando os Eletrodos Modificados com Azul da Prússia e Posteriormente Ativados em Solucãolontendo $1,0 \times 10^{-3} \mathrm{~mol} \mathrm{~L}^{-1}$ de $\mathrm{RhCl}_{3}$

O eletrodo de pasta de carbono modificado com Azul da Prússia e posteriormente ativado em solução contendo $1,0 \times 10^{-3} \mathrm{~mol} \mathrm{~L}^{-1}$ de $\mathrm{RhCl}_{3}$ (EPC-AP-Rh) foi utilizado na determinação amperométrica de $\mathrm{H}_{2} \mathrm{O}_{2}$. Para tanto, fixou-se o potencial aplicado ao eletrodo em 0,040 V e, após estabilização da linha base, efetuaram-se 3 adições de solução estoque de $\mathrm{H}_{2} \mathrm{O}_{2}$ à célula contendo tampão citrato de potássio/ ácido cítrico, pH 6,1 e $0,5 \mathrm{~mol} \mathrm{~L}^{-1}$ de $\mathrm{KCl}$. Após a última adição do analíto $\left(\left[\mathrm{H}_{2} \mathrm{O}_{2}\right]=2,4 \times 10^{-4} \mathrm{~mol} \mathrm{~L}^{-1}\right.$ na célula de medida), efetuouse uma adição de ácido ascórbico de modo a obter uma concentração final de $2,0 \times 10^{-5} \mathrm{~mol} \mathrm{~L}^{-1}$ do interferente. Este procedimento foi efetuado na presença e na ausência de $\mathrm{O}_{2}$. 


\section{III- RESULTADOS E DISCUSSŌES}

\section{III.1-Preparação de Eletrodos de Pasta de Carbono Modificados com Azul da Prússia por Voltametria Cíclica.}

\section{III.1.1- Formação do Filme de Azul da Prússia como Descrito por Chi et al ${ }^{(29)}$.}

Inicialmente, tentou-se reproduzir o trabalho de Chi et al ${ }^{(29)}$, porém nas condições de $\mathrm{pH}$ utilizadas ( $\mathrm{pH}=6,0 /$ tampão fosfato), o filme de Azul da Prússia não se formou.

Em vista deste resultado preliminar decidiu-se, avaliar a influência de diversos parâmetros, não somente na formação do filme, como também em sua estabilidade em eletrólito suporte. Os resultados serão abordados a seguir.

\section{III.1.2- Influência da Concentração de HCl na Solução Modificadora.}

Como anteriormente descrito no item II.1.1.a, página 30 , variou-se o volume de $\mathrm{HCl} 0,1 \mathrm{~mol} \mathrm{~L}^{-1}$ utilizado para dissolução de $\mathrm{FeCl}_{3}$, de modo que a concentração de $\mathrm{HCl}$ na célula eletroquímica variou no intervalo de $0,01 \mathrm{~mol} \mathrm{~L}^{-1} \leq[\mathrm{HCl}] \leq 0,1 \mathrm{~mol} \mathrm{~L}^{-1}$. Este procedimento foi adotado com o objetivo de evitar a hidrólise do ín $\mathrm{Fe}^{3+}$, durante o processo de preparação da solução modificadora. Os voltamogramas cíclicos registrados durante o processo de crescimento do filme são similares àqueles apresentados na Figura 7, página 23.

A influência da acidez do meio pode ser constatada durante o processo de formação do filme, uma vez que em $0,02 \mathrm{~mol} \mathrm{~L}^{-1}$ de $\mathrm{HCl}$ as correntes catódicas e anódicas correspondentes aos picos I e II, redução do Azul da Prússia ao Branco da Prússia e oxidação do Branco da Prússia ao Azul da Prússia respectivamente, 
foram as mais altas correntes de picos, atingindo-se valores estáveis de corrente a partir do $20^{\circ}$ voltamograma. Para concentrações de $\mathrm{HCl}$ superiores a $0,02 \mathrm{~mol} \mathrm{~L}^{-1}$, correntes de pico inferiores foram registradas, Figura 9. 


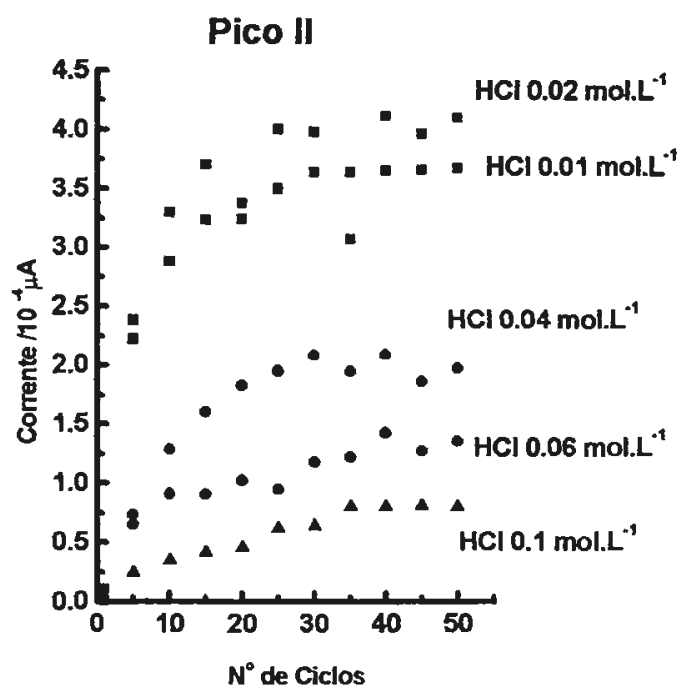

Pico I

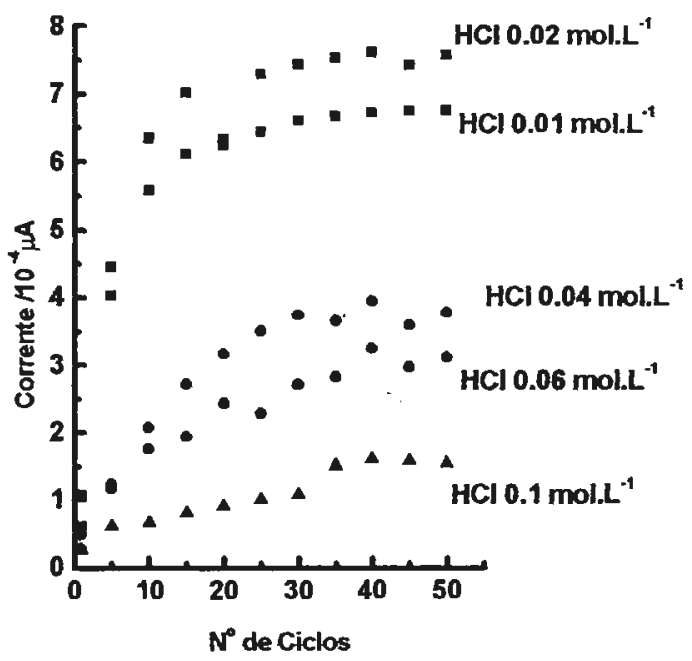

Figura 9. Correntes de pico obtidas durante a formação de filmes de Azul da Prússia em diversas concentrações de $\mathrm{HCl}$. Solução modificadora: $2 \mathrm{mmol}^{-1}$ de $\mathrm{K}_{3}\left[\mathrm{Fe}(\mathrm{CN})_{6}\right] ; 3 \mathrm{mmol} \mathrm{L}{ }^{-1}$ de $\mathrm{FeCl}_{3} ; 0,5 \mathrm{~mol} \mathrm{~L}^{-1}$ de $\mathrm{KNO}_{3} . E_{\mathrm{i}}=-0,4 \mathrm{~V} ; E_{\mathrm{f}}=1,2 \mathrm{Ve}$ velocidade de varredura $=60 \mathrm{mV} \mathrm{s}^{-1}$. 
Apesar disto, mesmo na concentração otimizada de $\mathrm{HCl}$, o filme não se manteve estável durante a ciclagem em eletrólito suporte, tampão fosfato, $\mathrm{pH} 6,5$, Figura 10. 

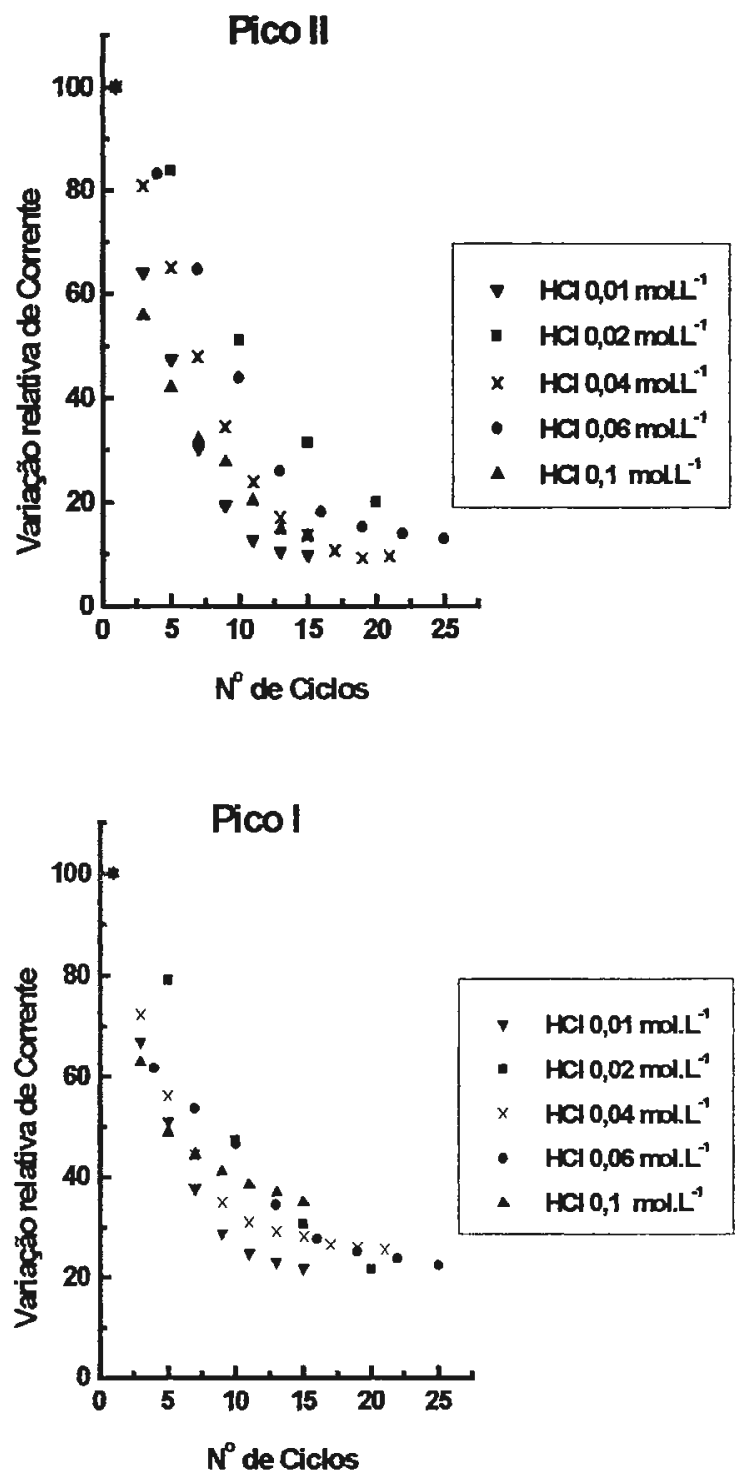

Figura 10. Variação relativa de correntes de pico anódico e catódico dos filmes de Azul da Prússia formados em diversas concentrações de $\mathrm{HCl}$, como função do número de voltamogramas cíclicos efetuados em solução tampão fosfato, $\mathrm{pH}=\mathbf{6 , 5}$.

$E_{i}=-0,4 V ; E_{f}=1,2 \mathrm{~V} ;$ velocidade de varredura $=60 \mathrm{~m} \mathrm{~V} \mathrm{~s}^{-1}$.

Variação relativa da corrente $=\left(i_{\text {ciclo considerado }} \times 100\right) / i_{1}{ }^{\circ}$ Ciclo medido. 


\section{III.1.3- Influência da Concentração de $\mathrm{KNO}_{3}$ na Solução Modificadora.}

Após verificar que existia uma condição de acidez que permitia a obtenção de mais altas correntes durante a formação dos filmes, apesar da pequena estabilidade dos mesmos, decidiu-se fixar a concentração de $\mathrm{HCl}$ na solução modificadora em $0,02 \mathrm{~mol} \mathrm{~L}^{-1}$, passando-se a variar a concentração do íon $\mathrm{K}^{+}$na composição da mesma.

Observou-se um aumento nas correntes de formação com o aumento da concentração de $\mathrm{KNO}_{3}$. Os melhores resultados foram obtidos em solução $0,35 \mathrm{~mol} \mathrm{~L}^{-1}$, Figura 11. 

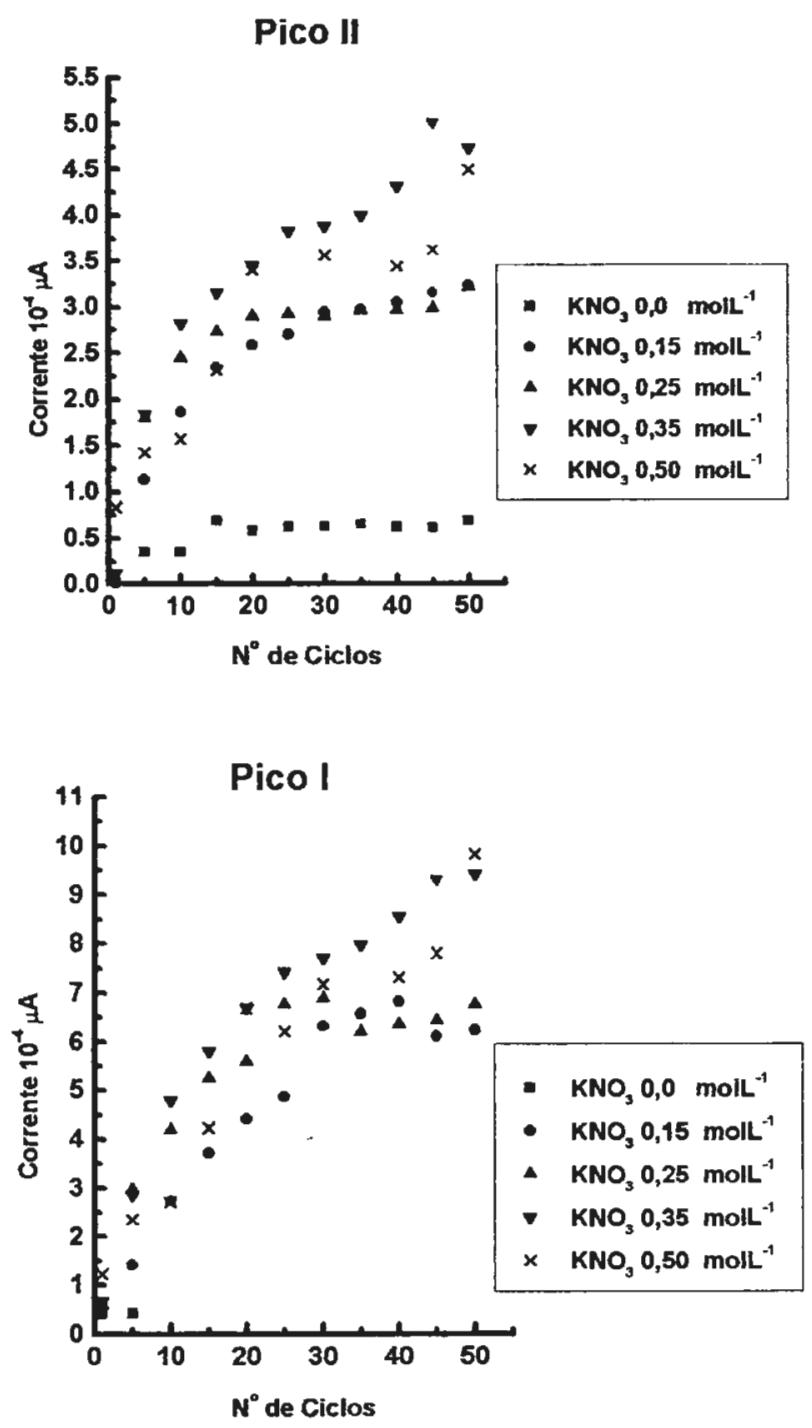

Figura 11. Correntes de pico obtidas durante a formação de filmes de Azul da Prússia em diversas concentrações de $\mathrm{KNO}_{3}$ como função do número de voltamogramas cíclicos. Solução modificadora: $2 \mathrm{mmol} \mathrm{L}^{-1}$ de $K_{3}\left[\mathrm{Fe}(\mathrm{CN})_{6}\right]$; $3 \mathrm{mmol} \mathrm{L}^{-1}$ de $\mathrm{FeCl}_{3}$ em 0,02 $\mathrm{mol} \mathrm{L}^{-1}$ de $\mathrm{HCl} . E_{i}=-0,4 \mathrm{~V} ; E_{\mathrm{f}}=1,2 \mathrm{~V}$ e velocidade de varredura $=60 \mathrm{mV} \mathrm{s}^{-1}$. 
Ao se efetuar a ciclagem em eletrólito suporte (tampão fosfato, $\mathrm{pH} \mathrm{6,5)}$ observou-se a perda de aproximadamente $80 \%$ do filme ativo após 30 ciclos, Figura 12. 

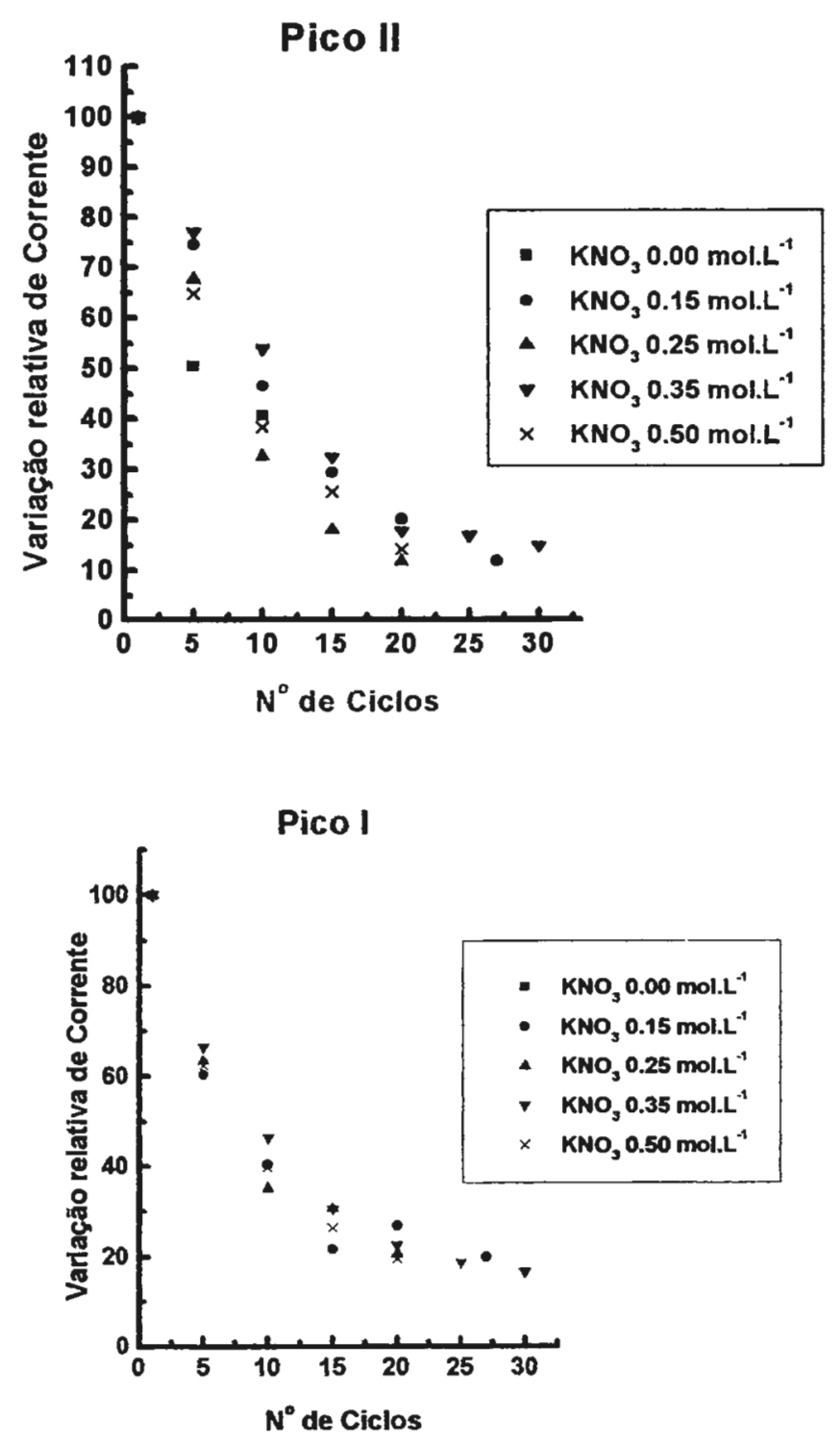

Figura 12. Variação relativa de corrente dos picos II e I de filmes de Azul da Prússia formados em diversas concentrações de $\mathrm{KNO}_{3}$, como função do número de voltamogramas cíclicos registrados em solução tampão fosfato, $\mathrm{pH}=\mathbf{6 , 5}$.

$E_{i}=-0,4 \mathrm{~V} ; E_{f}=1,2 \mathrm{~V} ;$ velocidade de varredura $=60 \mathrm{~m} \mathrm{~V} \mathrm{~s}^{-1}$.

Variação relativa da corrente $=\left(i_{\text {ciclo considerado }} \times 100\right) / i_{1}{ }^{\circ}$ Ciclo medido . 
Apesar da concentração de $0,35 \mathrm{~mol} \mathrm{~L}^{-1}$ de $\mathrm{KNO}_{3}$, apresentar os melhores resultados na formação, o mesmo não ocorre quando se efetua a ciclagem em eletrólito suporte (tampão fosfato, $\mathrm{pH}$ 6,5). Deste modo, utilizou-se a maior concentração de $\mathrm{KNO}_{3}\left(0,50 \mathrm{~mol} \mathrm{~L}^{-1}\right)$, como sendo a concentração ideal de ions $\mathrm{K}^{+}$, uma vez que esta concentração não interfere muito na formação do filme e ao efetuar ciclagens em eletrólito suporte não foi observada diferença em relação à porcentagem de queda do filme formado em solução de $0,35 \mathrm{~mol} \mathrm{~L}^{-1}$ de $\mathrm{KNO}_{3}$.

\section{III.1.4- Estabilidade dos Filmes da Azul da Prússia Durante Ciclagens Sucessivas em Solução de Eletrólito Suporte.}

\section{III.1.4.a- Influência da Secagem Prévia dos Filmes.}

De acordo com Ellis et al ${ }^{(39)}$ e Karyakin et al ${ }^{(30)}$ a estabilidade dos eletrodos modificados com Azul da Prússia aumenta com a secagem previa dos filmes à temperatura ambiente.

Para avaliar a influência deste parâmetro na estabilidade dos filmes em solução de eletrólito suportes, fixaram-se as concentraçōes de $\mathrm{HCl}$ e $\mathrm{KNO}_{3}$ na solução modificadora em $0,02 \mathrm{~mol} \mathrm{~L}^{-1}$ e $0,5 \mathrm{~mol} \mathrm{~L}^{-1}$, respectivamente. Após a formação do filme (50 ciclos), o eletrodo foi deixado em repouso à temperatura ambiente por 24 horas.

Após a secagem os eletrodos apresentaram maior estabilidade de modo que os resultados aqui obtidos estão em concordância com aqueles apresentados nas referências (30) e (39). 
III.1.4.b- Influência do pH da Solução de Eletrólito Suporte na Estabilidade dos Eletrodos Modificados.

Uma vez constatada que a presença dos íons $\mathrm{K}^{+}$é importante durante o processo de formação dos filmes de AP, avaliou-se a estabilidade dos filmes formados como função da introdução de $\mathrm{KNO}_{3}$ e variação de $\mathrm{pH}$ do eletrólito suporte. Os dados obtidos são apresentados na Figura 13. 

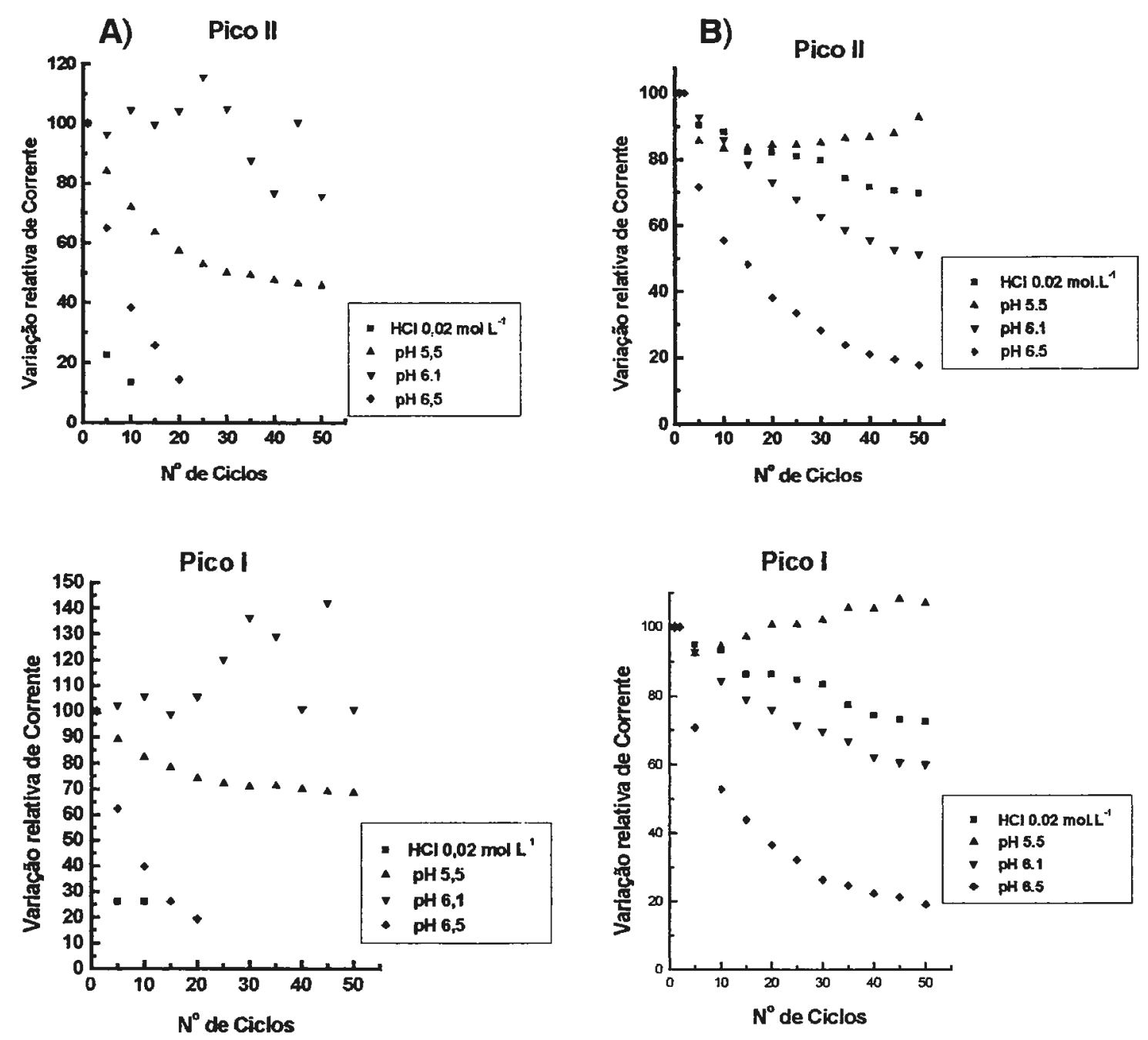

Figura 13. Efeito do $\mathrm{pH}$ e da introdução de $\mathrm{KNO}$ no eletrólito suporte na estabilidade dos Picos || e I dos filmes de Azul da Prússia. (A) na ausência de $\mathrm{KNO}_{3}$ e (B) na presença de $0,5 \mathrm{~mol} \mathrm{~L}^{-1}$ de $\mathrm{KNO}_{3}$. $E_{\mathrm{i}}=-0,4 \mathrm{~V}$; $E_{\mathrm{f}}=1,2 \mathrm{~V}$; velocidade de varredura $=60 \mathrm{~m} \mathrm{~V} \mathrm{~s}^{-1}$. Variação da corrente $=\left(i_{\text {ciclo considerado }} \times 100\right) / i_{1}{ }^{\circ}$ Ciclo medido . 
Estes resultados demonstraram que os filmes de Azul da Prússia são mais estáveis quando ciclados em solução de eletrólito suporte contendo íons $\mathrm{K}^{+}$.

Decorre de imediato destes resultados, que os filmes também são mais estáveis em meio ácido, no entanto constatou-se, que uma pequena variação de pH (de 6,1 para 6,5) causou um decréscimo acentuado na estabilidade dos filmes, o qual não pode ser explicado apenas por uma variação de 0,4 unidades de pH. Uma vez que tanto íons $\mathrm{PO}_{4}^{3+}$ quanto íons $\mathrm{OH}^{-}$, podem formar complexos estáveis com $\mathrm{Fe}^{3+}$, a presença destes íons podem causar a dissolução do filme de acordo com:

$$
\begin{aligned}
& \mathrm{Fe}^{3+}+2 \mathrm{HPO}_{4}{ }^{2-} \longleftrightarrow \\
& \mathrm{Fe}^{3+}+\mathrm{OH}^{-} \longleftrightarrow\left[\mathrm{Fe}\left(\mathrm{HPO}_{4}\right)_{2}\right]^{-}
\end{aligned}
$$

Para avaliar esta hipótese, os testes de estabilidade foram efetuados em $\mathrm{pH}$ 6,1 e 6,5 utilizando-se tampões com composição diferentes. Os dados obtidos são apresentados na figura 14. 
Pico II

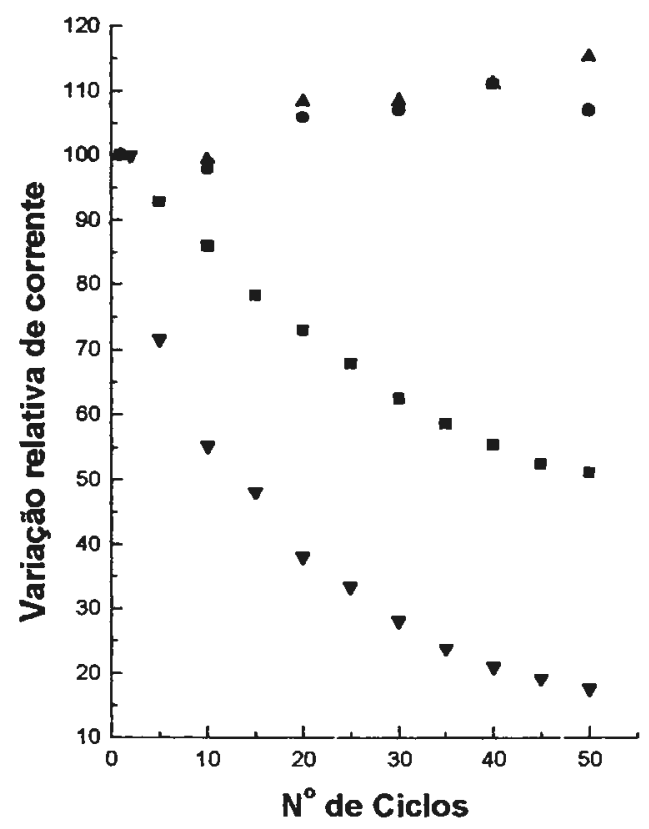

Pico I

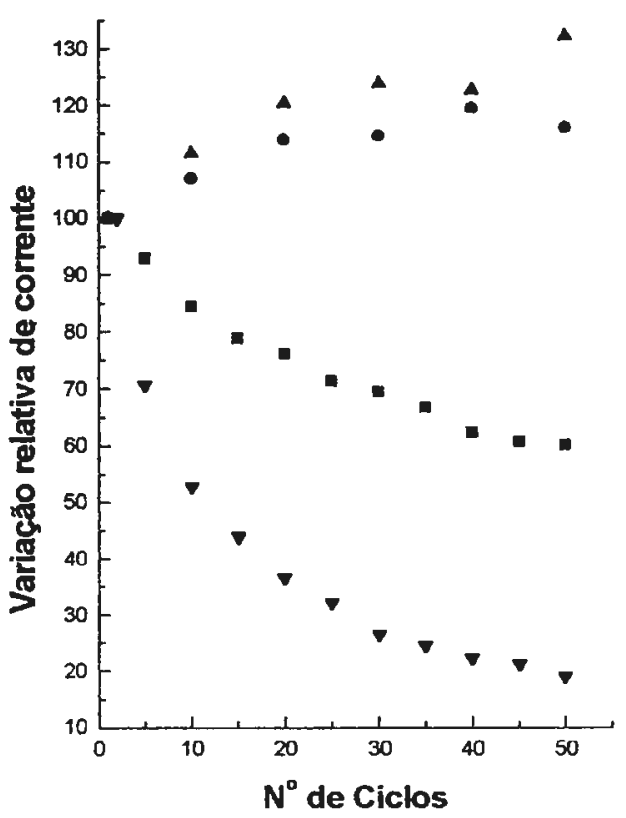

Figura 14. Variação das correntes de pico anódico e catódico de filmes de Azul da Prússia como função do número de voltamogramas cíclicos efetuados em soluçōes tampōes de pH 6,1 e 6,5, com composiçōes diferentes, mas contendo $0,5 \mathrm{~mol} \mathrm{~L}^{-1}$ de $\mathrm{KNO}_{3}$ :

- $\mathrm{Na} \mathrm{H}_{2} \mathrm{PO}_{4} 0,05 \mathrm{~mol} \mathrm{~L}^{-1} / \mathrm{Na}_{2} \mathrm{HPO}_{4} 0,05 \mathrm{~mol} \mathrm{~L}^{-1} \mathrm{pH}=6,1$;

$\checkmark \mathrm{Na} \mathrm{H}_{2} \mathrm{PO}_{4} 0,05 \mathrm{~mol} \mathrm{~L}^{-1} / \mathrm{Na}_{2} \mathrm{HPO}_{4} 0,05 \mathrm{~mol} \mathrm{~L}^{-1} \mathrm{pH}=6,5$;

- Ácido citríco 0,002 $\mathrm{mol} \mathrm{L}^{-1} /$ Citrato de Potássio 0,01 $\mathrm{mol} \mathrm{L}^{-1} \mathrm{pH}=6,1$;

$\triangle$ Ácido citríco $0,002 \mathrm{~mol} \mathrm{~L}^{-1} /$ Citrato de Potássio $0,01 \mathrm{~mol} \mathrm{~L}^{-1} \mathrm{pH}=6,5$;

Eletrodos secos a temperatura ambiente por 24 horas. $E_{i}=-0,4 V ; E_{f}=1,2 V$; velocidade de varredura $=60 \mathrm{~m} \mathrm{~V} \mathrm{~s}^{-1}$.

Variação da corrente $=\left(i_{\text {ciclo considerado }} \times 100\right) / i_{1^{\circ}}$ Ciclo medido 
Os dados apresentados na figura 14 confirmam a hipótese previamente formulada, de que íons $\mathrm{PO}_{4}{ }^{3-}$ desestabilizam os filmes de Azul da Prússia.

Deste modo é recomendável que o eletrólito suporte utilizado não contenha espécies derivadas do anion fosfato. Adotou-se então 0 tampão citrato de potássio / ácido cítrico contendo $0,5 \mathrm{~mol} \mathrm{~L}^{-1}$ de $\mathrm{KNO}_{3}$ como o eletrólito suporte mais adequado.

\section{III.1.4.C- Influência da Concentração de $\mathrm{FeCl}_{3}$ da Solução Modificadora na Estabilidade dos Eletrodos Modificados.}

Diminuiu-se a concentração de $\mathrm{FeCl}_{3}$ da solução modificadora de $3 \mathrm{mmol} \mathrm{L}{ }^{-1}$ para $2 \mathrm{mmol} \mathrm{L}^{-1} \mathrm{e}$ avaliou-se a estabilidade dos eletrodos modificados como função desta alteraçăo. As demais condições: $2 \mathrm{mmol} \mathrm{L}^{-1}$ de $\mathrm{K}_{3}\left[\mathrm{Fe}(\mathrm{CN})_{6}\right]$; $0,5 \mathrm{~mol} \mathrm{~L}^{-1}$ de $\mathrm{KNO}_{3}$ em $\mathrm{HCl} 0,02 \mathrm{~mol} \mathrm{~L}^{-1}$, intervalo de potencial $-0,4 \vee \leq$ Eapl $\leq 1,2 \vee$ e velocidade de varredura de $60 \mathrm{~m} \mathrm{~V} \mathrm{~s}^{-1}$, mantiveram-se inalteradas em relação ao procedimento otimizado. Os resultados obtidos são apresentados nas figuras 15.1, 15.2 e 16.

De acordo com a Figura 15.1, três picos de oxidação foram observados durante a formação e crescimento dos filmes os quais podem ser atribuídos à oxidação do $\operatorname{AP}(0,34 \mathrm{~V})$, um complexo misto entre o $\operatorname{AP}$ e o verde de Berlin $\left(\mathrm{Fe}^{\mathrm{III}}\left[\mathrm{Fe} \mathrm{e}^{\prime \prime}(\mathrm{CN})_{6}\right]_{3}+\mathrm{Fe}^{\mathrm{III}}\left[\mathrm{Fe} \mathrm{e}^{\mathrm{II \prime}}(\mathrm{CN})_{6}\right]_{3}\right) \quad(0,45 \mathrm{~V})$ e ao verde de Berlin $(1,0 \mathrm{~V})$, respectivamente, figura 15.1 (A 1). Quando o eletrodo modificado é estabilizado em tampão ácido cítrico/ citrato de potássio $\mathrm{pH} \mathrm{6,1}$ contendo $0,5 \mathrm{~mol} \mathrm{~L}^{-1}$ de $\mathrm{KNO}_{3}$, figura 15.1 (B 1), os picos apresentaram melhor definição, maiores valores de correntes, além do fato do pós-pico a 0,45 $\mathrm{V}$ ter desaparecido. Deste modo podese concluir que ao se estabilizar o filme em eletrólito suporte houve uma reorganização estrutural do filme.

Entretanto, ao se comparar às variações de corrente dos picos anódico e catódico deste filme com aquele filme formado na presença de excesso de $\mathrm{FeCl}_{3}$ 
(figura 15.2) não se observa, para 50 ciclos em solução tampão ácido cítrico/ citrato de potássio $\mathrm{pH} 6,1$ contendo $0,5 \mathrm{~mol} \mathrm{~L}^{-1}$ de $\mathrm{KNO}_{3}$, diferença significativa. 


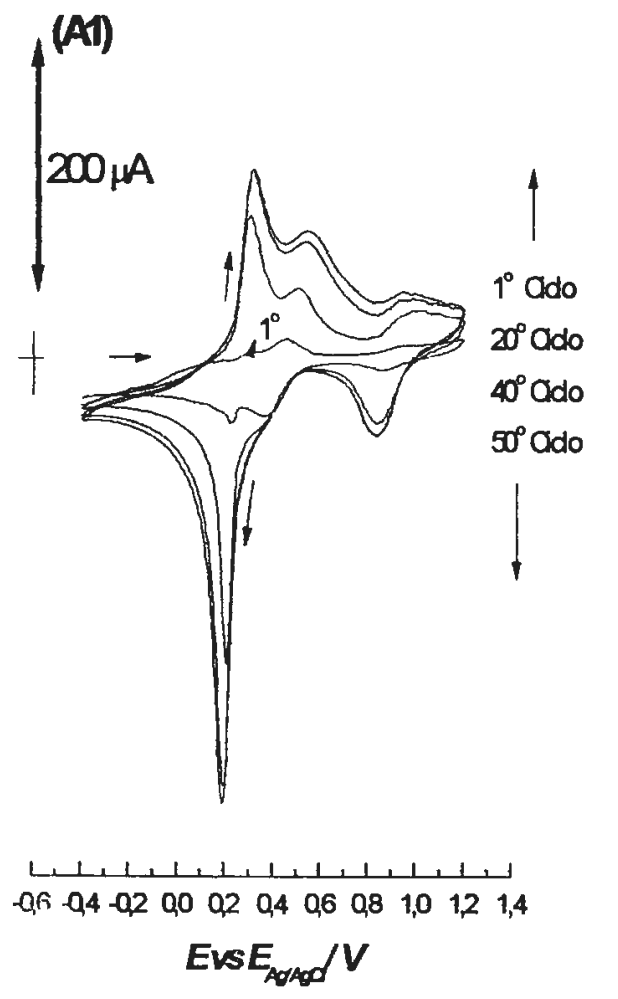

(B1)

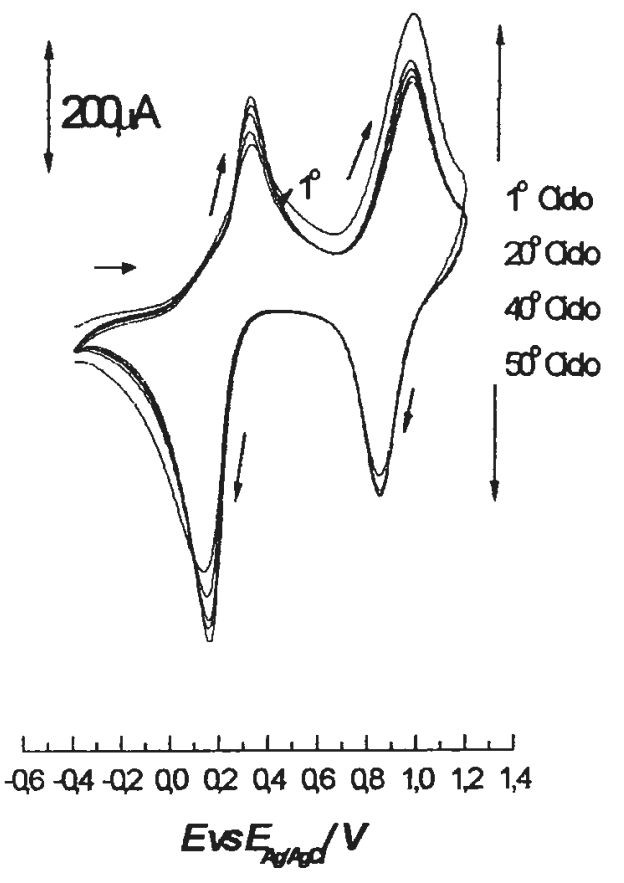

Figura 15.1. Voltamogramas cíclicos registrados em: (A 1) solução modificadora contendo $2 \mathrm{mmol} \mathrm{L}^{-1}$ de $\mathrm{K}_{3}\left[\mathrm{Fe}(\mathrm{CN})_{6}\right] ; 2 \mathrm{mmol} \mathrm{L}{ }^{-1}$ de $\mathrm{FeCl}_{3}$; $0,5 \mathrm{~mol} \mathrm{~L}^{-1}$ de $\mathrm{KNO}_{3}$ em HCl $0,02 \mathrm{~mol} \mathrm{~L}^{-1}$ e $-0,4 \mathrm{~V} \leq \mathrm{E}_{\mathrm{apl}} \leq 1,2 \mathrm{~V}$; (B 1) solução eletrólito suporte tampão ácido citrico/citrato de potássio $\mathrm{pH} \mathrm{6,1} \mathrm{contendo}$ $0,5 \mathrm{~mol} \mathrm{~L} \mathrm{~L}^{-1}$ de $\mathrm{KNO}_{3}$. Velocidade de varredura $=60 \mathrm{~m} \mathrm{~V} \mathrm{~s}^{-1} \mathrm{e}$ $-0,4 \mathrm{~V} \leq \mathrm{E}_{\mathrm{apl}} \leq 1,2 \mathrm{~V}$. 
(A2)

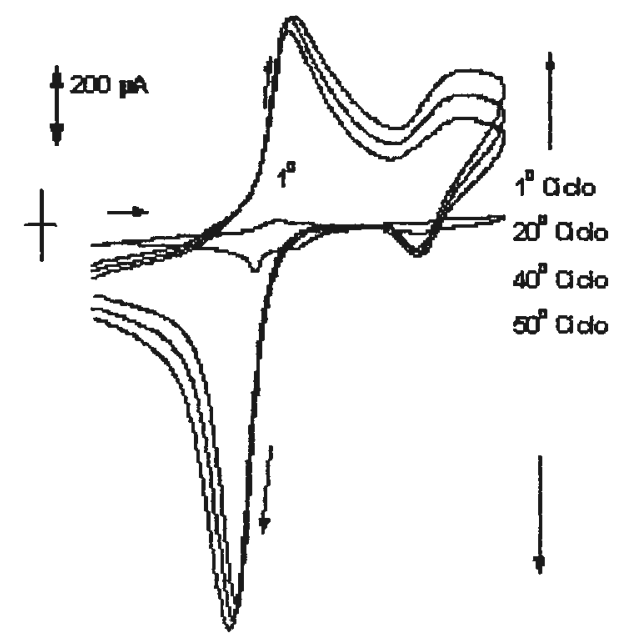

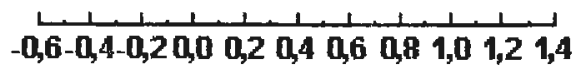

EvsE $E_{\text {abrod }} / V$
(B2)

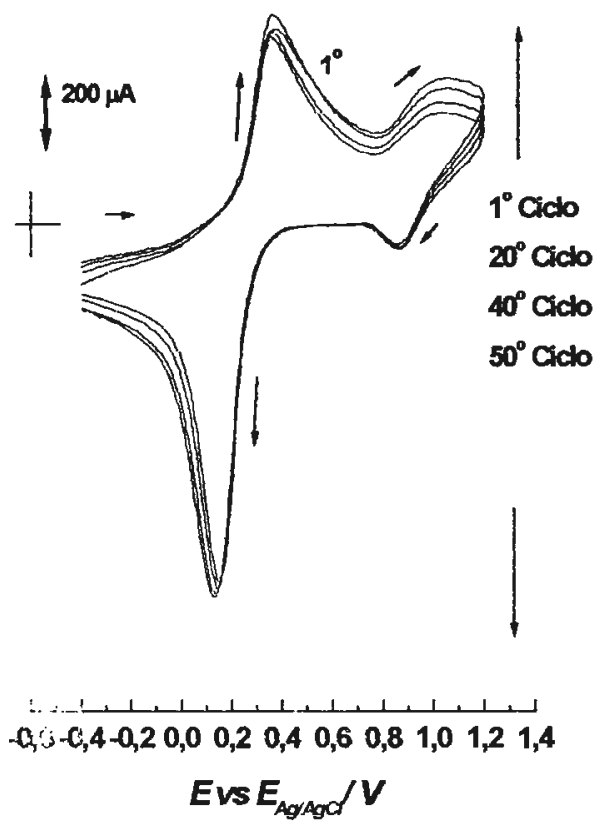

Figura 15.2. Voltamogramas cíclicos registrados em: (A 2) solução

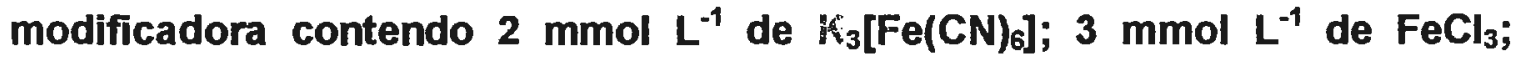

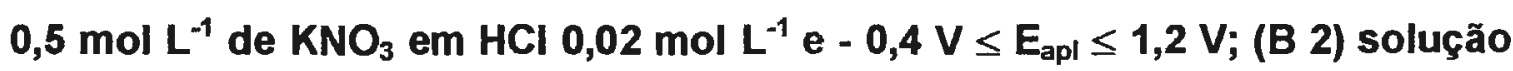
eletrólito suporte tampão ácido citríco/citrato de potássio pH 6,1 contendo $0,5 \mathrm{~mol} \mathrm{~L}^{-1}$ de $\mathrm{KNO}_{3}$. Velocidade de varredura $=60 \mathrm{~m} \mathrm{~V} \mathrm{~s}$ e $-0,4 \mathrm{~V} \leq \mathrm{E}_{\mathrm{apl}} \leq 1,2 \mathrm{~V}$. 
Deste modo com o intuito de compreender melhor a reação de oxi-redução AP/BP que está ocorrendo na superfície do eletrodo modificado ou ao redor desta superfície, os eletrodos modificados com Azul da Prússia foram ciclados em eletrólito suporte tampão citrato de potássio/ácido citríco $\mathrm{pH} \mathrm{5,5}$ contendo $0,5 \mathrm{~mol} \mathrm{~L}^{-1}$ de $\mathrm{KNO}_{3}$. Em seguida a solução de eletrólito suporte foi trocado por uma nova solução (tampão citrato de potássio/ácido cítrico pH 5,5 contendo adição de $0,5 \mathrm{~mol} \mathrm{~L}^{-1}$ de $\mathrm{KNO}_{3}$ ) de modo a não ter nenhuma espécie dissociada na solução ao redor do eletrodo. Os dados são apresentados na figura 16.

Independentemente da concentração de $\mathrm{FeCl}_{3}$ se encontrar ou não em excesso a proporção do pico II anódico (oxidação do Branco da Prússia ao Azul da Prússia) e pico I catódico (redução do Azul da Prússia ao Branco da Prússia) é de 1:2, ou seja, provavelmente há formação de AP "solúvel" (Pico II) que estaria se reduzindo a BP "solúvel" e "insolúvel" (Pico I). Uma outra possibilidade é que a corrente do Pico I possua a contribuição relativa à redução do excesso de ferricianeto a ferrocianeto de potássio, enquanto o processo inverso não pode ser detectadu, uma vez que ferrocianeto é consumido durante a formação do filme:

$$
\begin{aligned}
& \text { Pico (I): }\left[\mathrm{Fe}^{\prime \prime \prime}(\mathrm{CN})_{6}\right]^{3-}+1 e^{-} \rightleftarrows\left[\mathrm{Fe}^{\prime \prime}(\mathrm{CN})_{6}\right]^{4} \\
& \mathrm{Fe}_{(\mathrm{exc})}{ }^{3+}+\text { Ferrocianeto }^{4} \rightleftarrows \mathrm{Fe}_{4}\left[\mathrm{Fe}^{\prime \prime}(\mathrm{CN})_{6}\right]_{3} \\
& \text { (Azul da Prússia) } \\
& \mathrm{Fe}_{4}\left[\mathrm{Fe}^{\prime \prime}(\mathrm{CN})_{6}\right]_{3}+4 \mathrm{~K}^{+}+4 \mathrm{e}^{-} \rightleftarrows \mathrm{K}_{4} \mathrm{Fe}_{4}{ }_{4}\left[\mathrm{Fe}^{\prime \prime}(\mathrm{CN})_{6}\right]_{3} \\
& \text { (Branco da Prússia) } \\
& \text { Pico (II): } \mathrm{K}_{4} \mathrm{Fe}_{4}{ }_{4}^{\prime \prime}\left[\mathrm{Fe}^{\prime \prime}(\mathrm{CN})_{6}\right]_{3} \rightarrow \mathrm{Fe}_{4}\left[\mathrm{Fe}^{\prime \prime}(\mathrm{CN})_{6}\right]_{3}+4 \mathrm{~K}^{+}+4 \mathrm{e}^{-}
\end{aligned}
$$

Além disso, observou-se que o eletrodo modificado com filme de Azul da Prússia formado em solução modificadora contendo excesso de $\mathrm{FeCl}_{3}$ (Figura 16 A), após os 160 ciclos não apresentou queda nas correntes dos picos AP/BP enquanto que o eletrodo modificado com filme de Azul da Prússia formado em solução modificadora contendo concentrações equimolares de $\mathrm{FeCl}_{3}$ e $\mathrm{K}_{3}\left[\mathrm{Fe}(\mathrm{CN})_{6}\right]$ (Figura 16 B) apresentou uma queda nas correntes dos picos AP/BP. 
(A)

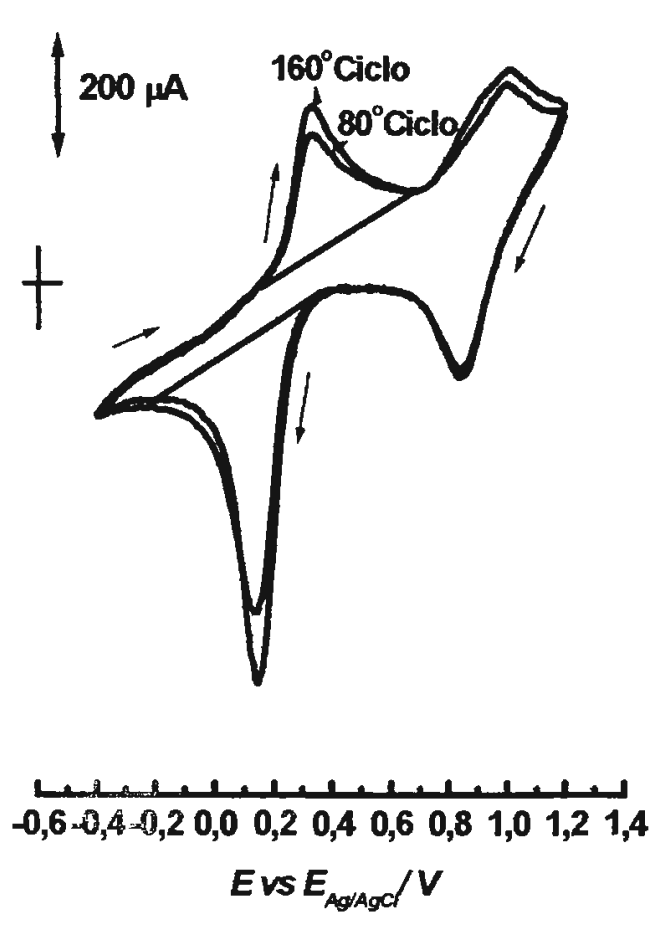

(B)

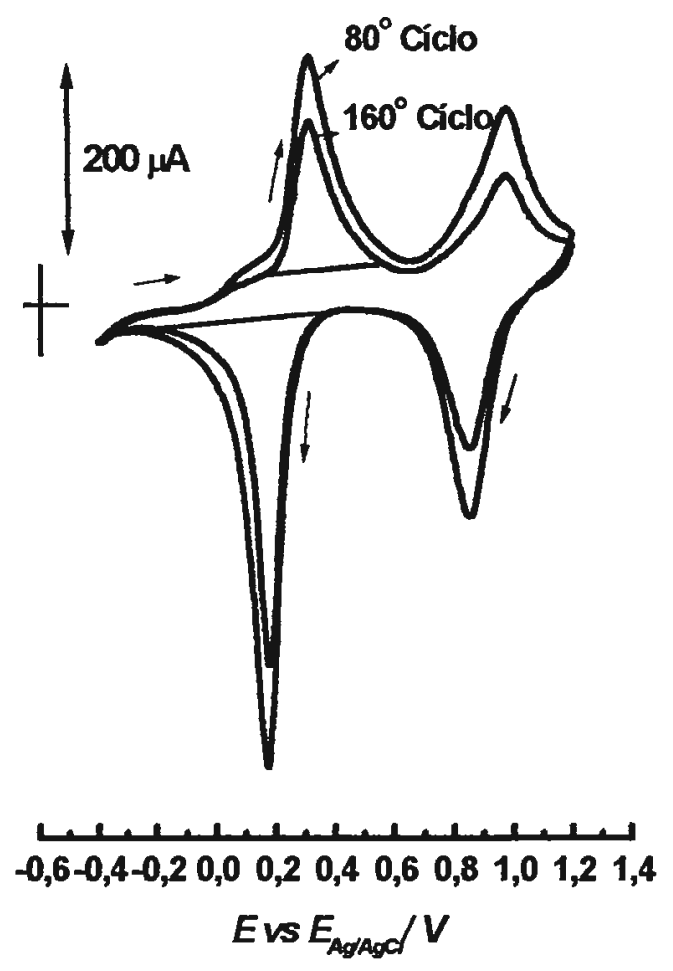

Figura 16. Voltamogramas cíclicos registrados em solução eletrólito suporte tampão ácido citrico/citrato de potássio pH 5,5 com $0,5 \mathrm{molL}^{-1}$ de $\mathrm{KNO}_{3}$, (A) filme formado em solução modificadora $2 \mathrm{mmol} \mathrm{L}^{-1}$ de $K_{3}\left[\mathrm{Fe}(\mathrm{CN})_{6}\right]$; $3 \mathrm{mmol} \mathrm{L}^{-1}$ de $\mathrm{FeCl}_{3} ; 0,5 \mathrm{~mol} \mathrm{~L}^{-1}$ de $\mathrm{KNO}_{3}$ em $\mathrm{HCl} 0,02 \mathrm{~mol} \mathrm{~L}^{-1}$ e (B) filme formado em solução modificadora: $2 \mathrm{mmol} \mathrm{L}^{-1}$ de $\mathrm{K}_{3}\left[\mathrm{Fe}(\mathrm{CN})_{6}\right] ; 2 \mathrm{mmol} \mathrm{L}^{-1} \mathrm{de}$ $\mathrm{FeCl}_{3} ; 0,5 \mathrm{~mol} \mathrm{~L}^{-1}$ de $\mathrm{KNO}_{3}$ em $\mathrm{HCl} 0,02 \mathrm{~mol} \mathrm{~L}^{-1}$.

Velocidade de varredura $=60 \mathrm{mVs}^{-1}$ e $-0,4 \vee \leq E_{\text {apl }} \leq 1,2 \mathrm{~V}$ 
Então, concluiu-se que a presença do excesso de $\mathrm{FeCl}_{3}$ na solução modificadora favoreceu a formação do AP "insolúvel", uma vez que o eletrodo modificado se manteve estável após um alto número de ciclos consecutivos ter sido efetuado em eletrólito suporte.

\section{III.1.5- Redução Catalítica de $\mathrm{H}_{2} \mathrm{O}_{2}$ em Eletrodos de Pasta de Carbono Modificados Com Filmes de Azul da Prússia}

\section{III.1.5.a- Redução Catalítica de $\mathrm{H}_{2} \mathrm{O}_{2}$ Usando Voltametria Cíclica.}

Chi Dong et al. ${ }^{(29)}$ utilizaram a voltametria cíclica e eletrodo de carbono pirolítico para demonstrar o efeito catalítico de filmes de Azul da Prússia na redução de $\mathrm{H}_{2} \mathrm{O}_{2}$. $\mathrm{O}$ pico de redução do $\mathrm{BP}$ (branco da Prússia) mantém-se constante enquanto o pico de AP cresce. Desta forma a $\mathrm{H}_{2} \mathrm{O}_{2}$ atua como agente oxidante do filme. 


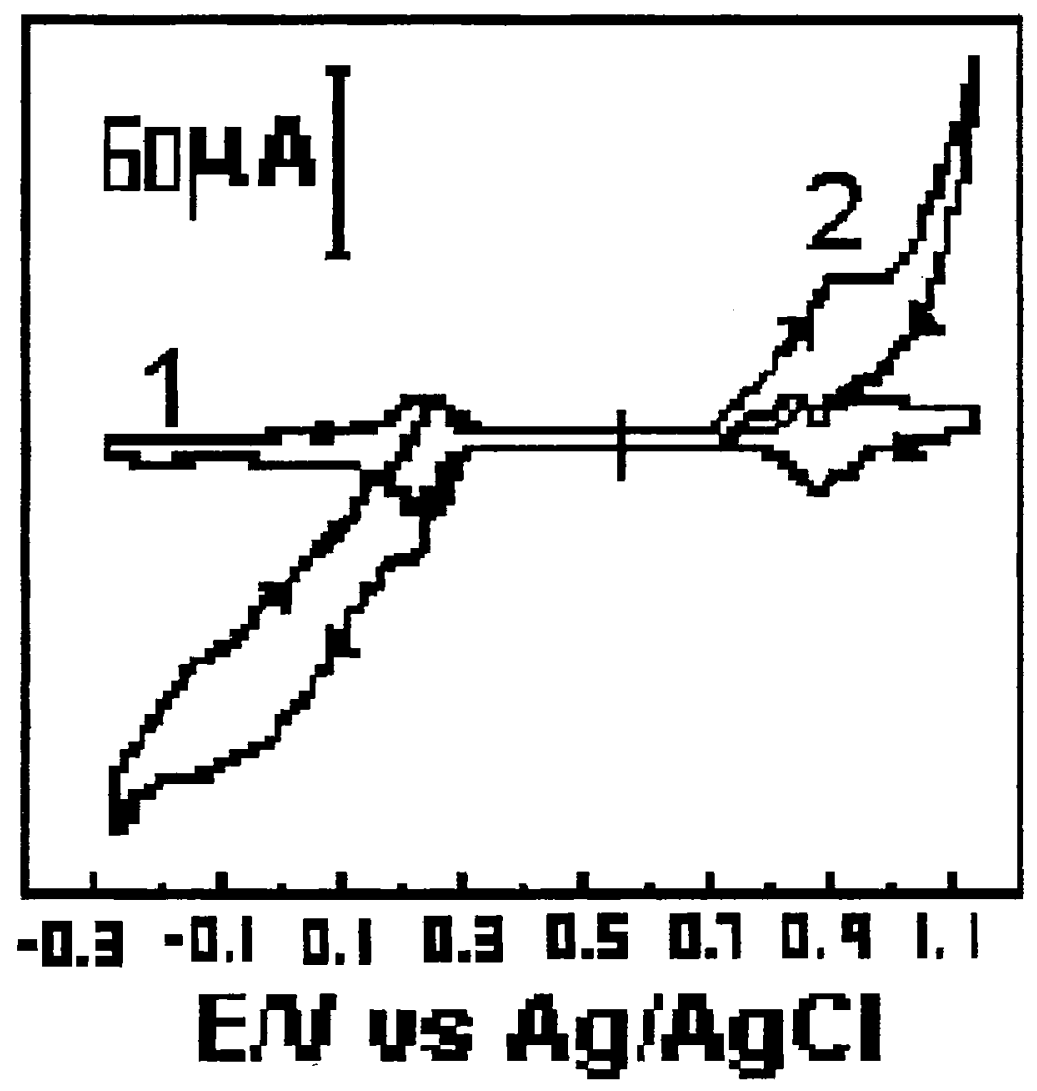

Figura 17. Voltamogramas cíclicos registrados em eletrólito suporte com eletrodo modificado com Azul da Prússia, apresentado por Chi Dong ${ }^{(29)}$ :

(1) na ausência de $\mathrm{H}_{2} \mathrm{O}_{2}$ e (2) na presença de 1 mmol L-1 de $\mathrm{H}_{2} \mathrm{O}_{2}$.

Eletrólito suporte: tampão $\mathrm{NaH}_{2} \mathrm{PO}_{4} / \mathrm{Na}_{2} \mathrm{HPO}_{4}, \mathrm{pH} 6,5 . \mathrm{E}_{\mathrm{i}}=-0,4 \mathrm{~V} ; \mathrm{E}_{\mathrm{f}}=1,2 \mathrm{~V}$; velocidade de varredura $=60 \mathrm{~m} \mathrm{~V} \mathrm{~s}^{-1}$. 
Uma vez estabelecida as melhores condições de formação dos filmes de AP, solução modificadora: $3 \mathrm{mmol} \mathrm{L}{ }^{-1}$ de $\mathrm{FeCl}_{3} ; 2 \mathrm{mmol} \mathrm{L}^{-1}$ de $\mathrm{K}_{3}\left[\mathrm{Fe}(\mathrm{CN})_{6}\right]$; $0,5 \mathrm{~mol} \mathrm{~L}^{-1}$ de $\mathrm{KNO}_{3}$ em $\mathrm{HCl} 0,02 \mathrm{~mol} \mathrm{~L}^{-1}$, intervalo de potencial $-0,4 \mathrm{~V} \leq \mathrm{E}_{\mathrm{apl}} \leq 1,2 \mathrm{~V}$, velocidade de varredura de $60 \mathrm{mV} \mathrm{s}^{-1}$, secagem a temperatura ambiente por 24 horas e estabilização em solução eletrólito suporte

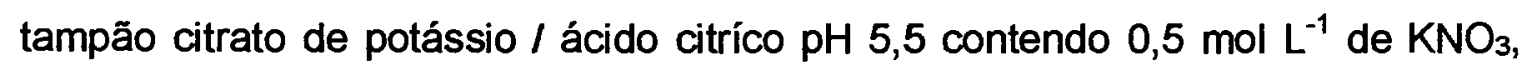
intervalo de potencial $-0,4 \mathrm{~V} \leq \mathrm{E}_{\mathrm{apt}} \leq 1,2 \mathrm{~V}$ e velocidade de varredura de $60 \mathrm{mVs}^{-1}$, reproduziu-se o procedimento dos autores acima citados. Os resultados, apresentados na Figura 18 demonstram que se houve redução da $\mathrm{H}_{2} \mathrm{O}_{2}$ pelo filme de Azul da Prússia, a reação não pode ser detectada utilizando-se a voltametria cíclica. Como a velocidade de varredura utilizada, $60 \mathrm{mV} \mathrm{s}^{-1}$, poderia ser muito alta para se detectar a reação de redução de $\mathrm{H}_{2} \mathrm{O}_{2}$ pelo filme de Azul da Prússia, diminuiu-se a velocidade de varredura para $10 \mathrm{mV} \mathrm{s}$. Os resultados são apresentados na figura 19. Mesmo a baixa velocidade de varredura a reação catalitica não foi observada e houve perda acentuada do filme ativo.

$O$ autor ${ }^{(54)}$ atribuiu à ciclagem sucessiva ao redor do par redox AP/BP, a formação do Azul da Prússia solúvel que conseqüentemente dissolveria o filme e não permitiria a deteç̧ão da catálise de $\mathrm{H}_{2} \mathrm{O}_{2}$. Porém foi observado na figura 16, que o excesso de $\mathrm{FeCl}_{3}$ na solução modificadora favoreceu a formação do AP "insolúvel", uma vez que o eletrodo modificado se manteve estável após serem efetuados um alto número de ciclos consecutivos em eletrólito suporte.

Então provavelmente apesar de termos encontrado as melhores condições de formação do filme de Azul da Prússia utilizando-se a voltametria cíclica, esta técnica não foi suficientemente sensivel para detecção da redução da $\mathrm{H}_{2} \mathrm{O}_{2}$. 


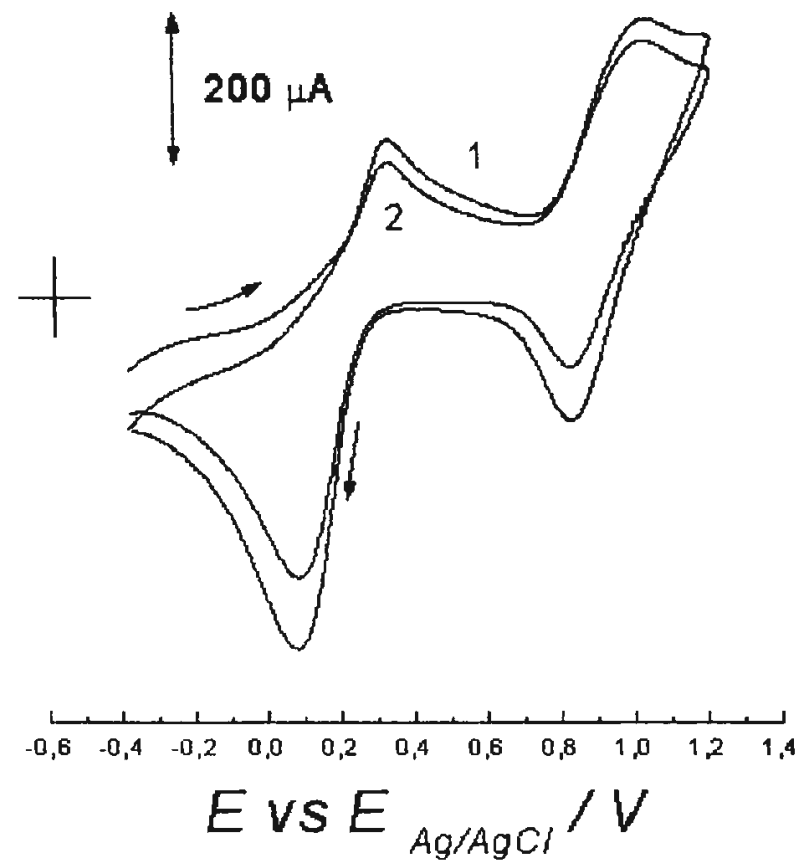

Figura 18. Voltamogramas cíclicos registrados em tampão ácido cítrico/citrato de potássio ( $\mathrm{pH} 5,5$ ) contendo $0,5 \mathrm{~mol} \mathrm{~L}^{-1}$ de $\mathrm{KNO}_{3}$ com eletrodo de pasta modificado com Azul da Prússia e previamente seco a temperatura ambiente por 24.

(1) $\mathrm{Na}$ ausência de $\mathrm{H}_{2} \mathrm{O}_{2}$;

(2) $\mathrm{Na}$ presença de $1 \mathrm{mmol} \mathrm{L} L^{-1}$ de $\mathrm{H}_{2} \mathrm{O}_{2}$;

$E_{i}=-0,4 V ; E_{f}=1,2 \mathrm{~V}$; velocidade de varredura $=60 \mathrm{mVs}^{-1}$. 


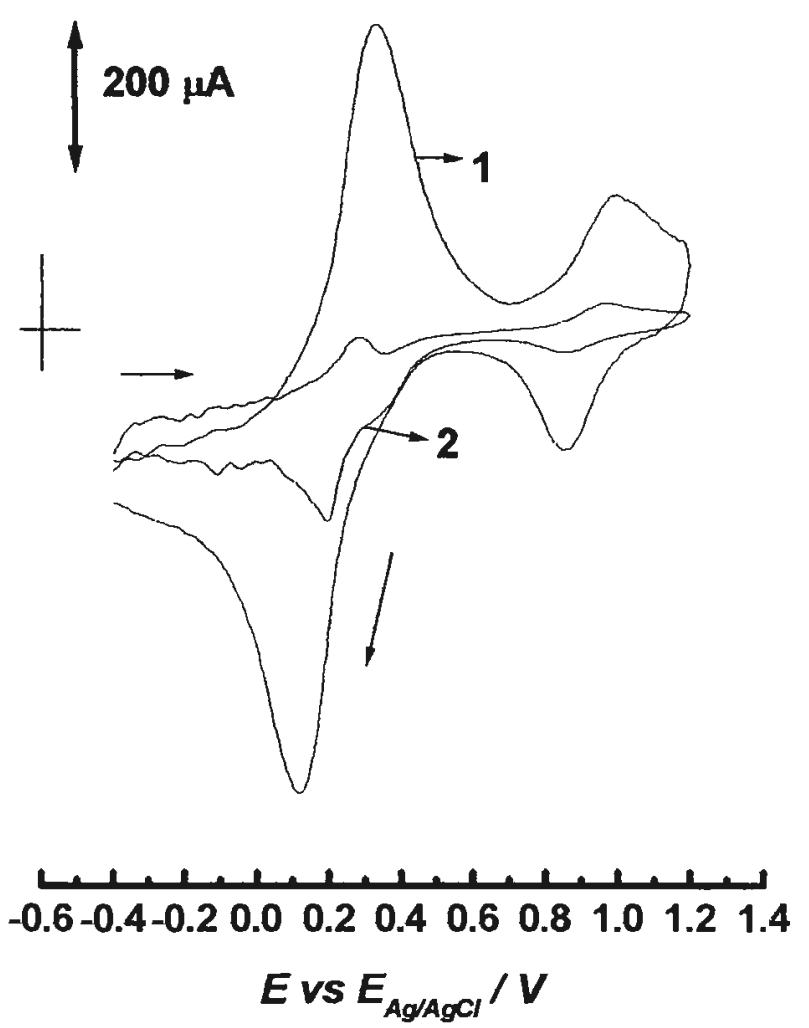

Figura 19. Voltamogramas cíclicos registrados em tampão ácido cítrico/citrato de potássio $(\mathrm{pH} 6,1)$ contendo $0,5 \mathrm{~mol} \mathrm{~L}^{-1}$ de $\mathrm{KCl}$ com eletrodo de pasta modificado com Azul da Prússia e previamente seco a temperatura ambiente por 24.

(1) $\mathrm{Na}$ ausência de $\mathrm{H}_{2} \mathrm{O}_{2}$;

(2) Na presença de $1 \mathrm{mmol} \mathrm{L}^{-1}$ de $\mathrm{H}_{2} \mathrm{O}_{2}$;

$E_{i}=-0,4 \mathrm{~V} ; E_{f}=1,2 \mathrm{~V}$; velocidade de varredura $=10 \mathrm{mV} \mathrm{s}^{-1}$. 
Comparando-se os resultados apresentados na Figura $15.2 \mathrm{com}$ os apresentados na Figura 19, percebe-se que nesta última as correntes dos Picos II e I são praticamente iguais. Isto mostra a importância da secagem prévia na reestruturação cristalina dos filmes.

\section{III.1.5.b- Escolha do Potencial Adequado para Redução Catalítica de $\mathrm{H}_{2} \mathrm{O}_{2}$.}

Em função dos resultados obtidos no item anterior avaliou-se a influência do potencial aplicado na corrente de redução catalítica de $\mathrm{H}_{2} \mathrm{O}_{2}$ utilizando os eletrodos modificados com Azul da Prússia, os quais foram preparados como descrito no item III.1.5.a, página 61. O potencial aplicado ao eletrodo foi variado ponto a ponto na faixa de $-210 \mathrm{a}+190 \mathrm{mV}$. Para cada potencial aplicado, a leitura de corrente foi efetuada após 5 minutos. Os dados obtidos são apresentados na figura 20 . 


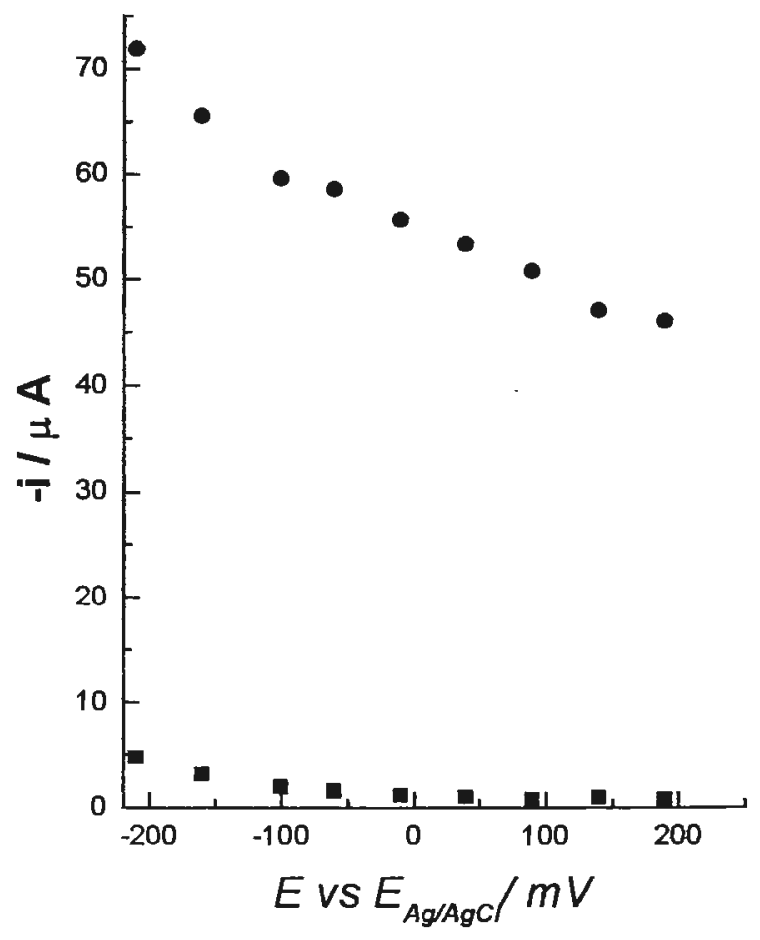

Figura 20. Influência do potencial aplicado nas correntes catalíticas de

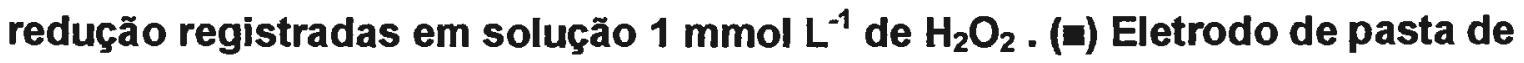
carbono e ( $($ ) Eletrodo de pasta de carbono modificado com o filme de Azul da Prússia.

Eletrodos secos a temperatura ambiente por 24 horas. Eletrólito suporte: tampão ácido citrico/citrato de potássio, $\mathrm{pH} 5,5$ contendo $0,5 \mathrm{~mol} \mathrm{~L}^{-1}$ de $\mathrm{KNO}_{3} . \mathrm{E}_{\mathrm{i}}=-0,4 \mathrm{~V}$; $E_{f}=1,2 \mathrm{~V}$; velocidade de varredura $=60 \mathrm{~m} \mathrm{~V} \mathrm{~s}^{-1}$. 
Analisando-se estes dados concluiu-se que:

i) Em eletrodos não modificados, não ocorre redução catalítica de $\mathrm{H}_{2} \mathrm{O}_{2}$;

ii) Para potenciais mais negativos que $200 \mathrm{~m} \mathrm{~V}$ (vs $\mathrm{Ag} / \mathrm{AgCl}$ ) já se observa a redução catálitica de $\mathrm{H}_{2} \mathrm{O}_{2}$ nos eletrodos modificados, de acordo com o mecanismo:

$$
\begin{gathered}
\mathrm{H}_{2} \mathrm{O}_{2}+\mathrm{Med}_{(\mathrm{Red})} \longrightarrow \mathrm{Med}_{(\mathrm{Oxi})}+2 \mathrm{H}_{2} \mathrm{O} \quad \text { (III.3) } \\
\text { Med }_{(\mathrm{Oxi})}+\mathrm{e}^{-} \longrightarrow \mathrm{Med}_{(\text {Red })} \quad \text { (no eletrodo) (III.4) }
\end{gathered}
$$

Uma vez que aplicando potenciais negativos, pode-se também registrar a redução catalítica do $\mathrm{O}_{2}$, avaliou-se a influência da corrente de redução do $\mathrm{O}_{2}$ na determinação catalítica de $\mathrm{H}_{2} \mathrm{O}_{2}$. Para tanto, registraram as curvas corrente-potencial com o eletrodo modificado, item II.2.3.2.a página 37. Os dados obtidos são apresentados na figura 21. 


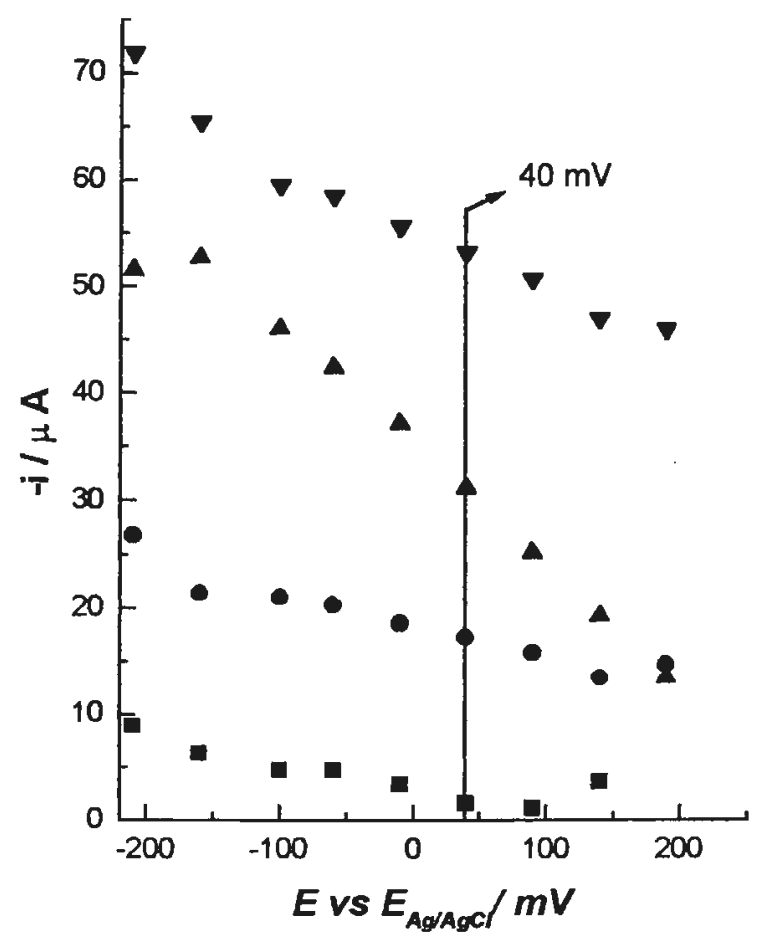

Figura 21. Influência do potencial aplicado nas correntes catalíticas de redução registradas com eletrodos de pasta de carbono modificados com filmes de Azul da Prússia em soluções não desaeradas, na presença e ausência de $\mathrm{H}_{2} \mathrm{O}_{2}$.

(a) $\mathrm{Na}$ ausência de $\mathrm{H}_{2} \mathrm{O}_{2}$;

(p) $\mathrm{Em} \mathrm{0,1} \mathrm{mmol} \mathrm{L-1} \mathrm{de} \mathrm{H}_{2} \mathrm{O}_{2}$;

A) Em $0,3 \mathrm{mmol} \mathrm{L}^{-1}$ de $\mathrm{H}_{2} \mathrm{O}_{2}$;

(v) $\mathrm{Em} 1 \mathrm{mmol} \mathrm{L}^{-1}$ de $\mathrm{H}_{2} \mathrm{O}_{2}$;

Eletrodos secos a temperatura ambiente por 24 horas. Eletrólito suporte: tampão

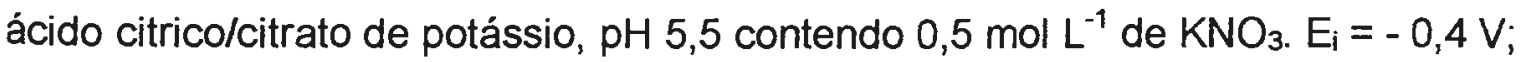
$E_{f}=1,2 \mathrm{~V}$; velocidade de varredura $=60 \mathrm{~m} \mathrm{~V} \mathrm{~s}^{-1}$. 
Pode-se concluir, a partir dos dados obtidos, que a influência do $\mathrm{O}_{2}$ torna-se mais significativa na presença de baixas concentrações de $\mathrm{H}_{2} \mathrm{O}_{2}$ e em potenciais mais negativos. Por isto, o potencial escolhido para determinações amperométricas de $\mathrm{H}_{2} \mathrm{O}_{2}$ foi $40 \mathrm{~m} \mathrm{~V}$ (vs Ag/AgCl).

\section{III.1.5.c- Determinação Amperométrica de $\mathrm{H}_{2} \mathrm{O}_{2}$.}

Estabelecidas as melhores condições de formação e estabilidade dos filmes de Azul da Prússia, efetuou-se a determinação amperométrica de $\mathrm{H}_{2} \mathrm{O}_{2}$ na faixa de $5,0 \times 10^{-5}$ a $8,6 \times 10^{-4} \mathrm{~mol} \mathrm{~L}^{-1}$ fixando-se o potencial em $40 \mathrm{mV}$ (vs Ag/AgCl).

A primeira curva analítica efetuada apresentou a seguinte equação de reta: Ip $=0,33+27,75\left[\mathrm{H}_{2} \mathrm{O}_{2}\right] ; r^{2}=0,998$ e relação linear no intervalo de $1,4 \times 10^{-4} \leq\left[\mathrm{H}_{2} \mathrm{O}_{2}\right] \leq 5,0 \times 10^{-4} \mathrm{~mol} \mathrm{~L}^{-1}$. Os dados obtidos são apresentados na figura 22 . 


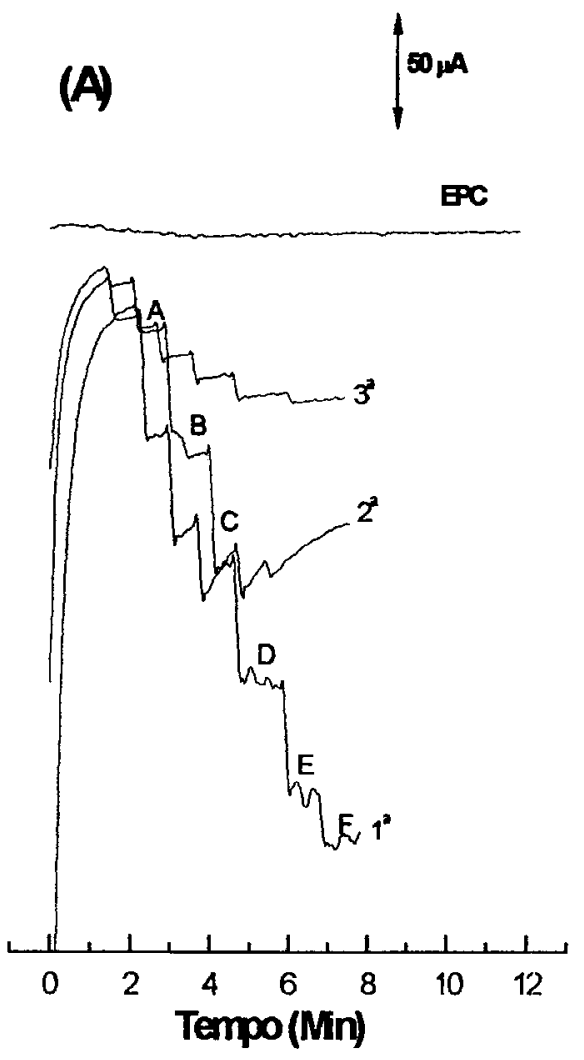

(B)

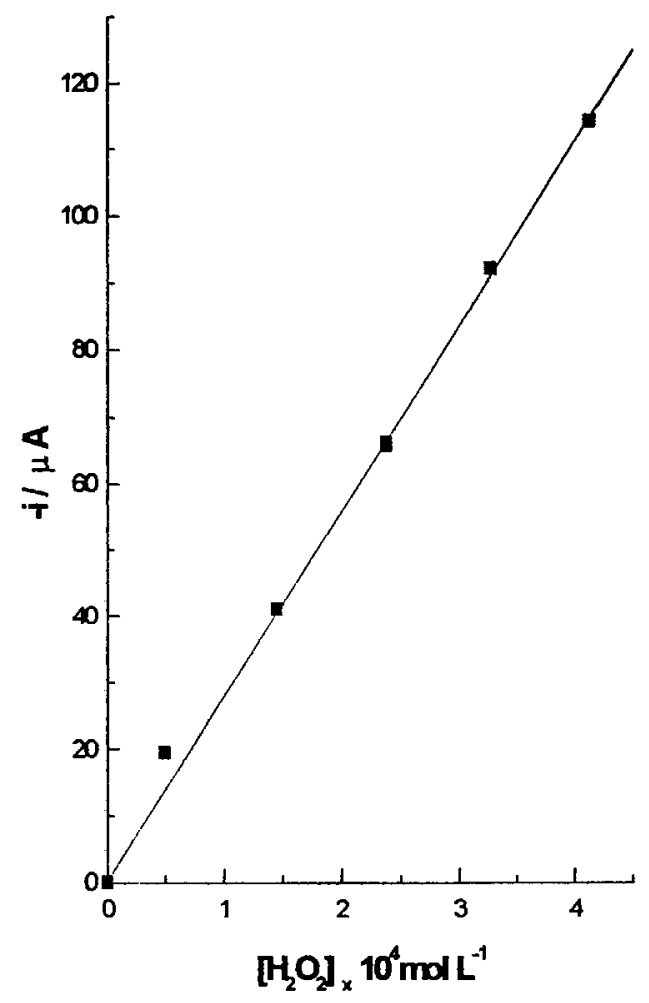

Figura 22. Determinação amperométrica de $\mathrm{H}_{2} \mathrm{O}_{2}$ em eletrodo de pasta de carbono (EPC) e eletrodo de pasta de carbono modificado com filme de Azul da Prússia. (A) Amperogramas registrados na presença de concentrações crescentes de $\mathrm{H}_{2} \mathrm{O}_{2}: A=5,0 \times 10^{-5} ; \mathrm{B}=1,4 \times 10^{-4} ; \mathrm{C}=2,4 \times 10^{-4} ; \mathrm{D}=3,3 \times 10^{-4}$; $E=4,1 \times 10^{-4} ; F=8,6 \times 10^{-4} \mathrm{~mol} \mathrm{~L}^{-1}$; (B) $1^{a}$ Curva analítica para determinação de $\mathrm{H}_{2} \mathrm{O}_{2}$.

Eletrodos secos a temperatura ambiente por 24 horas. Eletrólito suporte tampão ácido citríco / citrato de potássio, $\mathrm{pH} \mathrm{5,5}$ contendo $0,5 \mathrm{~mol} \mathrm{~L}^{-1}$ de $\mathrm{KNO}_{3}$.

$E_{\text {apl }}=40 \mathrm{~m} \mathrm{~V}(\mathrm{Ag} / \mathrm{AgCl})$. 
Como pode ser observado na figura $22 \mathrm{~A}$, o efeito catalítico diminuiu drasticamente após a realização da $1^{2}$ curva analítica.

Deste modo concluiu-se que os eletrodos modificados com filmes de AP obtidos por voltametria cíclica não tem estabilidade suficiente para a determinação de $\mathrm{H}_{2} \mathrm{O}_{2}$, pois durante a redução do peróxido de hidrogênio, um aumento local nos valores de $\mathrm{pH}$ pode favorecer a complexação do $\mathrm{Fe}^{3+}$ desestabilizando o filme (equação III.2., página 53), como proposto por Karyakin et al ${ }^{(53)}$.

\section{III.2- Preparação de Eletrodos de Pasta de Carbono Modificados com Azul da Prússia por Deposição a Um Potencial Controlado.}

\section{III.2.1- Crescimento dos Filmes de Azul da Prússia Durante Ciclagens Sucessivas em Solução de Eletrólito Suporte.}

Inicialmente tentou-se reproduzir em pasta de carbono o trabalho de Karyakin et al. ${ }^{(53)}$, no qual os eletrodos de carbono vítreo foram modificados com filmes de AP, por deposição a potencial controlado nas seguintes condições: potencial aplicado $0,4 \mathrm{~V}$ por 60 segundos em solução modificadora contendo $2 \mathrm{mmol} \mathrm{L}^{-1}$ de $\mathrm{FeCl}_{3}, 2 \mathrm{mmol} \mathrm{L}^{-1}$ de $\mathrm{K}_{3}\left[\mathrm{Fe}(\mathrm{CN})_{6}\right]$ em $0,02 \mathrm{~mol} \mathrm{~L}^{-1}$ de $\mathrm{HCl}$. Após a pré-concentração dos reagentes na superficie do eletrodo, este foi ciclado em solução $0,1 \mathrm{~mol} \mathrm{~L}^{-1}$ de $\mathrm{KCl}$ no intervalo de potencial de $-0,05 \mathrm{~V} \leq E_{\mathrm{apl}} \leq 0,35 \mathrm{~V}$, com velocidade de varredura de $50 \mathrm{~m} \mathrm{~V} \mathrm{~s}^{-1}$. Este processo foi denominado de ativação.

Adicionalmente avaliou-se o efeito do aumento da concentração de $\mathrm{FeCl}_{3}$ de 2 para $3 \mathrm{mmol} \mathrm{L}^{-1}$. Os resultados são apresentados na figura 23 .

O eletrodo modificado que apresentou maiores valores de corrente foi aquele preparado em soluções modificadoras contendo $3 \mathrm{mmol} \mathrm{L}^{-1}$ de $\mathrm{FeCl}_{3}$. Logo, o filme se comportou de maneira similar aquela observada para filmes formados 
por voltametria cíclica, em que o excesso de $\mathrm{FeCl}_{3}$ favoreceu a formação do $\mathrm{AP}$ "insolúvel" na superfície do eletrodo. 


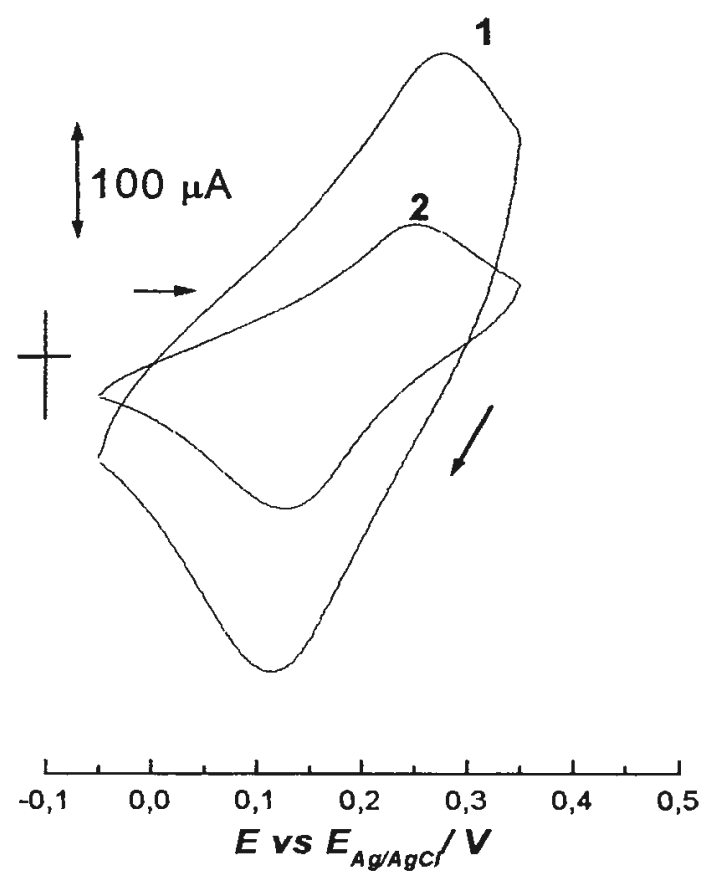

Figura 23. Voltamogramas cíclicos, registrados em eletrólito suporte, com eletrodos de pasta de carono modificados com filmes de Azul da Prússia depositados a $0,4 \mathrm{~V}$, a partir de soluções contendo:

(1) $3 \mathrm{mmol} \mathrm{L}^{-1}$ de $\mathrm{FeCl}_{3}, 2 \mathrm{mmol} \mathrm{L}^{-1}$ de $\mathrm{K}_{3}\left[\mathrm{Fe}(\mathrm{CN})_{6}\right] \mathrm{em} \mathrm{HCl} 0,02 \mathrm{~mol} \mathrm{~L}^{-1}$;

(2) $2 \mathrm{mmol} \mathrm{L}^{-1}$ de $\mathrm{FeCl}_{3}, 2 \mathrm{mmol} \mathrm{L}^{-1}$ de $\mathrm{K}_{3}\left[\mathrm{Fe}(\mathrm{CN})_{6}\right]$ em HCl 0,02 $\mathrm{mol} \mathrm{L}^{-1}$;

Eletrólito suporte: $0,1 \mathrm{~mol} \mathrm{~L} \mathrm{~L}^{-1} \mathrm{KCl} ; E_{i}=-0,05 \mathrm{~V} ; E_{f}=0,35 \mathrm{~V}$; velocidade de varredura $=50 \mathrm{~m} \mathrm{~V} \mathrm{~s}^{-1}$. Os eletrodos foram previamente secos a temperatura ambiente por 24 horas. 
Então, com o intuito de obter eletrodos modificados que apresentassem maior estabilidade, variaram-se os seguintes parâmetros: substituição do $\mathrm{KCl}$ pelo $\mathrm{KNO}_{3}$ na formação e avaliação da estabilidade dos filmes e adição de $0,1 \mathrm{~mol}^{-1}$ de $\mathrm{KCl}$ na solução modificadora.

\section{III.2.1.a- Influência do Ânion do Sal de Potássio nas Correntes de Picos dos Filmes de Azul da Prússia}

Estudou-se a influência da substituição do $\mathrm{KCl}$ pelo $\mathrm{KNO}_{3}$ nas correntes de picos dos eletrodos modificados, de acordo com as condiçōes descritas no item anterior. Os dados são apresentados na figura 24. 


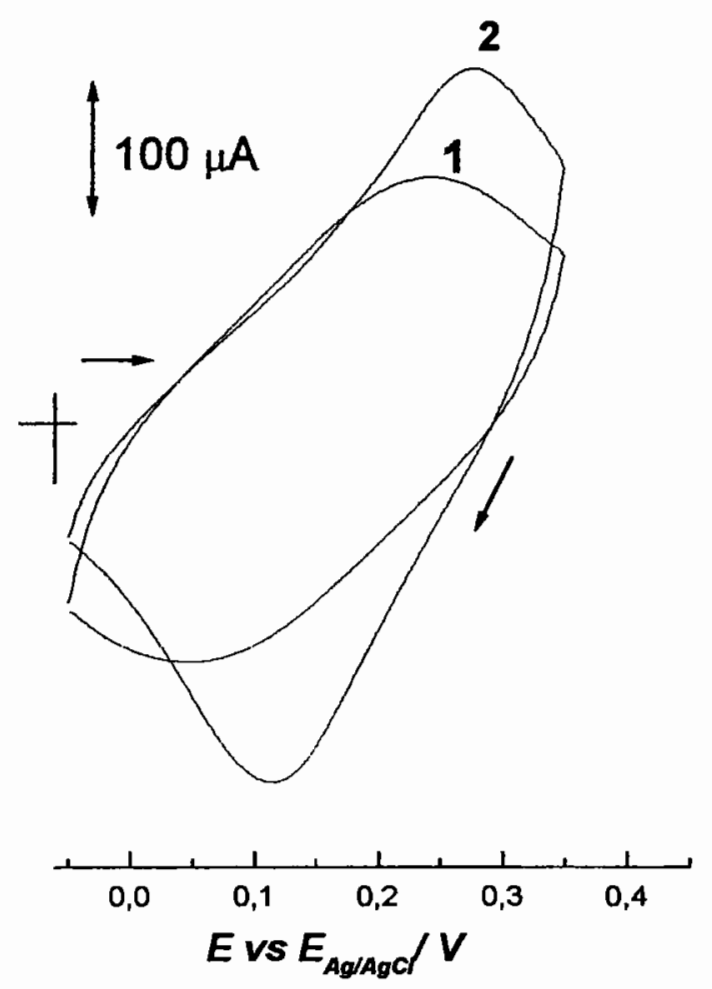

Figura 24. Voltamogramas cíclicos, registrados em eletrólito suporte, com eletrodos modificados com filmes de Azul da Prússia:

(1) Eletrólito suporte + $0,1 \mathrm{~mol} \mathrm{~L}{ }^{-1}$ de $\mathrm{KNO}_{3}$;

(2) Eletrólito suporte $+0,1 \mathrm{~mol} \mathrm{~L}^{-1}$ de $\mathrm{KCl}$;

$E_{i}=-0,05 V ; E_{f}=0,35 V ;$ velocidade de varredura $=50 \mathrm{~m} \mathrm{~V} \mathrm{~s}^{-1}$; Solução modificadora: $3 \mathrm{mmol} \mathrm{L}^{-1}$ de $\mathrm{FeCl}_{3}, 2 \mathrm{mmol} \mathrm{L}^{-1}$ de $\mathrm{K}_{3}\left[\mathrm{Fe}(\mathrm{CN})_{6}\right] \mathrm{em}$ $0,02 \mathrm{~mol} \mathrm{~L}^{-1}$ de $\mathrm{HCl}$; Potencial aplicado $0,4 \mathrm{~V}$ durante 60 segundos. Os filmes formados foram previamente secos a temperatura ambiente por 24 horas. 
Observou-se que os valores de corrente são maiores e os picos melhor definidos em soluções contendo $\mathrm{KCl}$ do que em soluções contendo $\mathrm{KNO}_{3}$.

Deste modo pode-se concluir que os íns cloreto também participam da formação e manutenção do balanceamento de carga do filme de AP. Estes resultados estão de acordo com os resultado Itaya et al. ${ }^{(41)}$ que propõem a entrada de ânions $\mathrm{Cl}^{-}$para manter a eletroneutralidade do filme.

\section{III.2.1.b- Influência da Introdução de $\mathrm{KCI}$ na Solução Modificadora Durante o Processo de Formação dos Filmes.}

A influência da adição de $0,1 \mathrm{~mol} \mathrm{~L}^{-1}$ de $\mathrm{KCl}$ na solução modificadora utilizada para preparação dos filmes por deposição a potencial controlado foi efetuada segundo procedimento descrito no item III.2.1, página 72 .

Os dados são apresentados na figura 25. 


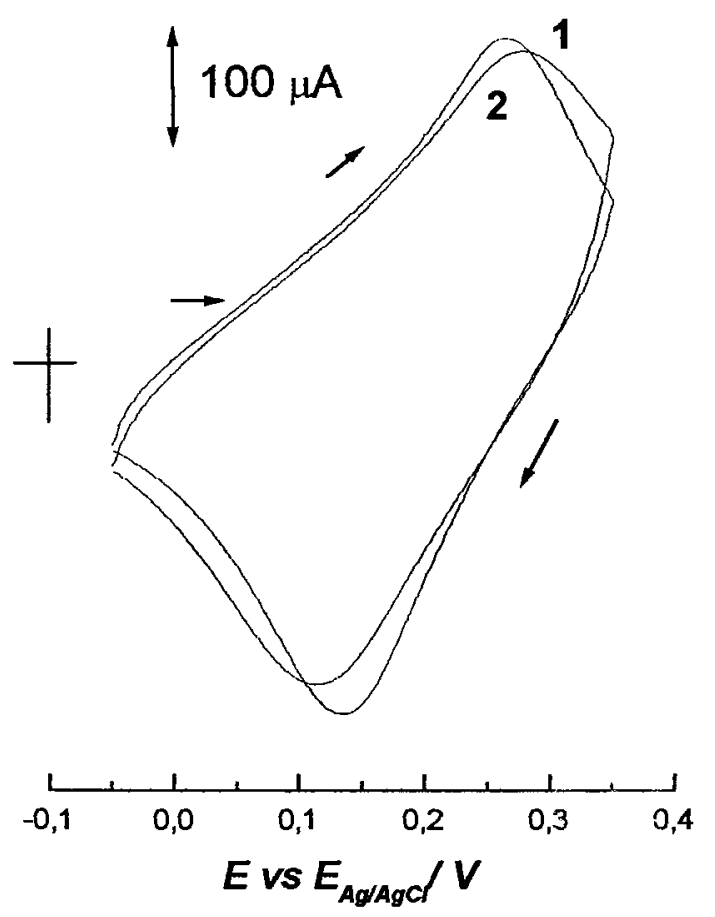

Figura 25. Voltamogramas cíclicos, registrados em eletrólito suporte contendo $0,02 \mathrm{~mol} \mathrm{~L}^{-1}$ de $\mathrm{HCl}$, com eletrodos modificados com filmes de Azul da Prússia depositados a $0,4 \mathrm{~V}$, formados em solução modificadora: $3 \mathrm{mmol} \mathrm{L}{ }^{-1}$ de $\mathrm{FeCl}_{3}, 2 \mathrm{mmol} \mathrm{L}^{-1}$ de $\mathrm{K}_{3}\left[\mathrm{Fe}(\mathrm{CN})_{6}\right]$ :

(1) Ausência de $\mathrm{KCl}$;

(2) $0,1 \mathrm{~mol} \mathrm{~L}^{-1}$ de KCl;

Tempo de secagem: 24 horas; Intervalo de varredura em eletrólito suporte $0,1 \mathrm{~mol} \mathrm{~L}^{-1}$ de $\mathrm{KCl}:-0,05 \mathrm{~V} \leq \mathrm{E}_{\text {apl }} \leq 0,35 \mathrm{~V}$; velocidade de varredura: $50 \mathrm{~m} \mathrm{~V} \mathrm{~s}^{-1}$. 
Observou-se que os valores de corrente pico dos eletrodos modificados em solução modificadora contendo $0,1 \mathrm{~mol} \mathrm{~L}^{-1}$ de $\mathrm{KCl}$ e ausente do íons $\mathrm{K}^{+}$, não apresentaram diferenças significativas.

\section{III.2.2- Determinação Amperométrica de $\mathrm{H}_{2} \mathrm{O}_{2}$.}

Uma vez encontradas as melhores condições de formação do filme, determinou-se $\mathrm{H}_{2} \mathrm{O}_{2}$ no intervalo de $5,0 \times 10^{-5} \mathrm{~mol} \mathrm{~L}^{-1}$ a $8,6 \times 10^{-4} \mathrm{~mol} \mathrm{~L}^{-1}$ utilizando a técnica de amperométrica ( $E_{a p l}=40 \mathrm{~m} \mathrm{~V}$ ) em solução tampão (citrato de potássio/ácido citrico) $\mathrm{pH}=6,1$ contendo $0,5 \mathrm{~mol} \mathrm{~L}^{-1}$ de $\mathrm{KCl}$.

Os amperogramas apresentados na figura 26 mostram que o filme apresentou pouca estabilidade durante a determinaçāo de $\mathrm{H}_{2} \mathrm{O}_{2}$. Este fato foi decorrente do rápido desprendimento do filme da superfície do eletrodo, constatado pela coloração azulada adquirida pelo eletrólito suporte. 


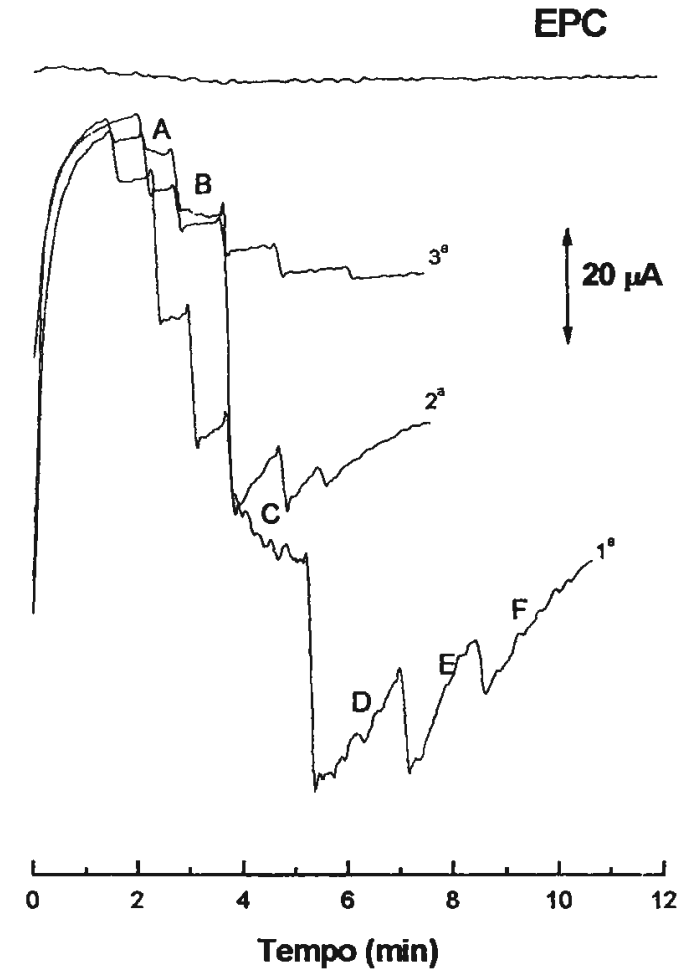

Figura 26. Amperogramas registrados na presença de $\mathrm{H}_{2} \mathrm{O}_{2}$ com eletrodos de pasta de carbono (EPC) e eletrodo de pasta de carbono modificado com filme de Azul da Prússia (EPC-AP) preparado utilizando-se deposiçăo a potencial controlado $0,4 \mathrm{~V}: A=5,0 \times 10^{-5} ; B=1,4 \times 10^{-4} ; C=2,4 \times 10^{-4}$; $D=3,3 \times 10^{-4} ; E=4,1 \times 10^{-4} ; \mathrm{F}=8,6 \times 10^{-4} \mathrm{~mol} \mathrm{~L}^{-1}$ de $\mathrm{H}_{2} \mathrm{O}_{2}$.

Eletrólito suporte: tampão citrato, $\mathrm{pH} 5,5$ contendo $0,5 \mathrm{~mol} \mathrm{~L}^{-1}$ de $\mathrm{KNO}_{3}$. Potencial aplicado para determinação de $\mathrm{H}_{2} \mathrm{O}_{2}=40 \mathrm{~m} \mathrm{~V}$. Eletrodo modificado foi previamente seco a temperatura ambiente por 24 horas. 


\section{III.3- Preparação de Eletrodos de Pasta de Carbono Modificados com Azul da Prússia por Deposição a Dois Potenciais Controlados}

Em função dos resultados obtidos no item anterior, e considerando que o melhor método de preparação do filme consiste em promover a formação do Azul da Prússia "insolúvel" na superfície do eletrodo para que este possa ser estável durante a determinação de $\mathrm{H}_{2} \mathrm{O}_{2}$, tentou-se então a preparação dos filmes de Azul da Prússia em eletrodos de pasta de carbono por deposição a dois potenciais controlados como descrito no item II.2.2.1c, página 34. A composição da solução modificadora foi: $3 \mathrm{mmol} \mathrm{L}^{-1}$ de $\mathrm{FeCl}_{3}, 2 \mathrm{mmol} \mathrm{L}^{-1}$ de $\mathrm{K}_{3}\left[\mathrm{Fe}(\mathrm{CN})_{6}\right]$ em $0,02 \mathrm{~mol} \mathrm{~L}^{-1}$ de $\mathrm{HCl}$.

Os dados são apresentados na figura 27. 
(A)

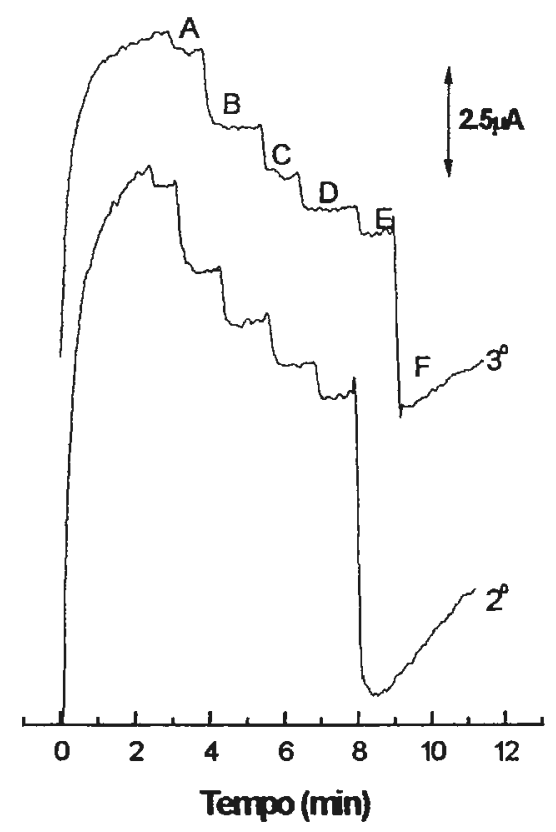

(B)

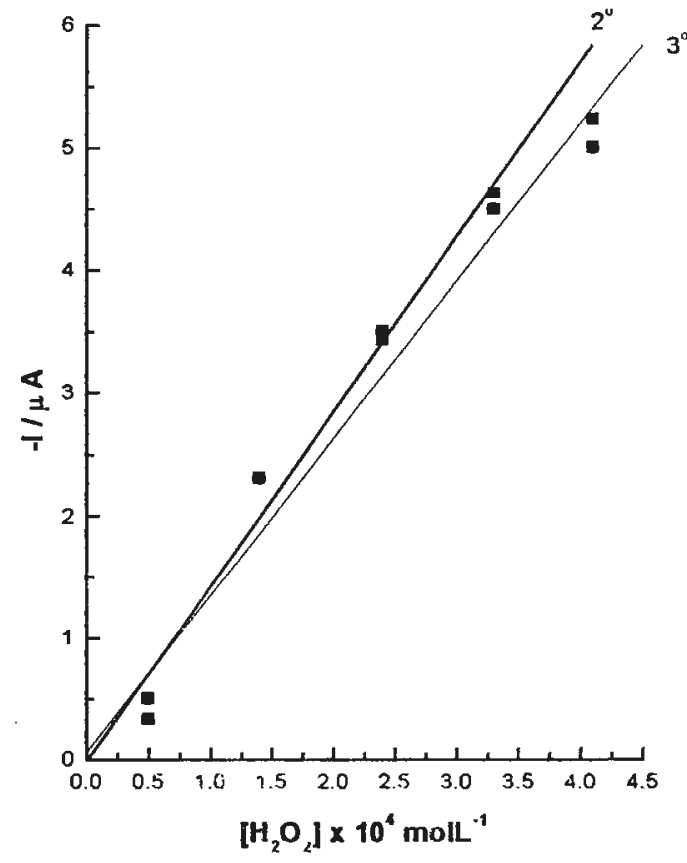

Figura 27. Amperogramas (A) e Curvas analiticas (B), obtidos com eletrodo de pasta de carbono modificado com filme de Azul da Prússia. $A=5,0 \times 10^{-5}$; $B=1,4 \times 10^{-4} ; C=2,4 \times 10^{-4} ; D=3,3 \times 10^{-4} ; E=4,1 \times 10^{-4} ; F=8,6 \times 10^{-4} \mathrm{~mol} \mathrm{~L}^{-1}$ de $\mathrm{H}_{2} \mathrm{O}_{2}$ para determinação $\mathrm{H}_{2} \mathrm{O}_{2}$.

Eletrodo preparado utilizando-se deposição a dois potenciais controlados e previamente seco a temperatura ambiente por 24 horas. Eletrólito suporte: tampão ácido citríco / citrato de potássio, $\mathrm{pH} \mathrm{6,1} \mathrm{contendo} \mathrm{0,5} \mathrm{mol} \mathrm{L}^{-1}$ de $\mathrm{KNO}_{3}$. Potencial aplicado $=40 \mathrm{~m} \mathrm{~V}$. 
No $1^{\circ}$ amperograma, não houve variação significativa de corrente mediante adições consecutivas de $\mathrm{H}_{2} \mathrm{O}_{2}$. Entretanto registraram-se mais dois amperogramas consecutivos, a partir dos quais foi possivel obter duas curvas analíticas. As equações que descrevem os parâmetros das curvas analíticas para determinação de $\mathrm{H}_{2} \mathrm{O}_{2}$ são apresentadas na tabela III.1.

Tabela III.1. Equações que descrevem os parâmetros das curvas analíticas.

\begin{tabular}{|c|c|c|}
\hline Equação & $r^{2}$ & Faixa de linearidade $\left(\mathrm{mol} \mathrm{L}^{-1}\right)$ \\
\hline $\mathrm{I}_{\mathrm{p} 2}=0,06+1,33\left[\mathrm{H}_{2} \mathrm{O}_{2}\right]$ & 0,985 & $5,0 \times 10^{-5}-8,6 \times 10^{-4}$ \\
\hline $\mathrm{I}_{\mathrm{p} 3}=0,06+1,28\left[\mathrm{H}_{2} \mathrm{O}_{2}\right]$ & 0,987 & $5,0 \times 10^{-5}-5,0 \times 10^{-4}$ \\
\hline
\end{tabular}

Concluiu-se que ocorreu uma pequena perda de sensibilidade, no entanto houve uma melhor estabilização do filme durante a determinação de $\mathrm{H}_{2} \mathrm{O}_{2}$. 


\section{III.3.1.a - Crescimento dos Filmes de Azul da Prússia Durante Ciclagens Sucessivas em Solução de Eletrólito Suporte contendo $\mathrm{RuCl}_{3}$.}

Benedetto et al ${ }^{(65)} \mathrm{e}$ outros autores estudaram o comportamento dos eletrodos de carbono vítreo modificados com Azul da Prússia ${ }^{(66)}$ e seus análogos ${ }^{(67-71)}$ durante ciclagens sucessivas em solução eletrólito suporte contendo $1 \mathrm{mmol} \mathrm{L}^{-1}$ de $\mathrm{RuCl}_{3}$. Os autores ${ }^{(65-71)}$ concluíram que o eletrodo modificado tem sua estabilidade e sua ação catalítica aumentado pela incorporação de Ru(III) e espécies dinucleares $\left(\mathrm{Ru}_{2} \mathrm{O}_{6}{ }^{3+}\right)$, na estrutura zeolitica com formação de ligações ciano e oxo, (Fe - CN - Ru e Fe - O - Ru).

Denominou-se ativação em solução de $\mathrm{RuCl}_{3}$, o eletrodo modificado com filme de Azul da Prússia, ciclado sucessivamente (50 cíclos) em solução $0,1 \mathrm{~mol} \mathrm{~L}^{-1}$ de $\mathrm{KCl}, 1 \mathrm{mmol} \mathrm{L}^{-1}$ de $\mathrm{RuCl}_{3}$ em $0,02 \mathrm{~mol} \mathrm{~L}^{-1}$ de $\mathrm{HCl}$ no intervalo de potencial $-0,4 \mathrm{~V} \leq \mathrm{E}_{\mathrm{apl}} \leq 0,6 \mathrm{~V}$, com velocidade de varredura $=60 \mathrm{~m} \mathrm{~V} \mathrm{~s}^{-1}$.

Deste modo estudou-se a influência da ativação em solução de $\mathrm{RuCl}_{3}$ do eletrodo de pasta de carbono modificado com Azul da Prússia, preparados como descrito no item II.2.2.1.d, página 34 , durante a determinação de $\mathrm{H}_{2} \mathrm{O}_{2}$ no intervalo de $5,0 \times 10^{-5} \mathrm{~mol} \mathrm{~L}^{-1}$ a $8,6 \times 10^{-4} \mathrm{~mol} \mathrm{~L}^{-1} \mathrm{em}$ solução tampão (citrato de potássio/ácido citrico) $\mathrm{pH}=6,1$ contendo $0,5 \mathrm{~mol} \mathrm{~L}^{-1}$ de $\mathrm{KCl}$.

Os dados são apresentados nas figuras 28 e 29. 


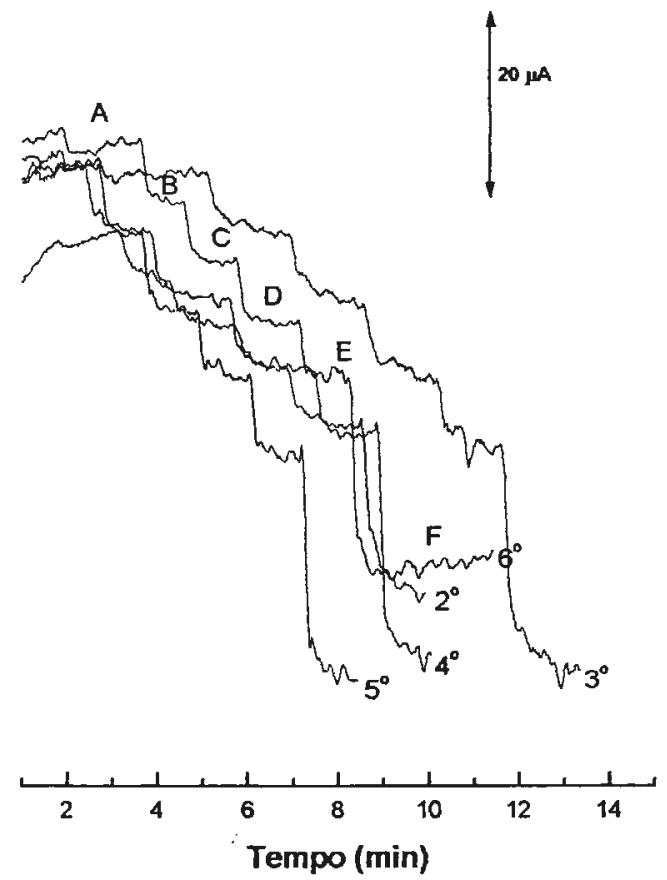

Figura 28. Amperogramas registrados na presença de $\mathrm{H}_{2} \mathrm{O}_{2}$ em eletrodo de pasta de carbono modificado com filme de Azul da Prússia e posteriormente ativado em solução de $\mathrm{RuCl}_{3}$. $A=5,0 \times 10^{-5} ; B=1,4 \times 10^{-4} ; \mathrm{C}=2,4 \times 10^{-4}$; $D=3,3 \times 10^{-4} ; E=4,1 \times 10^{-4} ; \mathrm{F}=8,6 \times 10^{-4} \mathrm{~mol} \mathrm{~L}^{-1}$ de $\mathrm{H}_{2} \mathrm{O}_{2}$.

Eletrodo preparado utilizando-se a deposição a dois potenciais controlados e secos a temperatura ambiente por 24 horas. Eletrólito suporte tampão ácido citríco / citrato de potássio, $\mathrm{pH} 6,1$ contendo $0,5 \mathrm{~mol} \mathrm{~L}^{-1}$ de $\mathrm{KNO}_{3}$. Potencial aplicado na determinação de $\mathrm{H}_{2} \mathrm{O}_{2}=40 \mathrm{~m} \mathrm{~V}$. 


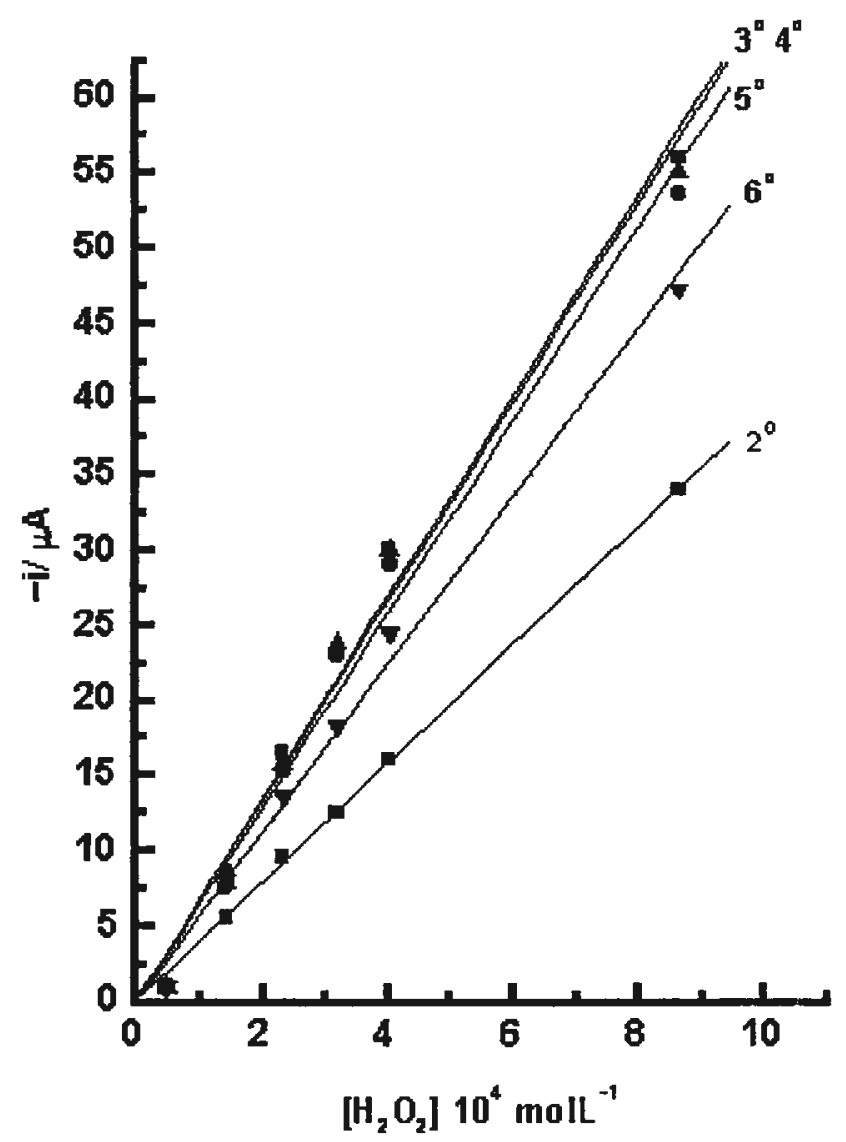

Figura 29. Curvas analíticas obtidas com eletrodo de pasta de carbono modificado com filme de Azul da Prússia e posteriormente ativado em solução contendo $\mathrm{RuCl}_{3}$, durante a determinação de $\mathrm{H}_{2} \mathrm{O}_{2}$.

Eletrodo preparado utilizando-se a deposição a dois potenciais controlados e secos a temperatura ambiente por 24 horas. Eletrólito suporte tampão ácido cítrico / citrato de potássio, $\mathrm{pH} \mathrm{6,1} \mathrm{contendo} 0,5 \mathrm{~mol} \mathrm{~L}^{-1}$ de $\mathrm{KNO}_{3}$. Potencial aplicado na determinação de $\mathrm{H}_{2} \mathrm{O}_{2}=40 \mathrm{~m} \mathrm{~V}$. 
No $1^{\circ}$ amperograma não foi possivel se determinar $\mathrm{H}_{2} \mathrm{O}_{2}$, entretanto registraram-se amperogramas consecutivos a partir dos quais foram feitas curvas analíticas para se determinar $\mathrm{H}_{2} \mathrm{O}_{2}$. As equaçōes que descrevem os parâmetros das curvas analíticas dos eletrodos modificados e ativados em solução $1 \mathrm{mmol} \mathrm{L}^{-1}$ de $\mathrm{RuCl}_{3}$ são apresentadas na tabela III.2.

Tabela III.2. Equações que descrevem os parâmetros das curvas analíticas obtidos para o eletrodo modificado com Azul da Prússia, ativados em 1 mmol L-1 de $\mathrm{RuCl}_{3}$.

\begin{tabular}{|c|c|c|}
\hline Equação & $r^{2}$ & Faixa de linearidade $\left(\mathrm{mol} \mathrm{L}^{-1}\right)$ \\
\hline $\mathrm{I}_{\mathrm{p} 2}=0,07+3,93\left[\mathrm{H}_{2} \mathrm{O}_{2}\right]$ & 0,999 & $1,4 \times 10^{-4}-8,6 \times 10^{-4}$ \\
\hline $\mathrm{l}_{\mathrm{p} 3}=0,08+6,68\left[\mathrm{H}_{2} \mathrm{O}_{2}\right]$ & 0,994 & $5,0 \times 10^{-5}-8,6 \times 10^{-4}$ \\
\hline $\mathrm{I}_{\mathrm{p} 4}=0,01+6,42\left[\mathrm{H}_{2} \mathrm{O}_{2}\right]$ & 0,992 & $5,0 \times 10^{-5}-8,6 \times 10^{-4}$ \\
\hline $\mathrm{I}_{\mathrm{p} 5}=0,09+6,61\left[\mathrm{H}_{2} \mathrm{O}_{2}\right]$ & 0,992 & $5,0 \times 10^{-5}-8,6 \times 10^{-4}$ \\
\hline $\mathrm{I}_{\mathrm{p} 6}=0,04+5,58\left[\mathrm{H}_{2} \mathrm{O}_{2}\right]$ & 0,996 & $5,0 \times 10^{-5}-8,6 \times 10^{-4}$ \\
\hline
\end{tabular}

Com a ativaçāo em solução de $\mathrm{RuCl}_{3}$ o eletrodo modificado com filme de

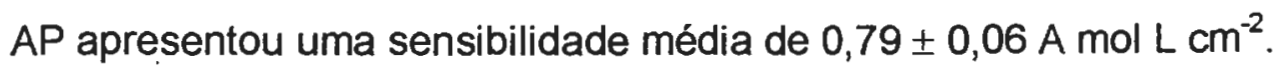

Deste modo conclui-se que o eletrodo modificado com filme de AP e ativado em solução de $\mathrm{RuCl}_{3}$ apresentou uma melhora na estabilidade durante determinação da redução catalítica de $\mathrm{H}_{2} \mathrm{O}_{2}$. 


\section{III.3.1.b- Crescimento dos Filmes de Azul da Prússia Durante Ciclagens Sucessivas em Solução de Eletrólito Suporte contendo $\mathrm{RhCl}_{3}$.}

No item anterior, uma considerável melhora na estabilidade do eletrodo modificado com Azul da Prússia e ativado em solução contendo $\mathrm{RuCl}_{3}$ foi apresentado, por isso decidiu-se estudar o comportamento do Rh(III) devido ao seus semelhantes estados de oxi-redução, como os do Ru(III).

Neste item denominou-se ativação em solução de $\mathrm{RhCl}_{3}, 0$ eletrodo modificado com Azul da Prússia e ciclado sucessivamente em solução $1 \mathrm{mmol} \mathrm{L}^{-1}$ de $\mathrm{RhCl}_{3}, 0,1 \mathrm{~mol} \mathrm{~L}^{-1}$ de $\mathrm{KCl}$ em $0,02 \mathrm{~mol} \mathrm{~L}^{-1}$ de $\mathrm{HCl}$, no intervalo de potencial $-0,4 \mathrm{~V} \leq \mathrm{E}_{\mathrm{apl}} \leq 0,6 \mathrm{~V}$ e com velocidade de varredura $=50 \mathrm{~m} \mathrm{~V} \mathrm{~s}^{-1}$.

Portanto eletrodos modificados com Azul da Prússia e ativados em solução de $\mathrm{RhCl}_{3}$ (preparados de acordo com o item II.2.2.1.e, pagina 35), foram utilizados na determinação de $\mathrm{H}_{2} \mathrm{O}_{2}$ no intervalo de $5,0 \times 10^{-5} \mathrm{~mol} \mathrm{~L}^{-1}$ a $8,6 \times 10^{-4} \mathrm{~mol} \mathrm{~L}^{-1} \mathrm{em}$ solução tampão (citrato de potássio/ácido citrico) $\mathrm{pH}=6,1$ conterido $0,5 \mathrm{~mol} \mathrm{~L}^{-1}$ de $\mathrm{KCl}$.

Os dados são apresentados nas figuras 30 e 31 . 


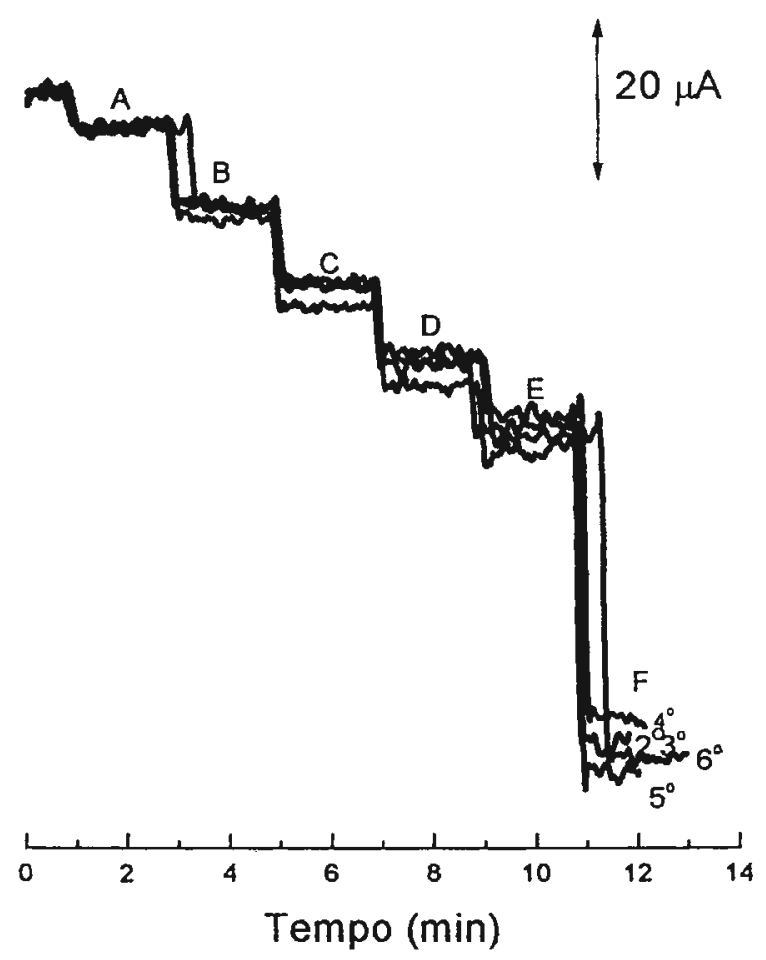

Figura 30. Amperogramas registrados na presença de $\mathrm{H}_{2} \mathrm{O}_{2}$ em eletrodo de pasta de carbono modificado com filme de Azul da Prússia e posteriormente ativado em solução de $\mathrm{RhCl}_{3} . \mathrm{A}=5,0 \times 10^{-5} ; \mathrm{B}=1,4 \times 10^{-4} ; \mathrm{C}=2,4 \times 10^{-4}$; $D=3,3 \times 10^{-4} ; E=4,1 \times 10^{-4} ; \mathrm{F}=8,6 \times 10^{-4} \mathrm{~mol} \mathrm{~L}^{-1}$ de $\mathrm{H}_{2} \mathrm{O}_{2}$.

Eletrodo preparado utilizando-se a deposição a dois potenciais controlados e secos a temperatura ambiente por 24 horas. Eletrólito suporte tampão ácido citríco / citrato de potássio, pH 6,1 contendo 0,5 mol L ${ }^{-1}$ de $\mathrm{KCl}$. Potencial aplicado na determinação de $\mathrm{H}_{2} \mathrm{O}_{2}=40 \mathrm{~m} \mathrm{~V}$. 


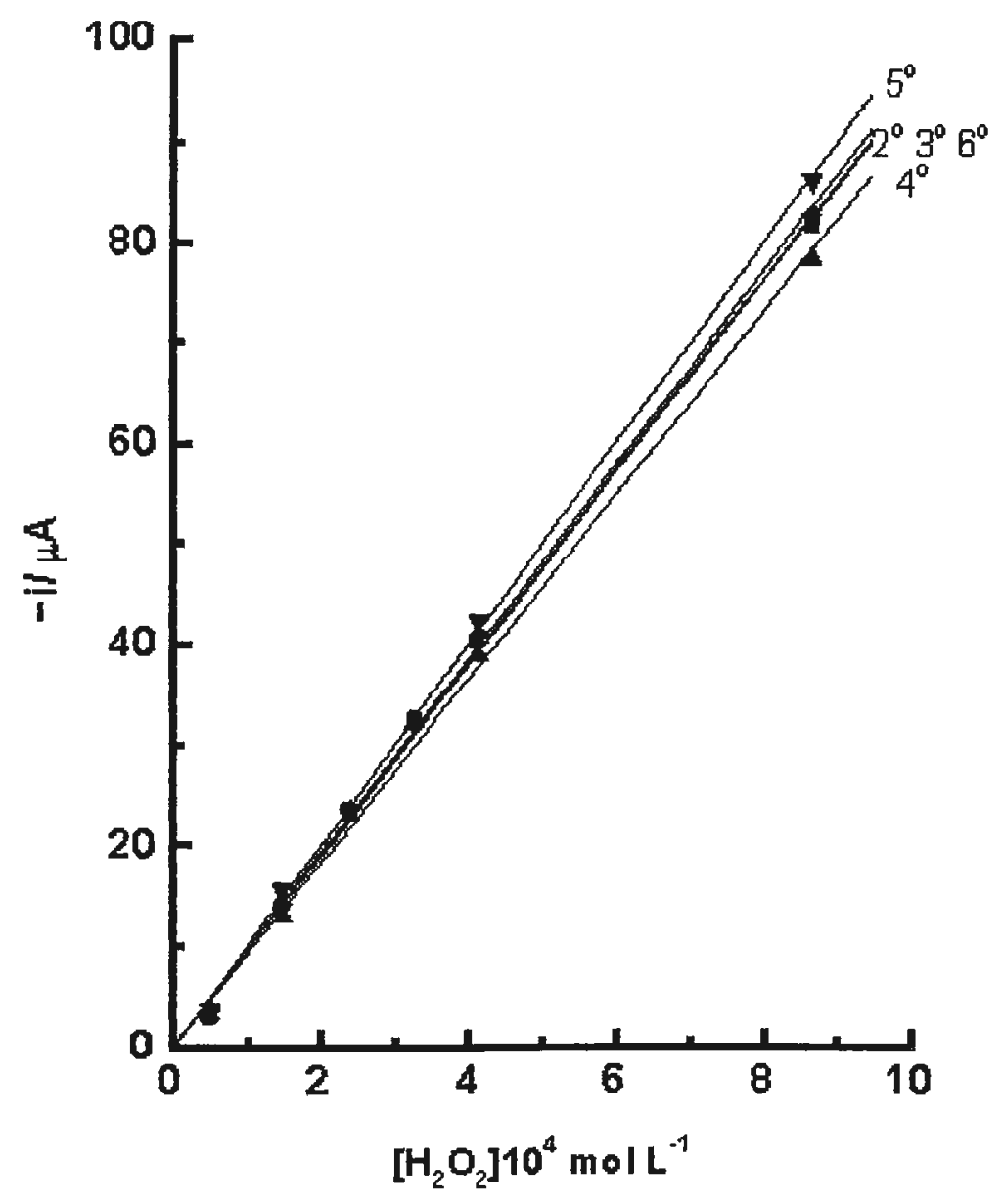

Figura 31. Curvas analíticas obtidas com eletrodo de pasta de carbono modificado com filme de Azul da Prússia e posteriormente ativado em solução de $\mathrm{RhCl}_{3}$, durante a determinação de $\mathrm{H}_{2} \mathrm{O}_{2}$.

Eletrodo preparado utilizando-se a deposição a dois potenciais controlados e secos a temperatura ambiente por 24 horas. Eletrólito suporte tampão ácido citríco / citrato de potássio, $\mathrm{pH} \mathrm{6,1}$ contendo $0,5 \mathrm{~mol} \mathrm{~L}^{-1}$ de $\mathrm{KNO}_{3}$. Potencial aplicado na determinação de $\mathrm{H}_{2} \mathrm{O}_{2}=40 \mathrm{~m} \mathrm{~V}$. 
Registraram-se amperogramas consecutivo dos quais foram feitas curvas analiticas para se determinar $\mathrm{H}_{2} \mathrm{O}_{2}$. As equações que descrevem os parâmetros das curvas analíticas dos eletrodos modificados ativados em $1 \mathrm{mmol} \mathrm{L}^{-1}$ de $\mathrm{RhCl}_{3}$ são apresentadas na tabela III.3.

Tabela III.3. Equações que descrevem os parâmetros das curvas analíticas do eletrodo modificado, posteriormente ativado em solução de $\mathbf{R h C l}_{3}$.

\begin{tabular}{|c|c|c|}
\hline Equação & $r^{2}$ & Faixa de linearidade $\left(\mathrm{mol} \mathrm{L}^{-1}\right)$ \\
\hline $\mathrm{I}_{\mathrm{p} 2}=0,01+9,52\left[\mathrm{H}_{2} \mathrm{O}_{2}\right]$ & 0,999 & $5,0 \times 10^{-5}-8,6 \times 10^{-4}$ \\
\hline $\mathrm{I}_{\mathrm{p} 3}=0,09+9,54\left[\mathrm{H}_{2} \mathrm{O}_{2}\right]$ & 0,999 & $5,0 \times 10^{-5}-8,6 \times 10^{-4}$ \\
\hline $\mathrm{I}_{\mathrm{p} 4}=0,05+9,14\left[\mathrm{H}_{2} \mathrm{O}_{2}\right]$ & 0,999 & $5,0 \times 10^{-5}-8,6 \times 10^{-4}$ \\
\hline $\mathrm{I}_{\mathrm{p} 5}=0,08+10,01\left[\mathrm{H}_{2} \mathrm{O}_{2}\right]$ & 0,994 & $5,0 \times 10^{-5}-8,6 \times 10^{-4}$ \\
\hline $\mathrm{I}_{\mathrm{p} 6}=0,08+9,64\left[\mathrm{H}_{2} \mathrm{O}_{2}\right]$ & 0,999 & $5,0 \times 10^{-5}-8,6 \times 10^{-4}$ \\
\hline
\end{tabular}

O eletrodo modificado com filme de AP quando ativado em solução de

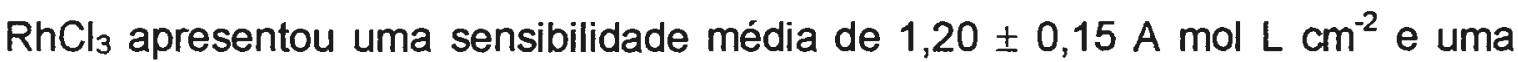
perda de sensibilidade de $1,26 \%$. Comparando-se os dados apresentados na Figura 27B com os apresentados na Figura 31 , observa-se que além do aumento de estabilidade, obteve-se também níveis maiores de corrente catalítica. $O$ aumento de corrente pode ser atribuido a uma melhor imobilização do filme na superfície do eletrodo após o tratamento em solução de $\mathrm{RhCl}_{3}$. Um dos motivos para que isto acontecesse pode ser atribuído à possibilidade de incorporação do ródio na estrutura zeolítica do Azul da Prússia, onde o diâmetro dos canais é da ordem de $3,2 \AA^{(71 a)}$. Desde que o diâmetro do íon $\mathrm{Rh}^{3+}$ hidratado $(\mathrm{NC}=6)$ é da ordem de $1,61 \AA$, é possível que o ródio seja incorporado na estrutura do AP através de ligações ciano e oxo ( $\mathrm{Fe}-\mathrm{CN}-\mathrm{Rh}$ e $\mathrm{Fe}-\mathrm{O}-\mathrm{Rh}$ ), similar ao proposto por Benedetto (65). 
III.3.2- Escolha do Potencial Adequado para Redução Catalítica de $\mathrm{H}_{2} \mathrm{O}_{2}$ em Eletrodos de Pasta de Carbono Modificados com Azul da Prússia e Posteriormente Ativados em solução contendo $0,5 \mathrm{~mol} \mathrm{~L}^{-1}$ de $\mathrm{KCl}$ e $1 \mathrm{mmol} \mathrm{L}{ }^{-1}$ de $\mathrm{RhCl}_{3}$ (EPCAP-Rh).

Uma vez que aplicando potenciais negativos, pode-se também registrar a corrente de redução do $\mathrm{O}_{2}$, avaliou-se esta influência na determinação de $\mathrm{H}_{2} \mathrm{O}_{2}$. Para tanto, registrou-se a curva corrente - potencial com eletrodo modificado EPCAP-Rh na ausência e presença de $\mathrm{H}_{2} \mathrm{O}_{2}$. Os dados obtidos são apresentados na figura 32. 


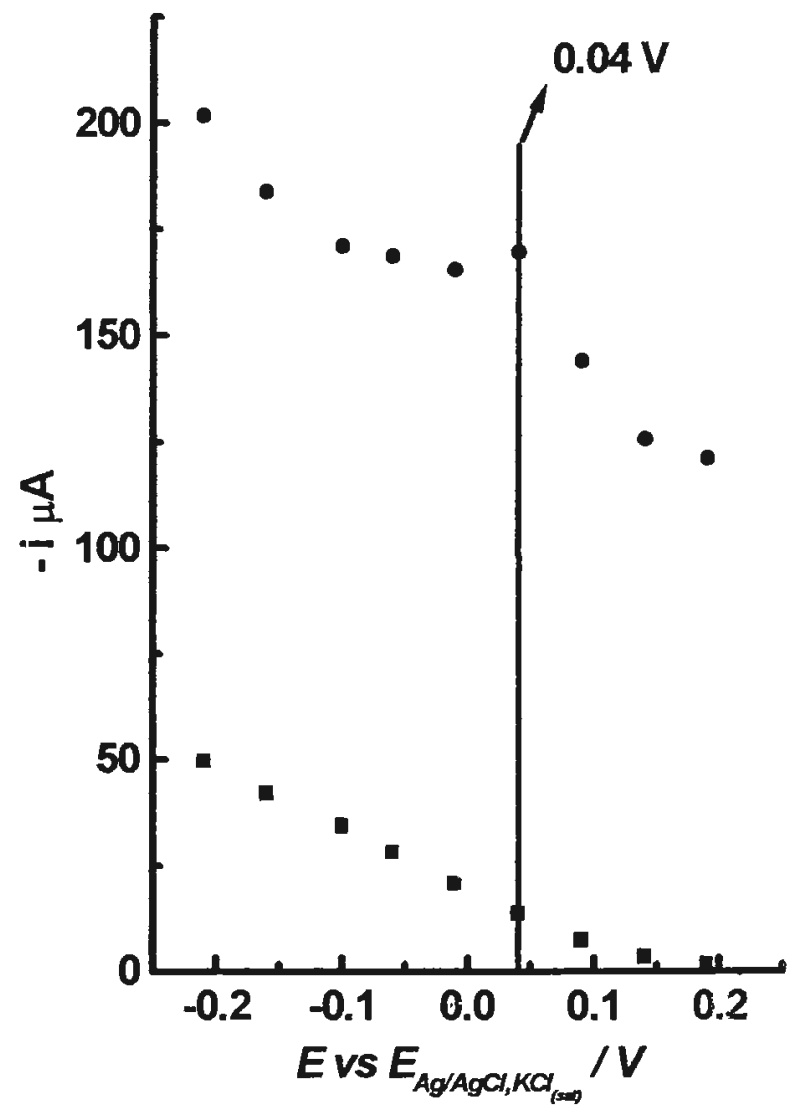

Figura 32. Curvas corrente vs potencial registradas com eletrodo de pasta de carbono modificado com filme de Azul da Prússia e posteriormente ativado em solução de $\mathrm{RhCl}_{3}$ :

(a) na ausência de $\mathrm{H}_{2} \mathrm{O}_{2}$;

(O) na presença de $1 \mathrm{mmol} \mathrm{L}^{-1}$ de $\mathrm{H}_{2} \mathrm{O}_{2}$

Eletrodos previamente secos a temperatura ambiente por 24 horas. Eletrólito suporte: tampão ácido cítrico/citrato de potássio, $\mathrm{pH} 5,5$ contendo $0,5 \mathrm{~mol} \mathrm{~L}^{-1}$ de $\mathrm{KCl} . E_{i}=-0,4 \mathrm{~V} ; E_{f}=1,2 \mathrm{~V}$; velocidade de varredura $=60 \mathrm{mVs}^{-1}$. 
Pode-se concluir, a partir dos dados obtidos, que a influência do $\mathrm{O}_{2}$ torna-se mais significativa em potenciais mais negativos. Por isto, o potencial escolhido para determinações amperométricas de $\mathrm{H}_{2} \mathrm{O}_{2}$ foi $40 \mathrm{mV}$ (vs $\mathrm{Ag} / \mathrm{AgCl}$ ). O EPCAP-Rh apresentou $8,0 \%$ de influência da corrente de $\mathrm{O}_{2}$, no potencial de $40 \mathrm{mV}$ (vs Ag/AgCl). Para concentrações mais baixas de $\mathrm{H}_{2} \mathrm{O}_{2}$ convém aumentar o potencial aplicado de modo a minimizar a interferência do $\mathrm{O}_{2}$.

\section{III.3.3- Preparação de Eletrodo de Pasta de Carbono Modificado em solução $1 \mathrm{mmol} \mathrm{L}^{-1}$ de $\mathrm{RhCl}_{3}$ por Deposição a Dois Potenciais Controlados (EPC-Rh).}

Para poder compreender melhor o efeito do $\mathrm{RhCl}_{3}$ nos eletrodos de pasta de carbono modificados com filme de Azul da Prússia, (EPCAP), estudou-se o comportamento do EPC modificado com $1 \mathrm{mmol} \mathrm{L}^{-1}$ de $\mathrm{RhCl}_{3}$, (EPC-Rh), como descrito no item II.2.2.2.a da página 35 , na determinação de $\mathrm{H}_{2} \mathrm{O}_{2}$ no intervalo de $5,0 \times 10^{-5} \mathrm{~mol} \mathrm{~L}^{-1}$ à $8,6 \times 10^{-4} \mathrm{~mol} \mathrm{~L}^{-1}$ utilizando amperometria ( $E_{\text {apl }}=40 \mathrm{mV}$ ) em solução tampão (citrato de potássio/ácido cítrico) $\mathrm{pH}=6,1$ contendo $0,5 \mathrm{~mol} \mathrm{~L}^{-1}$ de $\mathrm{KCl}$.

Os amperogramas e as curvas analítica do EPC-Rh são apresentados na figura 33 . 


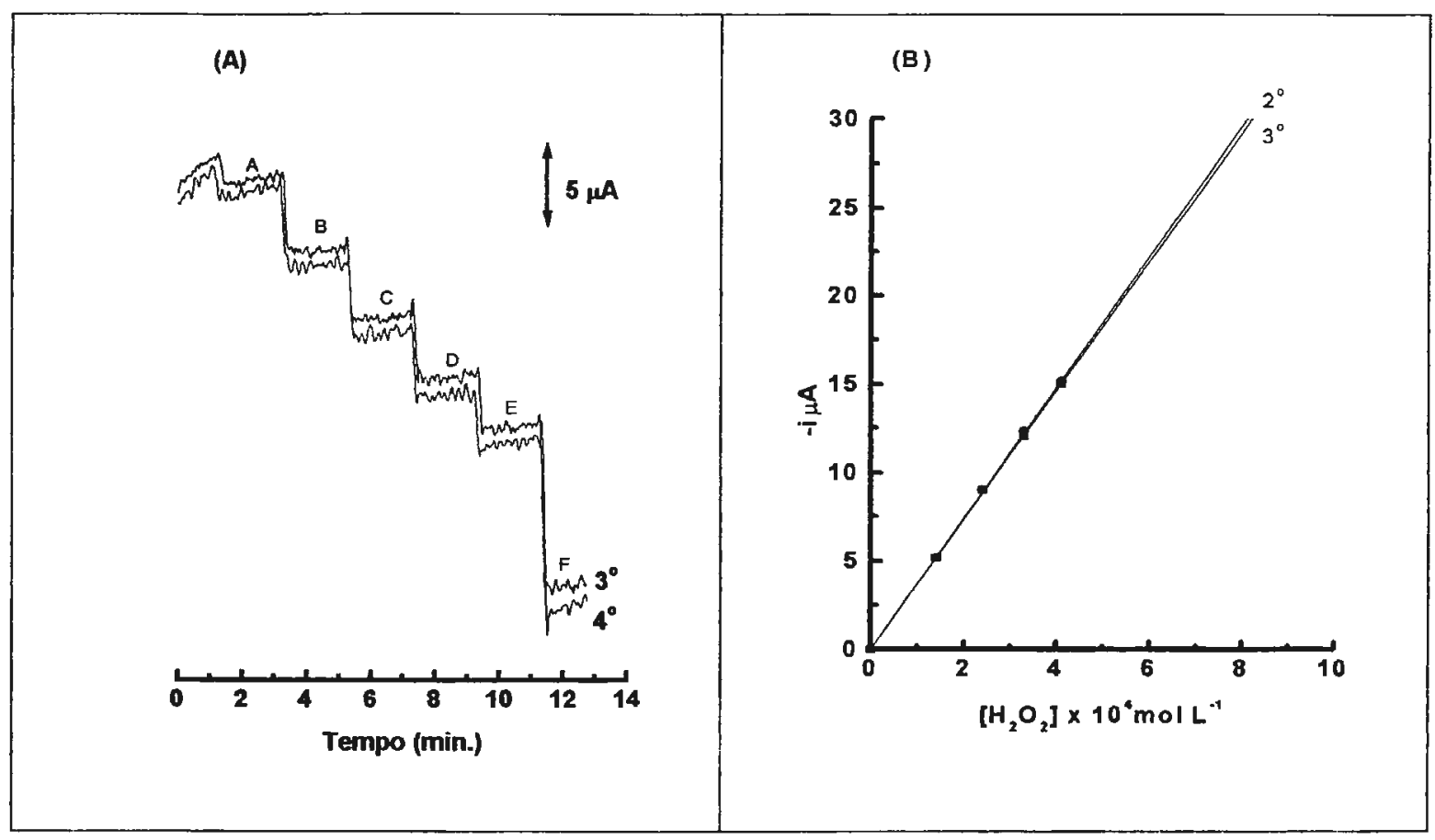

Figura 33. Determinação amperometrica de $\mathrm{H}_{2} \mathrm{O}_{2}$ em eletrodo de pasta de carbono modificado em solução de $\mathrm{RhCl}_{3}$ : (A) Amperogramas registrados na presença de concentrações crescentes de $\mathrm{H}_{2} \mathrm{O}_{2}: A=5,0 \times 10^{-5} ; \mathrm{B}=1,4 \times 10^{-4}$; $C=2,4 \times 10^{-4} ; \mathrm{D}=3,3 \times 10^{-4} ; \mathrm{E}=4,1 \times 10^{-4} ; \mathrm{F}=8,6 \times 10^{-4} \mathrm{~mol} \mathrm{~L}^{-1} \mathrm{de} \mathrm{H}_{2} \mathrm{O}_{2}$. (B) Curvas analiticas para determinação $\mathrm{H}_{2} \mathrm{O}_{2}$;

Eletrodo preparado utilizando-se a deposição a dois potenciais controlados e seco a temperatura ambiente por 24 horas. Eletrólito suporte: tampão ácido citríco / citrato de potássio, $\mathrm{pH} \mathrm{6,1} \mathrm{contendo} \mathrm{0,5} \mathrm{mol} \mathrm{L}^{-1}$ de $\mathrm{KCl}$. Potencial aplicado para determinação de $\mathrm{H}_{2} \mathrm{O}_{2}=40 \mathrm{~m} \mathrm{~V}$. 
As equações que descrevem os parâmetros das curvas analíticas são apresentadas na tabela III.4.

Tabela III.4. Equações que descrevem os parâmetros das curvas analíticas dos EPC-Rh preparado por deposição a dois potenciais controlados e ciclado em solução $0,1 \mathrm{~mol} \mathrm{~L}^{-1}$ de $\mathrm{KCl} \mathrm{em} 0,02 \mathrm{~mol} \mathrm{~L}^{-1} \mathrm{de} \mathrm{HCl}$.

\begin{tabular}{|c|c|c|}
\hline Equação & $\mathrm{r}^{2}$ & Faixa de linearidade \\
\hline $\mathrm{I}_{\mathrm{p} 2}=0,05+3,65\left[\mathrm{H}_{2} \mathrm{O}_{2}\right]$ & 0,999 & $1,4 \times 10^{-4}-4,1 \times 10^{-4}$ \\
\hline $\mathrm{p}_{\mathrm{p} 3}=0,03+3,71\left[\mathrm{H}_{2} \mathrm{O}_{2}\right]$ & 0,999 & $1,4 \times 10^{-4}-4,1 \times 10^{-4}$ \\
\hline
\end{tabular}

Na figura 34 são comparados os voltamogramas obtidos com o eletrodo de pasta de carbono modificado com filme de Azul da Prússia (EPCAP), com o voltamograma obtido do eletrodo de pasta de carbono modificado com filme de Azul da Prússia e ativado em solução contendo $0,5 \mathrm{~mol} \mathrm{~L}^{-1}$ de $\mathrm{KCl}$ e $1 \mathrm{mmol} \mathrm{L}^{-1}$ de $\mathrm{RhCl}_{3}$ (EPCAP-Rh) e com o voltamograma obtido do eletrodo de pasta de carbono modificado em solução $1 \mathrm{mmol} \mathrm{L}^{-1}$ de $\mathrm{RhCl}_{3}$ (EPC-Rh). 


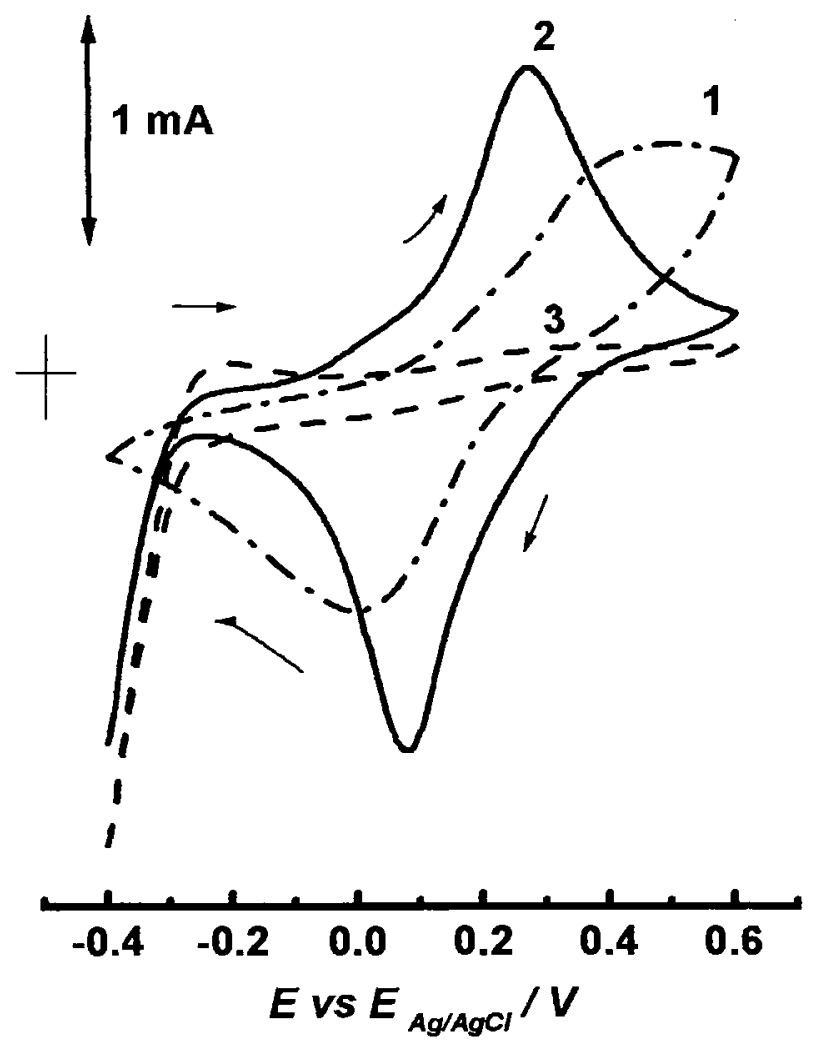

Figura 34. Voltamogramas cíclicos, registrados em eletrólito suporte, com eletrodos de pasta de carbono modificados a dois potenciais controlados.

(1) Eletrodo de pasta de carbono modificado com filme de Azul da Prússia EPCAP;

(2) Eletrodo de pasta de carbono modificado com filme de Azul da Prússia e ativado em solução contendo $0,5 \mathrm{~mol} \mathrm{~L}^{-1}$ de $\mathrm{KCl}$ e $1 \mathrm{mmol} \mathrm{L^{-1 }}$ de $\mathrm{RhCl}_{3}$ EPCAP-Rh;

(3) Eletrodo de pasta de carbono modificado em solução contendo $0,5 \mathrm{~mol} \mathrm{~L}^{-1}$ de $\mathrm{KCl}$ e $1 \mathrm{mmol} \mathrm{L}^{-1}$ de $\mathrm{RhCl}_{3} \mathrm{EPC}-\mathrm{Rh}$;

Os eletrodos foram secos a temperatura ambiente por 24 horas.

Eletrólito suporte: tampão ácido citríco / citrato de potássio, pH 6,1 contendo $0,5 \mathrm{~mol} \mathrm{~L}^{-1}$ de KCl. $E_{i}=-0,40 \mathrm{~V} . E_{f}=0,60 \mathrm{~V}$. velocidade de varredura $=50 \mathrm{~m} \mathrm{~V} \mathrm{~s}^{-1}$. 
$O$ eletrodo modificado em solução $1 \mathrm{mmol} \mathrm{L}^{-1}$ de $\mathrm{RhCl}_{3}$ (EPC-Rh) apresentou a formação de um pico de oxidação a $-0,3 \vee$ e o pico de redução ocorre junto com a redução do hidrogênio $\left(2 \mathrm{H}^{+}+2 \mathrm{e}^{-} \rightarrow \mathrm{H}_{2}\right)$. Este fato pode ser comprovado pela formação de micros bolhas na superfície do eletrodo.

Observou-se que no EPCAP-Rh o pico de oxidação do $\mathrm{RhCl}_{3}$ foi obtido no mesmo valor $(-0,3 \mathrm{~V})$ daquele obtido com EPC-Rh e o EPCAP-Rh apresentou maior nivel de corrente e um deslocamento do potencial de pico de oxidação para valores mais próximos do zero do que o EPCAP.

$\mathrm{Na}$ figura 35 são comparados os amperogramas obtidos com os eletrodos de pasta de carbono modificados com filme de Azul da Prússia (EPCAP), com o EPCAP e ativado em solução contendo $0,5 \mathrm{~mol} \mathrm{~L}^{-1}$ de $\mathrm{KCl}$ e $1 \mathrm{mmol} \mathrm{L}^{-1}$ de $\mathrm{RhCl}_{3}$ (EPCAP-Rh) e com o eletrodo de pasta de carbono modificado em solução de $1 \mathrm{mmol} \mathrm{L}^{-1}$ de $\mathrm{RhCl}_{3}$ (EPC-Rh). Os eletrodos foram utilizados na determinação de $\mathrm{H}_{2} \mathrm{O}_{2}$ no intervalo de $5,0 \times 10^{-5} \mathrm{~mol} \mathrm{~L}^{-1}$ a $8,6 \times 10^{-4} \mathrm{~mol} \mathrm{~L}^{-1}$ em solução tampão (citrato de potássio/ácido cítrico) $\mathrm{pH}=6,1$ contendo $0,5 \mathrm{~mol} \mathrm{~L}^{-1}$ de $\mathrm{KCl}$. 


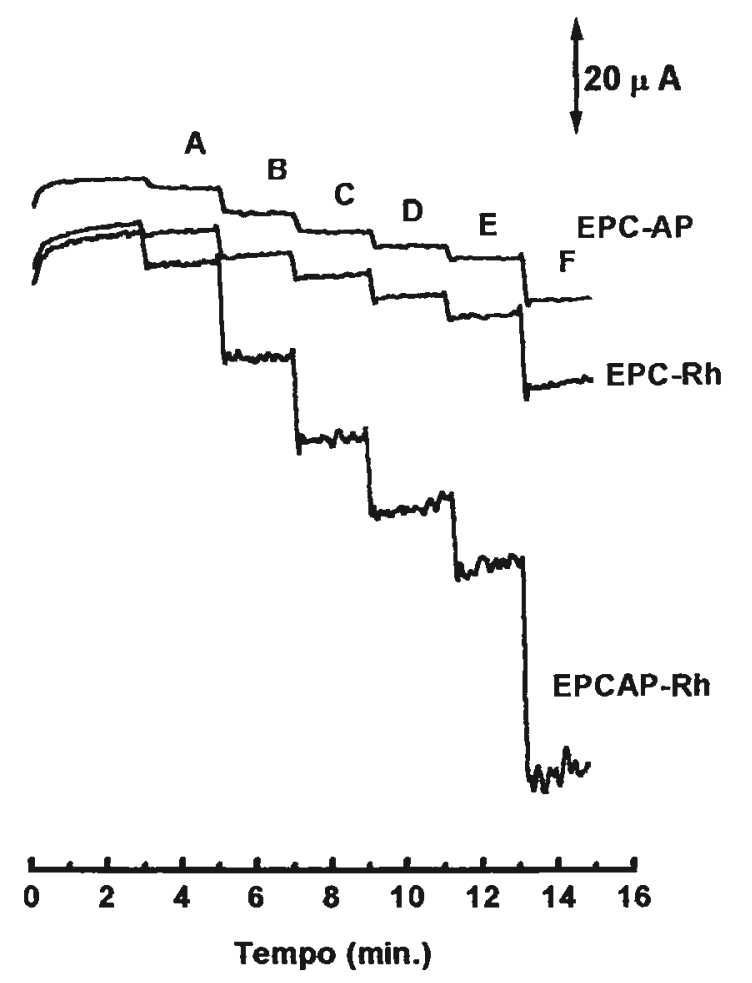

Figura 35. Amperogramas registrados com EPCAP, EPC-Rh e EPCAP-Rh na presença de concentraçōes crescentes de $\mathrm{H}_{2} \mathrm{O}_{2 .} A=5,0 \times 10^{-5}$; $\mathrm{B}=1,4 \times 10^{-4}$; $C=2,4 \times 10^{-4} ; \mathrm{D}=3,3 \times 10^{-4} ; \mathrm{E}=4,1 \times 10^{-4} ; \mathrm{F}=8,6 \times 10^{-4} \mathrm{~mol} \mathrm{~L}^{-1}$ de $\mathrm{H}_{2} \mathrm{O}_{2}$.

Eletrodos preparados utilizando-se a deposição a dois potenciais controlados e secos a temperatura ambiente por 24 horas. Eletrólito suporte tampão ácido citríco / citrato de potássio, $\mathrm{pH} \mathrm{6,1} \mathrm{contendo} 0,5 \mathrm{~mol} \mathrm{~L}^{-1}$ de $\mathrm{KCl}$. Potencial aplicado na determinação de $\mathrm{H}_{2} \mathrm{O}_{2}=40 \mathrm{~m} \mathrm{~V}$. 
Deste modo pode-se concluir que os eletrodos modificados em solução $1 \mathrm{mmol} \mathrm{L}^{-1}$ de $\mathrm{RhCl}_{3}$ (EPC-Rh) e o eletrodo de pasta de carbono modificado com filme de Azul da Prússia (EPCAP) apresentam menor sensibilidade do que o eletrodo modificado com filme de Azul da Prússia e ativado em solução contendo $0,5 \mathrm{~mol} \mathrm{~L}^{-1}$ de $\mathrm{KCl}$ e $1 \mathrm{mmol} \mathrm{L}^{-1}$ de $\mathrm{RhCl}_{3}$ (EPCAP-Rh), deste modo o $\mathrm{RhCl}_{3}$ não está somente estabilizando o filme, mas também está reforçando o efeito catalitico da redução de $\mathrm{H}_{2} \mathrm{O}_{2}$.

\section{III.3.4- Comportamento Eletroquímico do Eletrodo de Pasta de Carbono} Modificado com Filme de Azul da Prússia ativado em solução contendo $0,5 \mathrm{~mol} \mathrm{~L}^{-1}$ de $\mathrm{KCl}_{\text {e }} 1 \mathrm{mmol} \mathrm{L}^{-1}$ de $\mathrm{RhCl}_{3}$, (EPCAP-Rh).

Avaliou-se o comportamento eletroquímico dos eletrodos de pasta de carbono modificados com AP e posteriormente ativados em solução de $\mathrm{RhCl}_{3}$. A figura 36 mostra o voltamograma cíclico registrado em tampão ácido cítrico/ citrato de potássio, pH 6,1, contendo $0,5 \mathrm{~mol} \mathrm{~L}^{-1}$ de $\mathrm{KCl}$. Em 0,3 V o branco da Prússia é oxidado ao Azul da Prússia, enquanto a 0,18 V, o Azul da Prússia é reduzido ao branco da Prússia. O potencial redox do sistema pode ser estimado como $0,24 \mathrm{~V}$ vs $\mathrm{E}_{\mathrm{Ag} / \mathrm{AgCl}, \mathrm{KCl}(\mathrm{sat})}$ e corresponde a $(\mathrm{Ep}, \mathrm{a}+\mathrm{Ep}, \mathrm{c}) / 2 \mathrm{~V}$. 


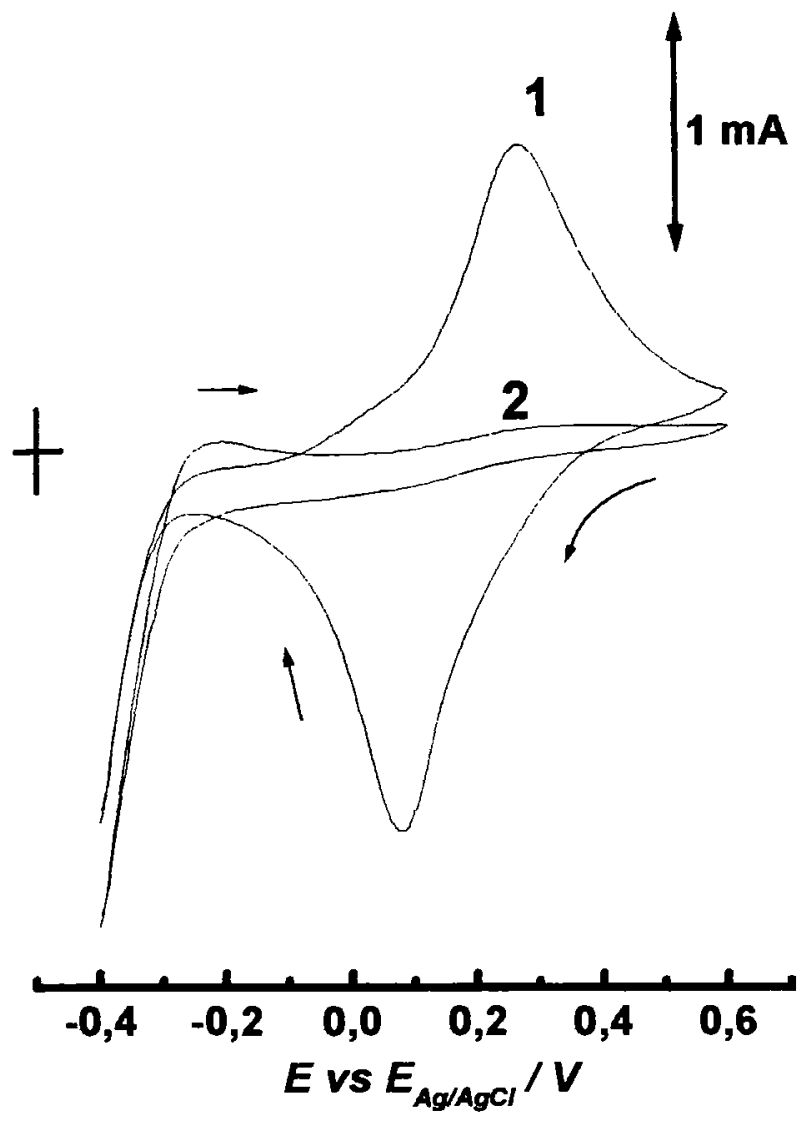

Figura 36. Voltamogramas cíclicos, registrados em eletrólito suporte, com eletrodos de pasta de carbono modificados a dois potenciais controlados.

(1) Eletrodo de pasta de carbono modificado com filme de Azul da Prússia e ativado em solução contendo $0,5 \mathrm{~mol} \mathrm{~L}^{-1}$ de $\mathrm{KCl}$ e $1 \mathrm{mmol} \mathrm{L}{ }^{-1}$ de $\mathrm{RhCl}_{3}$;

(2) Eletrodo de pasta de carbono modificado em solução contendo $0,5 \mathrm{~mol} \mathrm{~L}^{-1}$ de $\mathrm{KCl}$ e $1 \mathrm{mmol} \mathrm{L}^{-1}$ de $\mathrm{RhCl}_{3}$;

Eletrodos foram secos a temperatura ambiente por 24 horas. Eletrólito suporte: tampão ácido citríco / citrato de potássio, $\mathrm{pH} \mathrm{6,1} \mathrm{contendo} 0,1 \mathrm{~mol} \mathrm{~L}^{-1}$ de $\mathrm{KCl}$. $E_{i}=-0,40 \vee . E_{f}=0,60 \vee$. Velocidade de varredura $=50 \mathrm{mV} \mathrm{s}^{-1}$. 
O voltamograma cíclico apresentado na figura 36 foi utilizado para estimar o excesso superficial ou concentração superficial de Azul da Prússia imobilizado no eletrodo.

Para tanto, determinou-se a carga do pico anódico, após descontar a contribuição da corrente capacitiva, encontrando-se o valor de $1,3 \times 10^{-3} \mathrm{C}$. Considerando-se que $n=$ numero de elétrons $=4$ elétrons $^{(36,56)}$ estão envolvidos no processo eletródico e que o eletrodo possui uma área de $A=0,080 \mathrm{~cm}^{2}$, o valor estimado do excesso superficial foi calculado através da formula, $\int \mathrm{i} d t=Q /(n F A)=\Gamma, F=9,6485 \times 10^{4} \mathrm{C} \mathrm{mol}$, sendo $Q=$ quantidade de carga na superficie do eletrodo e $\Gamma=$ excesso superficial que foi igual a $4,3 \times 10^{-8} \mathrm{~cm}^{-2} \mathrm{~mol}^{-1}$. Este último valor é maior do que outros dados apresentados na literatura ${ }^{(28,30,36)}$ que se encontram na ordem de $10^{-9} \mathrm{~cm}^{-2} \mathrm{~mol}^{-1}$ e deve refletir o maior tempo de deposição utilizado neste trabalho, já o diâmetro dos eletrodos aqui empregados săo muito próximos daqueles utilizados na literatura.

A figura 37 mostra que o processo é controlado por difusão na faixa de $25 \leq \mathrm{v} \leq 400 \mathrm{Vs}^{-1}$. Desde que o filme encontra-se imobilizado na superfície do eletrodo este comportamento reflete a incorporação de íons $\mathrm{K}^{+}$no filme durante $\mathrm{o}$ processo de redução e difusão destes íons para fora do filme durante o processo de redução. 

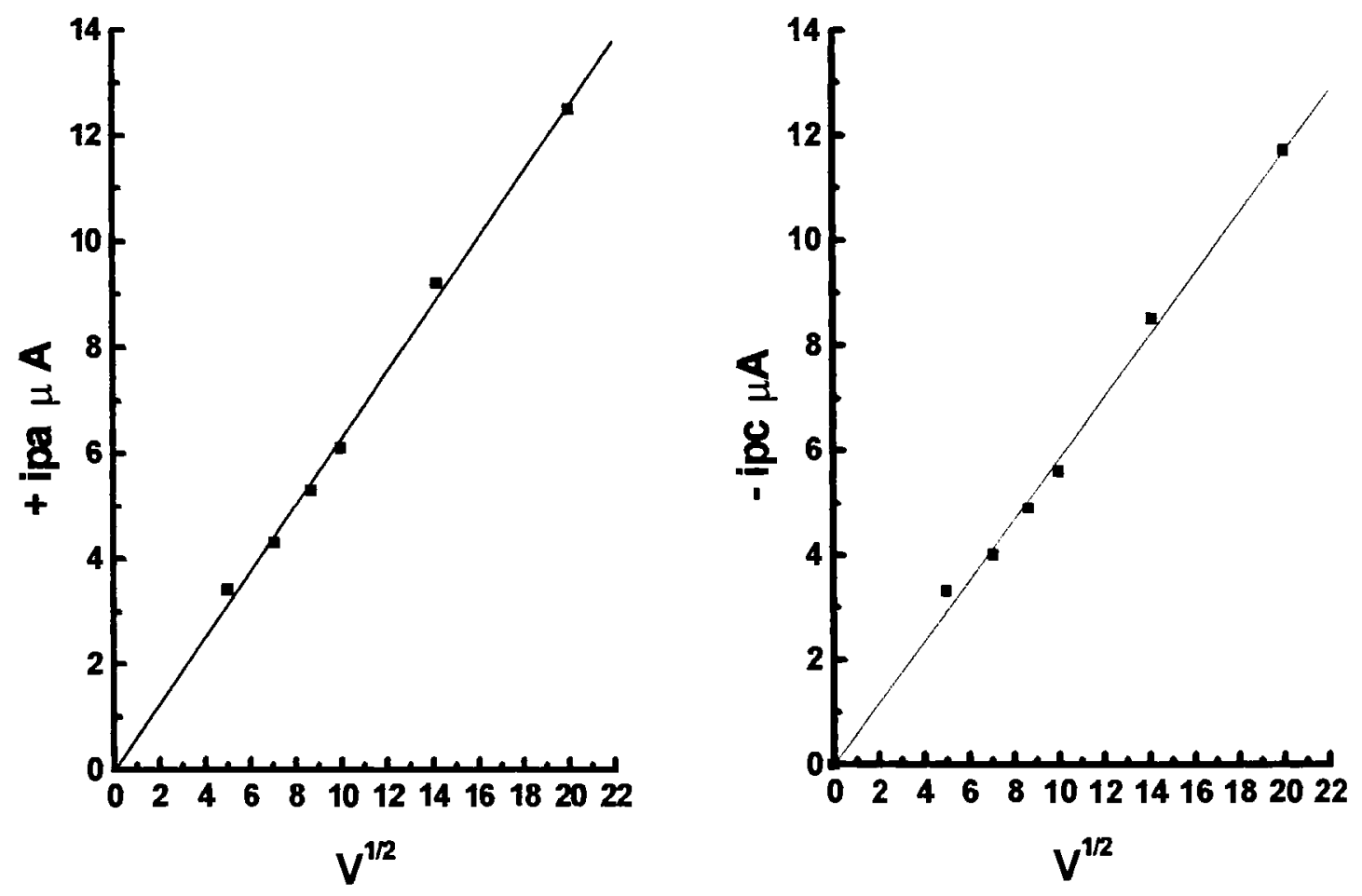

Figura 37. Curvas das correntes de picos anódica e catódica vs a raiz quadrada da velocidade de varredura dos eletrodos de pasta de carbono modificados com filmes de Azul da Prússia e ativados em solução contendo $0,5 \mathrm{~mol} \mathrm{~L}^{-1}$ de $\mathrm{KCl}$ e $1 \mathrm{mmol} \mathrm{L}^{-1}$ de $\mathrm{RhCl}_{3}$.

Eletrólito suporte tampão ácido citrico / citrato de potássio, pH 6,1 contendo $0,5 \mathrm{~mol} \mathrm{~L}^{-1}$ de KCl. $E_{\mathrm{apl}}=40 \mathrm{~m} \mathrm{~V}$.

$$
\begin{aligned}
& \mid p, c=0,006+0,63 v^{1 / 2}\left(r^{2}=0,999\right) \\
& \mid p, a=0,017+0,58 v^{1 / 2}\left(r^{2}=0,998\right)
\end{aligned}
$$


III.3.5- Faixas Lineares e Limites de Deteç̧ão para Determinação de $\mathrm{H}_{2} \mathrm{O}_{2}$ em Eletrodos de Pasta de Carbono Modificados com AP ativados com $\mathrm{RhCl}_{3}$ (EPCAP- Rh).

A faixa linear e limite de deteç̧ão para a determinação de $\mathrm{H}_{2} \mathrm{O}_{2}$ com o EPCAP-Rh, no intervalo de $9,34 \times 10^{-8} \mathrm{~mol} \mathrm{~L}^{-1}$ a $4,98 \times 10^{-4} \mathrm{~mol} \mathrm{~L}^{-1}$ foram calculados como descrito na referência (80). Os dados utilizados foram provenientes da realização de curvas analíticas efetuadas utilizando-se tampão (citrato de potássio/ácido cítrico) $\mathrm{pH}=6,1$ contendo $0,5 \mathrm{~mol} \mathrm{~L}^{-1}$ de $\mathrm{KCl}$ e potencial aplicado de $40 \mathrm{~m} \mathrm{~V}$.

Os dados são apresentados na tabela III.5. 
Tabela III.5. Equações que descrevem os parâmetros das curvas analíticas e os limites de detecção obtidos para determinação de $\mathrm{H}_{2} \mathrm{O}_{2}$ com EPCAP-Rh.

\begin{tabular}{|c|c|c|c|c|}
\hline Equação & $\begin{array}{c}\text { Faixa de linearidade } \\
\left(\mathrm{mol} \mathrm{L}^{-1}\right)\end{array}$ & $r^{2}$ & $\begin{array}{c}\text { Desvio Padrão } \\
(\mu \mathrm{A})\end{array}$ & $\begin{array}{c}\text { Limite de detecção } \\
\left(10^{-4} \mathrm{~mol} \mathrm{~L}^{-1}\right)\end{array}$ \\
\hline$l_{p 2}=0,044+10,4\left[\mathrm{H}_{2} \mathrm{O}_{2}\right]$ & $5,12 \times 10^{-5}-1,13 \times 10^{-4}$ & 0,999 & 1,07 & 0,31 \\
\hline$l_{p 3}=0,023+13,0\left[\mathrm{H}_{2} \mathrm{O}_{2}\right]$ & $5,12 \times 10^{-5}-1,13 \times 10^{-4}$ & 0,999 & 0,060 & $0,01^{*}$ \\
\hline$l_{p 4}=0,090+9,45\left[\mathrm{H}_{2} \mathrm{O}_{2}\right]$ & $5,12 \times 10^{-5}-1,13 \times 10^{-4}$ & 0,999 & 1,71 & 0,54 \\
\hline$l_{p 5}=0,043+8,96\left[\mathrm{H}_{2} \mathrm{O}_{2}\right]$ & $5,12 \times 10^{-5}-1,13 \times 10^{-4}$ & 0,999 & 1,24 & 0,42 \\
\hline$l_{p 6}=0,070+11,4\left[\mathrm{H}_{2} \mathrm{O}_{2}\right]$ & $5,12 \times 10^{-5}-1,13 \times 10^{-4}$ & 0,999 & 1,18 & 0,31 \\
\hline$l_{p 7}=0,044+11,9\left[\mathrm{H}_{2} \mathrm{O}_{2}\right]$ & $5,12 \times 10^{-5}-1,13 \times 10^{-4}$ & 0,999 & 0,879 & 0,22 \\
\hline$l_{p 8}=0,030+11,9\left[\mathrm{H}_{2} \mathrm{O}_{2}\right]$ & $5,12 \times 10^{-5}-1,13 \times 10^{-4}$ & 0,999 & 0,369 & 0,09 \\
\hline$l_{p 9}=0,040+12,1\left[\mathrm{H}_{2} \mathrm{O}_{2}\right]$ & $5,12 \times 10^{-5}-1,13 \times 10^{-4}$ & 0,999 & 1,32 & 0,33 \\
\hline$I_{p 10}=0,030+11,9\left[\mathrm{H}_{2} \mathrm{O}_{2}\right]$ & $5,12 \times 10^{-5}-1,13 \times 10^{-4}$ & 0,999 & 0,369 & 0,09 \\
\hline
\end{tabular}

* Valores rejeitados para cálculo de limite de deteç̧ão.

A sensibilidade, calculada dividindo-se o valor médio do coeficiente angular das curvas analíticas pela área do eletrodo $\left(0,080 \mathrm{~cm}^{2}\right)$, foi de $1,4 \pm 0,2 \mathrm{~A} \mathrm{~mol} \mathrm{~L}^{-1} \mathrm{~cm}^{-2}$ e o limite de detecção médio foi de $2,5 \pm 0,02 \times 10^{-5} \mathrm{~mol} \mathrm{~L}^{-1}$. 


\section{III.3.6- Armazenamento e Tempo de Vida dos EPCAP-Rh.}

Os eletrodos de pasta de carbono modificados com filmes de Azul da Prússia e ativados em solução contendo $0,5 \mathrm{~mol} \mathrm{~L}^{-1}$ de $\mathrm{KCl}$ e $1 \mathrm{mmol} \mathrm{L}^{-1}$ de $\mathrm{RhCl}_{3}$ (EPCAP-Rh), foram preparados como descrito no item I1.2.2.1.e, página 35. As curvas analiticas utilizadas para o limite de deteç̧ão foram preparadas como descrito no item II.2.3.1.c, página 36. Cabe salientar que diariamente foram efetuadas 6 curvas analíticas consecutivas. Quando fora de uso o eletrodo foi armazenado em solução $0,5 \mathrm{~mol} \mathrm{~L}^{-1}$ de $\mathrm{KCl}$. Os dados são apresentados na figura 38 e na tabela III. 6 . 


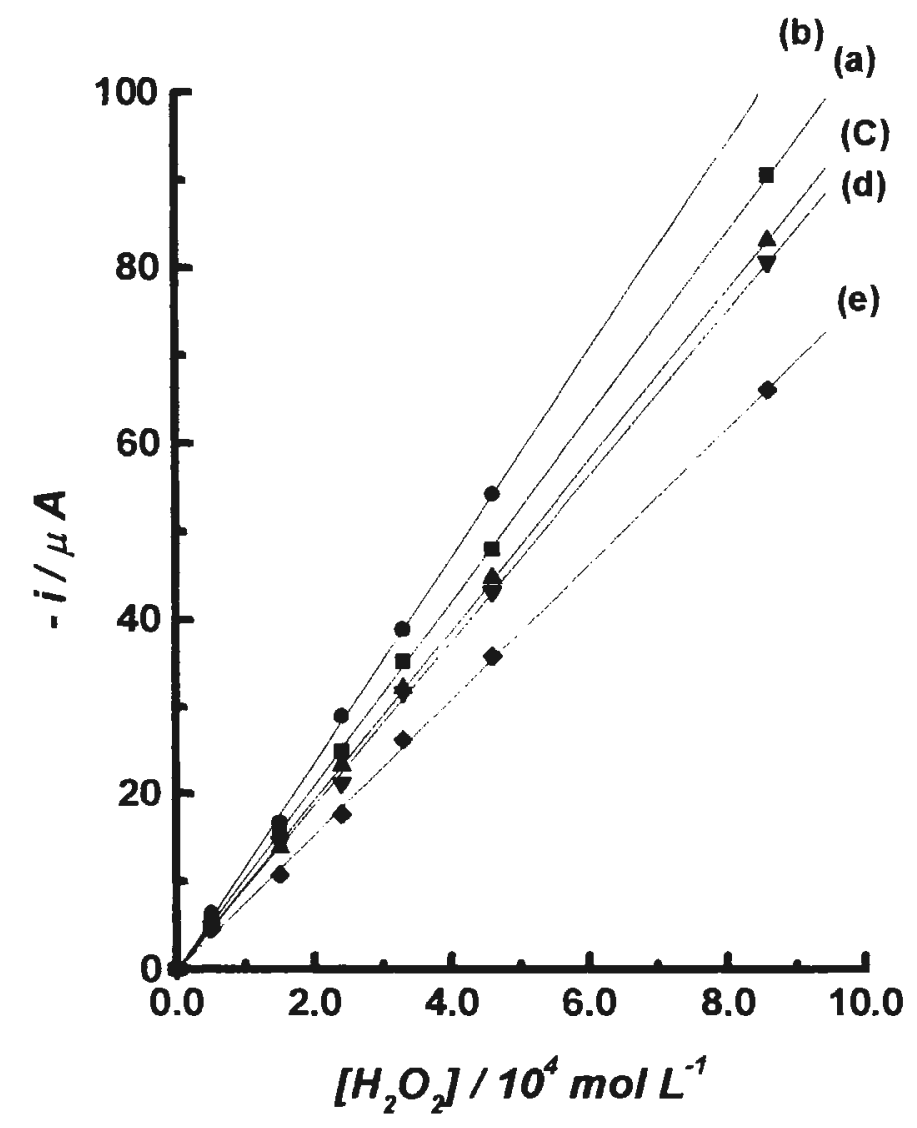

Figura 38. Curvas analíticas obtidas com eletrodos de pasta de carbono modificados com filmes de Azul da Prússia e ativados em solução contendo $0,5 \mathrm{~mol} \mathrm{~L}^{-1}$ de $\mathrm{KCl}$ e $1 \mathrm{mmol} \mathrm{L} \mathrm{L}^{-1}$ de $\mathrm{RhCl}_{3}$, durante a determinação de $\mathrm{H}_{2} \mathrm{O}_{2 \cdot}$ (a) $1^{\circ}$, (b) $2^{\circ}$, (c) $3^{\circ}$, (d) $4^{\circ}$ e (e) $5^{\circ}$ dias.

Eletrodo preparado utilizando-se a deposição a dois potenciais controlados e secos a temperatura ambiente por 24 horas. Eletrólito suporte tampão ácido citríco / citrato de potássio, $\mathrm{pH} \mathrm{6,1} \mathrm{contendo} \mathrm{0,5} \mathrm{mol} \mathrm{L}^{-1}$ de $\mathrm{KNO}_{3}$. Potencial aplicado na determinação de $\mathrm{H}_{2} \mathrm{O}_{2}=40 \mathrm{~m} \mathrm{~V}$. 
As equações que descrevem os parâmetros das curvas analiticas médias são apresentadas na tabela III.6.

Tabela III.6. Equações que descrevem os parâmetros das curvas analiticas médias dos EPCAP-Rh preparado por deposição a dois potenciais controlados.

\begin{tabular}{|c|c|c|c|c|c|c|}
\hline Dia & Equação Média & $\begin{array}{l}\text { Faixa linear } \\
10^{-5} \mathrm{~mol} \mathrm{~L}^{-1}\end{array}$ & $\begin{array}{l}\text { Sensibilidade } \\
A \mathrm{~mol}^{-1} \mathrm{~L} \mathrm{~cm}^{-2}\end{array}$ & $\begin{array}{c}\text { Sensibildade } \\
(\%)\end{array}$ & $\begin{array}{l}\text { Desvio } \\
\text { Padrão }\end{array}$ & $r^{2}$ \\
\hline $1^{\circ}$ & $\mathrm{Ip}=0,0029+10,5\left[\mathrm{H}_{2} \mathrm{O}_{2}\right]$ & $5,0-86$ & 1,32 & 100 & 0,02 & 0,999 \\
\hline $2^{\circ}$ & $I p=0,0439+11,8\left[\mathrm{H}_{2} \mathrm{O}_{2}\right]$ & $5,0-86$ & 1,47 & 111 & 0,03 & 0,999 \\
\hline $3^{\circ}$ & $I p=0,0262+9,68\left[\mathrm{H}_{2} \mathrm{O}_{2}\right]$ & $5,0-86$ & 1,21 & 92 & 0,02 & 0,999 \\
\hline $4^{\circ}$ & $\mid p=0,0107+9,38\left[\mathrm{H}_{2} \mathrm{O}_{2}\right]$ & $5,0-86$ & 1,17 & 89 & 0,03 & 0,999 \\
\hline $5^{\circ}$ & $\mathrm{I}=0.0271+7.71\left[\mathrm{H}_{2} \mathrm{O}_{3}\right]$ & $5.0-86$ & 0.96 & 73 & 0.02 & 0999 \\
\hline
\end{tabular}

Depois de 5 dias de utilização nestas condições, a sensibilidade do eletrodo diminuiu $27 \%$.

III.3.7- Avaliação da Interferência dos ácidos Ascórbico e Úrico Durante a Determinação de $\mathrm{H}_{2} \mathrm{O}_{2}$ Utilizando se Eletrodos Modificados com Azul da Prússia e Posteriormente Ativados em Solução contendo $1,0 \times 10^{-3} \mathrm{~mol} \mathrm{~L}^{-1} \mathrm{de}$ $\mathrm{RhCl}_{3}$

Sabe-se da literatura que os principais interferentes para determinação de $\mathrm{H}_{2} \mathrm{O}_{2}$ utilizando-se eletrodos modificado com filme de Azul da Prússia são o ácido ascórbico e o ácido úrico ${ }^{(27)}$. Deste modo estudou-se o comportamento dos eletrodos modificados com filme de Azul da Prússia e posteriormente ativados em solução de $\mathrm{RhCl}_{3}$ na determinação de $\mathrm{H}_{2} \mathrm{O}_{2}$ na presença de $1,0 \times 10^{-3} \mathrm{~mol} \mathrm{~L}^{-1}$ de ácido ascórbico e na presença de $1,0 \times 10^{-3} \mathrm{~mol} \mathrm{~L}^{-1}$ de ácido úrico. A figura 39 mostra as curvas correntes vs potencial obtidas como descrito no item II.2.3.3.a, página 38. 


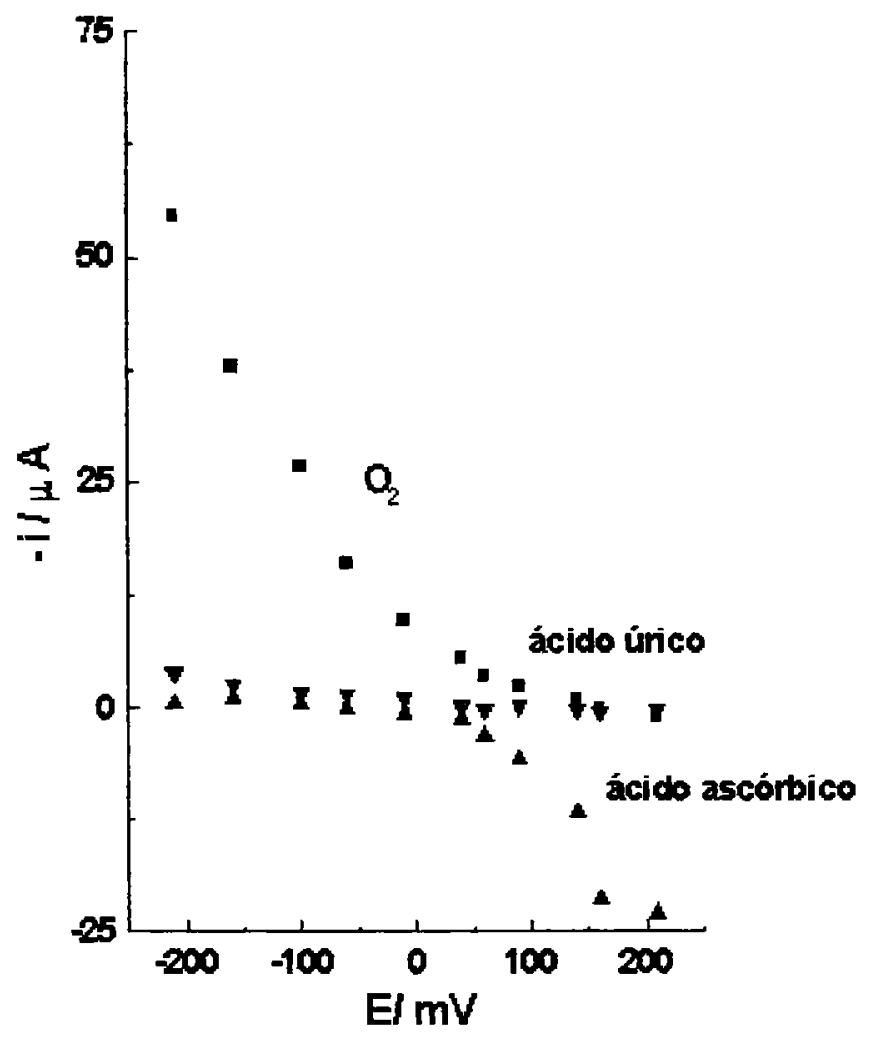

Figura 39. Variação das corrente de redução de 1,0 mmoll-1 de ácido úrico, 1,0 mmoll-1 de ácido ascórbico e $\mathrm{O}_{2}$ como função do potencial aplicado ao EPC-AP-Rh. Eletrodos previamente secos a temperatura ambiente por 24 horas. Eletrólito suporte: tampão ácido cítrico/citrato de potássio, pH 5,5 contendo $0,5 \mathrm{~mol} \mathrm{~L}^{-1}$ de $\mathrm{KCl}$. 
A corrente de redução registrada em solução $1,0 \times 10^{-3} \mathrm{~mol} \mathrm{~L}^{-1}$ de $\mathrm{H}_{2} \mathrm{O}_{2}$ (em potencial de $40 \mathrm{mV}$ ) não foi alterada pela presença de ácido úrico na mesma concentração. O eletrodo não apresentou, na faixa de $-0,21 \mathrm{~V} \leq \mathrm{E}_{\text {apli }} \leq 0,19 \mathrm{~V}$, nenhum sinal amperométrico devido à oxidação direta deste componente.

Nas mesmas condições anteriormente descritas, a oxidação direta do ácido ascórbico na superfície do eletrodo somente foi detectada em potenciais iguais ou superiores a $0,060 \mathrm{~V}$.

Avaliou-se a interferência do ácido ascórbico durante a determinação de $\mathrm{H}_{2} \mathrm{O}_{2}$, como descrito no item II.2.3.3.b, página 38. Os resultados são apresentados na figura 40. A adição do ácido ascórbico causou uma diminuição de apenas $4 \%$ na corrente catalítica de redução da $\mathrm{H}_{2} \mathrm{O}_{2}$ devido a um ligeiro consumo desta última por reação direta com o ácido ascórbico ${ }^{(81)}$. Este valor aumentou para $30 \%$ na presença de $\mathrm{O}_{2}$, indicando que a oxidação do ácido ascórbico pela $\mathrm{H}_{2} \mathrm{O}_{2}$ pode, evidentemente estar sendo catalisada pelo oxigênio dissolvido. 


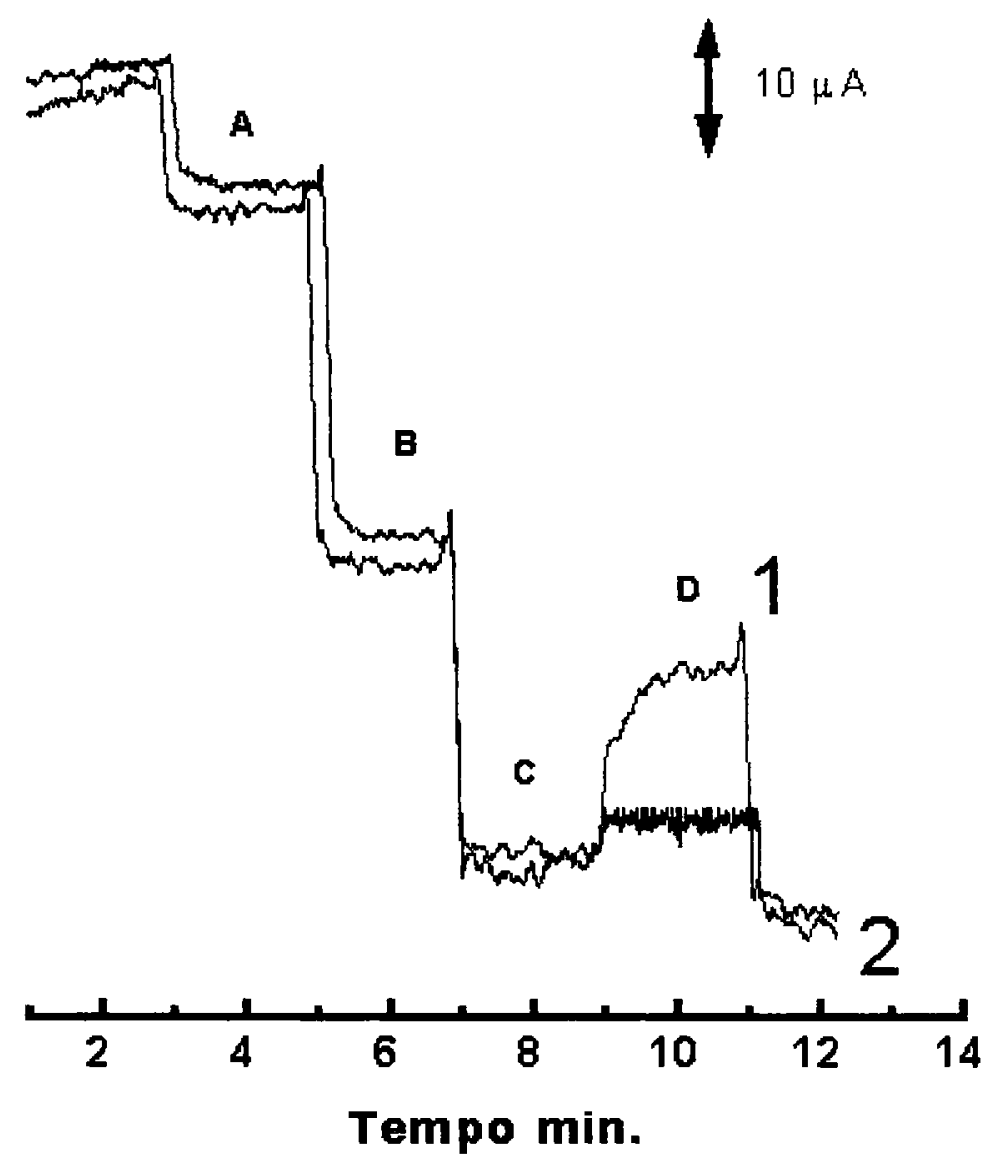

Figura 40. Amperogramas registrados na presença de $\mathrm{H}_{2} \mathrm{O}_{2}$ e ácido ascórbico com eletrodo de pasta de carbono modificado com filme de Azul da Prússia e ativado em solução de $\mathrm{RhCl}_{3}$ (EPCAP-Rh) preparado utilizandose a deposição a dois potenciais controlados: $A=4,95 \times 10^{-5} ; B=1,45 \times 10^{-4}$; $\mathrm{C}=2,38 \times 10^{-4} \mathrm{~mol} \mathrm{~L}^{-1}$ de $\mathrm{H}_{2} \mathrm{O}_{2}$ e $\mathrm{D}=2,0 \times 10^{-5} \mathrm{~mol} \mathrm{~L}^{-1}$ de ácido ascórbico.

(1) na presença de $\mathrm{O}_{2}$ e (2) na ausência de $\mathrm{O}_{2}$.

Eletrodo foi seco a temperatura ambiente por 24 horas. Eletrólito suporte tampão ácido citrico / citrato de potássio, $\mathrm{pH} 6,1$ contendo $0,5 \mathrm{~mol} \mathrm{~L}^{-1}$ de $\mathrm{KCl}$. $E_{\text {apt }}=40 \mathrm{~m} \mathrm{~V}$. 


\section{IV- CONCLUSÕES}

1) O mecanismo para a formação eletroquímica do filme de Azul da Prússia deve envolver a redução de ions $\left[\mathrm{Fe}(\mathrm{CN})_{6}\right]^{3-}$ a $\left[\mathrm{Fe}(\mathrm{CN})_{6}\right]^{4}$ na superfície do eletrodo $\left(1^{\circ}\right.$ ciclo de varredura). Estes últimos precipitam com íons $\mathrm{Fe}^{3+}$, originando o Azul da Prússia na superfície do eletrodo, o qual é reduzido ao branco da Prússia no pico I (figura 7, página 23). Assim, tem-se:

(Pico l $\rightarrow$ Redução do azul da prússia à branco da prússia)

$$
\mathrm{KFe}^{\prime \prime \prime} \mathrm{Fe}^{\prime \prime}(\mathrm{CN})_{6}+\mathrm{e}^{-}+\mathrm{K}^{+} \longrightarrow \mathrm{K}_{2} \mathrm{Fe}^{\prime \prime} \mathrm{Fe} \mathrm{C}^{\prime \prime}(\mathrm{CN})_{6}
$$

(azul da prússia solúvel) (branco da prússia)

$$
\mathrm{Fe}^{\prime \prime \prime}\left[\mathrm{Fe}^{\prime \prime}(\mathrm{CN})_{6}\right]_{3}+4 \mathrm{e}^{-}+4 \mathrm{~K} \stackrel{\text { ou }}{=} \mathrm{K}_{4} \mathrm{Fe}_{4}{ }^{\prime \prime}\left[\mathrm{Fe}^{\prime \prime}(\mathrm{CN})_{6}\right]_{3}
$$

(azul da prússia insolúvel)

(branco da prússia)

$$
E p_{1 c}=0,18 \mathrm{~V}
$$

(Pico $\| \rightarrow$ Oxidação do branco da prússia à azul da prússia)

$$
\mathrm{K}_{2} \mathrm{Fe}^{\prime \prime} \mathrm{Fe}^{\prime \prime}(\mathrm{CN})_{6}=-\mathrm{KFe}^{\prime \prime \prime} \mathrm{Fe}^{\prime \prime}(\mathrm{CN})_{6}-+\mathrm{e}^{-}+\mathrm{K}^{+}
$$

(branco da prússia) (azul da prússia solúvel)

ou

$$
\mathrm{K}_{4} \mathrm{Fe}_{4}{ }^{\prime \prime}\left[\mathrm{Fe}^{\prime \prime}(\mathrm{CN})_{6}\right]_{3} \Longrightarrow \mathrm{Fe}^{\prime \prime \prime}\left[\mathrm{Fe}^{\prime \prime}(\mathrm{CN})_{6}\right]_{3}+4 \mathrm{e}^{-}+4 \mathrm{~K}^{+}
$$

(branco da prússia) (azul da prússia insolúvel)

$$
E p_{1 a}=0,34 \mathrm{~V}
$$

(Pico III $\rightarrow$ Oxidação do azul da prússia à verde de berlim)

$$
\mathrm{KFe}^{\prime \prime \prime} \mathrm{Fe}^{\prime \prime}(\mathrm{CN})_{6} \longrightarrow \mathrm{Fe}^{\prime \prime \prime} \mathrm{Fe}^{\prime \prime \prime}(\mathrm{CN})_{6}+\mathrm{e}^{-}+\mathrm{K}^{+}
$$

(azul da prússia solúvel)

(verde de berlim)

ou

$\mathrm{Fe}_{4}{ }^{\prime \prime \prime}\left[\mathrm{Fe}^{\prime \prime}(\mathrm{CN})_{6}\right]_{3}+3 \mathrm{Cl}^{-}=\mathrm{Fe}^{\prime \prime \prime}\left[\mathrm{Fe}^{\prime \prime \prime}(\mathrm{CN})_{6} \mathrm{Cl}\right]_{3}+3 \mathrm{e}^{-}$

(azul da prússia insolúvel)

(verde de berlim)

$$
E p_{2 a}=1,00 \mathrm{~V}
$$


(Pico IV $\rightarrow$ Redução do verde de berlim à azul da prússia

$$
\begin{array}{ll}
\mathrm{Fe}^{\prime \prime \prime} \mathrm{Fe}^{\prime \prime \prime}(\mathrm{CN})_{6}+\mathrm{e}^{-}+\mathrm{K}^{+} \longrightarrow & \mathrm{KFe}^{\prime \prime \prime} \mathrm{Fe} e^{\prime \prime}(\mathrm{CN})_{6} \\
\text { (verde de berlim) } & \text { (azul da prússia solúvel) } \\
\mathrm{Fe}^{\prime \prime \prime}\left[\mathrm{Fe}{ }^{\prime \prime \prime}(\mathrm{CN})_{6} \mathrm{Cl}\right]_{3}+3 e^{-} \longrightarrow \mathrm{Fe}_{4}{ }^{\prime \prime \prime}\left[\mathrm{Fe}^{\prime \prime}(\mathrm{CN})_{6}\right]_{3}+3 \mathrm{Cl}^{-}
\end{array}
$$

(verde de berlim)

(azul da prússia insolúvel)

$$
\mathrm{Ep}_{2 \mathrm{C}}=0,86 \mathrm{~V}
$$

Deste modo, no primeiro voltamograma cíclico observa-se, apenas na região negativa de potencial, um ombro a $0,4 \mathrm{~V}$ seguido de um pico a $0,25 \mathrm{~V}$. Este ombro pode ser atribuído à formação de um filme de Azul da Prússia sobre o eletrodo, enquanto o pico à $0,25 \mathrm{~V}$ pode ser atribuído à redução deste filme ao branco da Prússia;

2) Deve-se evitar quando possível, a presença de espécies derivadas de $\mathrm{PO}_{4}{ }^{3-} \mathrm{e}$ a utilização dos eletrodos modificados em meio alcalino, porque ambos os ions $\mathrm{PO}_{4}{ }^{3-} \mathrm{e} \mathrm{OH}^{-}$formam complexos estáveis com os ions de $\mathrm{Fe}^{3+}$;

3) Os filmes apresentaram maior estabilidade após secagem à temperatura ambiente por 24 horas;

4) Para que os filmes de Azul das Prússia mantenham-se estáveis na superficie do eletrodo é recomendável que a solução de medida contenha íons $\mathrm{K}^{+}$, os quais atuam no balanceamento de carga durante o processo redox e também no aumento da resistência do filme à acidez do meio;

5) Utilizando-se a voltametria cíclica para determinação de $\mathrm{H}_{2} \mathrm{O}_{2}$ não foi possivel observar nenhum aumento no pico anódico, não apenas devido á ciclagem sucessiva ao redor do par redox AP/BP a qual favorece a, formação de uma mistura do Azul da Prússia solúvel e insolúvel, como também devido ao consumo local de $\mathrm{H}^{+}$para redução do peróxido de hidrogênio, o qual facilita a desestabilização do filme; 
6) A melhor composição para a solução modificadora foi $2 \mathrm{mmol} \mathrm{L}^{-1}$ de $\mathrm{K}_{3}\left[\mathrm{Fe}(\mathrm{CN})_{6}\right], 3 \mathrm{mmol} \mathrm{L}^{-1}$ de $\mathrm{FeCl}_{3}$ em $\mathrm{HCl} \mathrm{0,02} \mathrm{mol} \mathrm{L}^{-1}$. A presença do excesso de $\mathrm{FeCl}_{3}$ na solução modificadora favorece a formação do AP "insolúvel";

7) $\mathrm{O}$ melhor potencial aplicado para a determinação de $\mathrm{H}_{2} \mathrm{O}_{2}$ foi de $0,040 \mathrm{~V}$, onde a influência da redução do oxigênio é de apenas $8,0 \%$. Este valor foi determinado para concentrações de $\mathrm{H}_{2} \mathrm{O}_{2}$ na ordem de $1,0 \mathrm{mmol} \mathrm{L} \mathrm{L}^{-1}$. Para concentrações mais baixas do analíto o potencial deve ser ligeiramente aumentado totalmente à contribuição do $\mathrm{O}_{2}$ para a corrente catalítica de redução da $\mathrm{H}_{2} \mathrm{O}_{2}$;

8) O melhor eletrodo modificado com Azul da Prússia foi aquele obtido por deposição a dois potenciais controlados: $0,4 \mathrm{~V}$ por 120 segundos (adsorção dos reagentes) $l-0,4 \vee$ por 120 segundos (redução dos reagentes - formando o AP "insolúvel"), ciclo repetido por três vezes;

9) Os eletrodos modificados com Azul da Prússia devem ser ativados em solução $0,1 \mathrm{~mol} \mathrm{~L}^{-1}, 1 \mathrm{~m} \mathrm{~mol} \mathrm{~L}^{-1} \mathrm{RhCl}_{3}$ em $0,02 \mathrm{~mol} \mathrm{~L}^{-1}$ de $\mathrm{HCl}$ no intervalo de $-0,4 \mathrm{~V} \leq \mathrm{E}_{\mathrm{apl}} \leq 0,6 \mathrm{~V}$ com velocidade de $60 \mathrm{~m} \mathrm{~V} \mathrm{~s}^{-1}$ e posteriormente seco a temperatura ambiente por 24 ;

10) A ciclagem do eletrodo modificado com AP em solução de $\mathrm{RhCl}_{3}$ exerce efeito catalítico adicional na redução de água oxigenada (figura 34, página 95);

11) Curvas ip vs $v^{1 / 2}$ indicam que o sistema é governado pela difusão de íns $K^{+}$ para interior do filme de AP durante o processo de redução e do interior do filme para a solução durante o processo de oxidação;

12) O valor estimado para o excesso superficial foi de a $4,3 \times 10^{-8} \mathrm{~cm}^{-2} \mathrm{~mol}^{-1}$;

13) $\mathrm{O}$ limite de detecção e sensibilidade para a determinação de $\mathrm{H}_{2} \mathrm{O}_{2}$ com eletrodos de pasta de carbono modificados com Azul da Prússia e posteriormente "ativados em" solução " de " $\mathrm{RhCl}_{3}$, foram de $2,5 \pm 0,02 \times 10^{-5} \mathrm{~mol} \mathrm{~L}^{-1} \mathrm{e} 1,4 \pm 0,2 \mathrm{~A} \mathrm{~mol} \mathrm{~L}^{-1} \mathrm{~cm}^{-2}$ respectivamente;

14) Os eletrodos modificados de acordo com os itens 8 e 9 depois de 5 dias de utilização intensa perda de sensibilidade de $27 \%$. Quando fora de uso o eletrodo foi armazenado em solução $0,5 \mathrm{~mol} \mathrm{~L}^{-1}$ de $\mathrm{KCl}$; 
15) A corrente de redução registrada em solução $1,0 \times 10^{-3} \mathrm{~mol} \mathrm{~L}^{-1}$ de $\mathrm{H}_{2} \mathrm{O}_{2}$ (em potencial de $40 \mathrm{mV}$ ) não foi alterada pela presença de ácido úrico na mesma concentração. O eletrodo não apresentou, na faixa de $-0,21 \mathrm{~V} \leq \mathrm{E}_{\text {apli }} \leq 0,19 \mathrm{~V}$, nenhum sinal amperométrico devido à oxidação direta deste componente;

16) A corrente de oxidação direta de $1,0 \times 10^{-3} \mathrm{~mol} \mathrm{~L}^{-1}$ de ácido ascórbico na superfície do eletrodo somente foi detectada em potenciais iguais ou superiores a $0,060 \mathrm{~V}$;

17) A adição do ácido ascórbico durante a determinação de $\mathrm{H}_{2} \mathrm{O}_{2}$ causou uma diminuição de apenas $4 \%$ na corrente catalítica de redução da $\mathrm{H}_{2} \mathrm{O}_{2}$ devido a um ligeiro consumo desta última por reação direta com o ácido ascórbico ${ }^{(81)}$. Este valor aumentou para $30 \%$ na presença de $\mathrm{O}_{2}$, indicando que a oxidação do ácido ascórbico pela $\mathrm{H}_{2} \mathrm{O}_{2}$ pode, eventualmente, ser catalisada pelo oxigênio dissolvido. 


\section{V-REFERÊNCIA BIBLIOGRÁFICAS}

(1) Augusto, O., Hix, S., Morais, M. S. e Vasquez-Vivar, J., Ciência e Cultura, $\underline{47}$ (5/6), 280, (1995).

(2) Pinto, T. J. A, Revista Publica, São Paulo, 29 , (1), 75, (1995).

(3) Rocha, F.R., Dissertação de Mestrado, IQ-USP, (1999).

(4) Rover, L., Höechr, N. F., Vellasco, A. P.e Kubota, L. T., Quimica Nova, 24, (1), 112, (2001).

(5) Neves, J.M. e Otsuki, H., Congresso Anual de Celulose e Papel da Abtap, $\underline{3}$ São Paulo, 333, (1990).

(6) Hall, S. B., Khudaish, A. E., Hart, A. L., Electrochim. Acta, 45, 3573, (2000).

(7) Brett, A. M. e Brett, C.M.A. "Electroquímica - Princípios, Métodos e Aplicações", Livraria Almedina: Coimbra, (1996).

(8) Hall, S. B., Khudaish, A. E., Hart, A. L., Electrochim. Acta, 43, 579, (1998).

(9) Gorton, L., Electroanalysis, Z, (1), 23 (1995).

(10) Hall, E. A., Gooding, J. J. e Hall, C. E., Mikrochim. Acta, 121, 119 (1995).

(11) Ruzgas, T., Csoregi, E., Emnéus, J. e Gorton, L., Anal. Chim. Acta, $\underline{309}, 35$ (1995).

(12) Guindilis, A.L., Atanasov, P.e Wilkins, E., Eletroanalysis, $\underline{9}$, (9), 661, (1997).

(13) Rosatto, S.S., Freire, R.S., Durán, N. e Kubota, L.T., Quimica Nova, 24, (1), 77, (2001).

(14) Wiseman, A.,"Manual de Biotecnologia de Los Enzimas", Editora Acribia, S.A.: Zaragonza, (1985).

(15) O’Brien, E.M., Tipton, K.F.,McCrodden, J.M. and Youdim, M.B.H., Biochem. Pharmacol., 47, (4), 617, (1994).

(16) Yagodina, O.V., Nikolskaya, E.B., Sens. Actuators B, 44, 566, (1997).

(17) Rosatto, S.S., Freire, S., Duran, N. and Kubota, L.T., Química Nova, 24, 77, (2001).

(18) Guilbault, G. G., Kuan, S. S .and Brignac, Jr P .J., Anal. Chim. Acta, 47503 (1969). 
(19) Rocha, R. T., Bertotti, M., Richter, E. M. R, Souza, A. S.; Gavini, G., Encontro Nacional de Química Analítica, São Carlos, $\underline{9}$, (1997).

(20) Oliveira, M.C., Nogueira, R.F.P., Resende, U.M. e Boaventura, M.A. D., Quimica Nova, 24, (2), 188, (2001).

(21) Tsukagoshi, K., Tomita, Y. and Nakajima, R., Chem. Lett., 486, (2001).

(22) Zhang, K., Mao, L., Cai, R., Talanta, 51, 179, (2000).

(23) Chen, X., Li, D., Yang, H., Zhu, Q.,Zheng, H. and Xu, J., Analyst, 126, 523, (2001).

(24) Liu, Z., Cai, R., Mao, L., Huang, H. and Ma, W., Analyst, 124, 173, (1999).

(25) Hong, J., Maguhn, J., Freitag, D. and Kettrup, A., Fresenius J. Anal. Chem., 361, 124, (1998).

(26) Zhou, J. and Wang, E., J. Electroanal. Chem., 331, 1029, (1992).

(27) Karyakin, A. A., Gitelmacher, O. V. and Karyakina, E. E., Anal. Lett., 27 . (15), 2861, (1994).

(28) Karyakin, A. A., Gitelmacher, O.V. and Karyakina, E. E.,Anal. Chem., $\underline{67}$ (14), 2419 (1995).

(29) Chi, Qijin, Dong, Shaojun, Anal. Chim. Acta, $\underline{310}, 429$ (1995).

(30) Karyakin, A. A., Karyakina, E. E. e Gorton, L., Talanta 43 ,1597, (1996).

(31) Q. Deng, B. Lin and S. Dong, Analyst, 123 (10), 1995 (1998).

(32) Karyakin, A. A., Karyakina, E. E., Sens. Actuators B, $\underline{57}$ (1-3), 268 (1999).

(33) Zhang, X., Wang, J., Ogorivc, B. and Spichiger, U. E., Electroanalysis, 11(13), 945 (1999).

(34) Garjonyte, R. and Malinauskas, A., Sens. Actuators B, $\underline{63}$ (1-2), 122 (2000).

(35) Wilkins, E., Carter, M., Voss, J. and Ivnitski, D., Electrochem. Commun., 2(11), 786 (2000).

(36) Karyakin, A. A., Karyakina, E. E. and Gorton, L., Anal. Chem., 72, 1720, (2000).

(37) Yabuki, S., Mizutani, F. And Hirata, Y., Sens. Actuators B, $\underline{65}$ (49), 51, (2000). 
(38) Mattos, I.L., Lukachova, L.V., Gorton, L., laurell, T. and Karyakin, A.A., Talanta $\underline{54}$ (5), 963, (2001).

(39) Ellis, D., Eckhoff, M. and Neff, V. D, J. Phys. Chem., 85, 1225, (1981).

(40) Buser, H.J., Schwarzench, D., Petter, W., Ludi, A., Inorg. Chem., 16, 2704, (1977).

(41) Itaya, K., Ataka, T. e Toshima, S., J. Am. chem. Soc., 104, 4767, (1982).

(42) Robin, M.B., Inorg. Chem., 1, 337, (1962).

(43) Keggin, J.F. and Miles, F.D., Nature, 137,577, (1936).

(44) Pharr, C.M. and Griffiths, P.R., Anal. Chem., 69, 4673, (1997).

(45) Herren, F., Ludi, A., Güdel, H. U., Hulliger, F. and Givord, D., Helv. Chim. Acta, $63,148,(1980)$.

(46) Herren, F., Fisher, P.,Ludi, A. e Hälg, W., Inorg. Chem., 19, 956, (1980).

(47) Ganguli, S., and Bhattacharya, M., J. Chem. Soc., Faraday Trans., 79 (1), 1513, (1983).

(48) Bal, B., Ganguli, S. and Bhattacharya, M., J. Phys. Chem., 88, 4575, (1984).

(49) Ducan, J. F. and Wigley, P. W. R., J. Chem. Soc., 1120, (1963).

(50) Neff, V. D., J. Electrochem. Soc, 125, (6), 886, (1978).

(51) Neff, V. D., J. Electrochem. Soc., 132, 1382, (1985).

(52) Plichon, V. e Besbes, S., J. Electroanal. Chem., 284, 141, (1990).

(53) Karyakin, A .A., Karyakina, E. E. e Gorton, L., Electrochem. Commun. 1,78, (1999).

(54) Garcia-Jareño, J.J., Sanmatias, A., Vicente, F., Gabrielli, C., Keddam, M., Perrot, H., Electrochim. Acta, 45, 3765, (2000).

(55) Mattos, I.L., Gorton, L., Ruzgas, T. and Karyakin, A .A ., Anal. Sci., 16, 795, (2000).

(56) Itaya, K., Akahoshi, H. e Toshima, S., J. Electrochem. Soc., 129, (7), 1498, (1982).

(57) Itaya, K., Ataka, T. e Toshima, S., J. Phys. Chem., 86, 2415, (1982).

(58) Itaya, K. e Uchida, I., Inorg. chem., 25, 389, (1996).

(59) Lundgren, C.A. e Murray, R. W., Inorg. chem., 27, 933, (1988). 
(60) Plichon, V. e Besbes, S., Electrochim. Acta, 37, 501, (1992).

(61) Voguel, A., "Química Analítica Qualitativa", $1^{a}$ Edição, Editora Mestre Jou, São Paulo, (1981).

(62) Ibers, J. A. e Davidison, N., J. Am. Chem. Soc., $\underline{73}$, 476, (1951).

(63) Mortimer, R. J., Rosseinsky, D. R., J. Chem. Soc. Dalton Trans., 2059 (1984).

(64) Feldman, B. J. E Melroy, O. R., J. Electroanal. Chem., 234, 213, (1987).

(65) Benedetto,G.E. and Cataldi, T. R.I., Langmuir, 14, 6274, (1998).

(66) Kaneko, M., Teratani, S. and Harashima, K., J. Electroanal. Chem., $\underline{325}$, 325, (1992).

(67) Rajan, K. and Neff, V.D., J. Phys. Chem., 86, 4361, (1982).

(68) Cataldi, T.R.I., Benedetto, G.D. and Campa, C., J. Electroanal.Chem., 437, 93, (1997).

(69) Cataldi, T.R.I., Benedetto, G.D., J. Electroanal.Chem., 458, 149, (1998).

(70) Cataldi, T.R.I., Benedetto, G.D. and Bianchini, A., Electroanalysis, 10, (17), 1163, (1998).

(71) Benedetto, G.D., Guascito, M.R., Ciriello, R., Cataldi, T.R.I., Anal. Chim. Acta, $\underline{410}, 143,(2000)$.

(71a) Angelini, G., Fornarini, S. and Speranza, M., J. Am. Chem. Soc., 104, 4773, (1982).

(72) Cox, J.A. and Kulesza, P.J., Anal. Chem., $\underline{56}$, 1021, (1984).

(73) Cox, J.A. and Gorski, W., J. Electroanal.Chem., 389, 123, (1995).

(74) Karyakin, A .A., Gitelmacher, O.V. and Karyakina, E. E., Anal. Chem., 67, 101, (1995).

(75) Cataldi, T.R.I., Centonze, D., Desimoni, E., Forastiero, V., Anal. Chim. Acta, 310, 257, (1995).

(76) O'Connel, P.J., O'Sullivan, C.K. and Guilbault, G.G., Anal. Chim. Acta, $\underline{373}$, 261, (1998).

(77) Voguel, A., "Análise Quimica Quantitativa", Livros Técnicos e Cientificos Editora A.S., Rio de Janeiro, (1992). 
(78) D.D. Perrim; B. Dempsey; "Buffer for $\mathrm{pH}$ and Metal Ion Control", Chapman and Hall Ltda: New York, (1974).

(79) Pedrotti, J. J., Agnes, L., Gutz, I. G. R., Electroanalysis, $\underline{8}, 673$, (1996).

(80) Miller, J.C. and Miller, J.N., Statistics For Analytical Chemistry, Ellis Horwood Limited, New York, (1988).

(81) Deng, Q., Li, B. and Dong, S., Analysty, 123, 1995, (1998). 
